NBER WORKING PAPER SERIES

\title{
ACHIEVING SCALE COLLECTIVELY
}

\author{
Vittorio Bassi \\ Raffaela Muoio \\ Tommaso Porzio \\ Ritwika Sen \\ Esau Tugume \\ Working Paper 28928 \\ http://www.nber.org/papers/w28928
NATIONAL BUREAU OF ECONOMIC RESEARCH
1050 Massachusetts Avenue
Cambridge, MA 02138
June 2021

We thank Kevin Donovan, Joe Kaboski, and Guo Xu for insightful discussions of the paper. We also thank Shameel Ahmad, David Atkin, Oriana Bandiera, Lauren Falcao Bergquist, Julieta Caunedo, Giorgio Chiovelli, Giacomo De Giorgi, Dave Donaldson, Ben Faber, Bob Gibbons, Selim Gulesci, Matt Kahn, Pablo Kurlat, David Lagakos, Ted Miguel, Monica Morlacco, Melanie Morten, Paul Niehaus, Andrea Prat, Adriano Rampini, Mark Rosenzweig, Martin Rotemberg, Nick Ryan, Meredith Startz, John Strauss, Eric Verhoogen, Jeff Weaver and Chris Woodruff as well as many seminar and conference participants for useful comments. We are also grateful to everyone at the Ministry of Trade in Uganda and BRAC who made this project possible, in particular Joshua Mutambi, Stephen Emuria, Munshi Sulaiman, Arianna Cima, Alessandro Giambrone, Maddalena Grignani, Sebastian Quaade and Monia Tomasella. Kasey Chatterji-Len, Usman Ghaus, Arushi Kaushik, Jung Hyuk Lee, Jeanne Sorin and Mitchell Vanvuren provided excellent research assistance. We gratefully acknowledge financial support from CEGA, IGC, PEDL, USC and the World Bank. This study received ethical approval from the Mildmay Research Ethics Committee of Uganda (MUREC), Reference No. 1106-2018. All errors are our own. The views expressed herein are those of the authors and do not necessarily reflect the views of the National Bureau of Economic Research.

NBER working papers are circulated for discussion and comment purposes. They have not been peer-reviewed or been subject to the review by the NBER Board of Directors that accompanies official NBER publications.

(C) 2021 by Vittorio Bassi, Raffaela Muoio, Tommaso Porzio, Ritwika Sen, and Esau Tugume. All rights reserved. Short sections of text, not to exceed two paragraphs, may be quoted without explicit permission provided that full credit, including $\odot$ notice, is given to the source. 
Achieving Scale Collectively

Vittorio Bassi, Raffaela Muoio, Tommaso Porzio, Ritwika Sen, and Esau Tugume

NBER Working Paper No. 28928

June 2021

JEL No. E0,O1

\begin{abstract}
$\underline{\text { ABSTRACT }}$
This paper argues that rental market interactions allow small firms to increase their effective scale and mechanize production, even when each individual firm would be too small to invest in expensive machines. We conduct a novel survey of manufacturing firms in Uganda, which uncovers an active rental market for large machines between small firms in informal clusters. We then build an equilibrium model of firm behavior and estimate it with our data. Our results show that the rental market is quantitatively important for mechanization and productivity since it provides a workaround for other market imperfections that keep firms small. We also show that the rental market shapes the effectiveness of policies to foster mechanization, such as subsidies to purchase machines.

Vittorio Bassi

University of Southern California

Department of Economics

3620 South Vermont Avenue, Kaprielian Hall

Los Angeles, CA 90089

vbassi@usc.edu

Raffaela Muoio

BRAC Uganda

raffaelamuoio@hotmail.it.

Tommaso Porzio

Columbia Business School

3022 Broadway

Uris Hall 824

New York, NY 10027

and NBER

tommaso.porzio@columbia.edu

Ritwika Sen

Northwestern University

ritwika.sen@kellogg.northwestern.edu

Esau Tugume

BRAC Uganda

tugume.esau@brac.net
\end{abstract}




\section{Introduction}

Technology is often embodied in large capital inputs, such as production machines, which can be too expensive for small firms to purchase. ${ }^{1}$ The small scale of operations of firms in developing countries could thus limit their ability to adopt technology, ultimately hindering their productivity and contributing to the large income gaps that still persist between rich and poor countries (Hall and Jones, 1999; Caselli, 2005; Bloom et al., 2010). ${ }^{2}$

While firms in developing countries are small, they also tend to operate near each other in large informal clusters. ${ }^{3}$ In this paper, we show that this feature of the organization of production improves the ability of small firms to adopt technology and mechanize by increasing their effective scale. To do so, we design and implement a novel firm survey in urban Uganda, and we interpret the evidence through an equilibrium model of firm behavior. The survey uncovers an active rental market for large machines between small firms. The model estimates reveal that rental markets are effective at increasing mechanization and productivity, thus providing a workaround for other frictions that keep firms small. That is, even when machines are too expensive for each individual firm, rental market interactions allow small firms to achieve scale collectively and mechanize. Finally, we show that taking rental markets into account has important implications for the design of development policies.

We surveyed a representative sample of over 1,000 firms in three manufacturing sectors: carpentry, metal fabrication and grain milling. The key innovation of our survey is to collect disaggregated information on the types of capital, labor and managerial inputs used in production. To measure the capital input, we collect data at the individual machine level, such as whether the machine is owned or rented, its price and hours used. To measure the labor input we gather information on the skills and time allocation of employees. To measure the managerial input, we collect information on the business practices of firm owners.

We use the data to describe how firms produce output in these sectors, with a focus on the role of scale and mechanization. In doing so, we provide a set of descriptive statistics and empirical relationships that inform our model and are used as targets in its estimation. We include results for all the three sectors, but we focus on carpentry since the role of scale for mechanization is more striking there. We organize the discussion around four key facts.

First, mechanization has clear benefits. While firms produce similar products, they do so at different capital intensity. Some firms rely mostly on labor, while others use modern, electricpowered machines, and this latter group has higher revenues per worker. Second, the small

\footnotetext{
${ }^{1}$ Griliches (1997), Janes et al. (2019) and Caunedo and Keller (2021) study capital embodied technology.

${ }^{2}$ Hsieh and Olken (2014) show the prevalence of small firms, and De Mel et al. (2008), Banerjee and Duflo (2014), Jensen and Miller (2018), Hardy and McCasland (2020), De Mel et al. (2019) and Akcigit et al. (2021) are recent studies on constraints to firm expansion in developing countries.

${ }^{3}$ For instance, Atkin et al. (2017) study clusters of soccer ball producers in Pakistan; Rabellotti (1995) describes clusters of footwear enterprises in Mexico; Shapiro et al. (2020) study clusters of carpenters in Kenya.
} 
scale of firms limits investment since machines are expensive and have high capacity relative to the size of firms. One example is the thickness planer, a key machine in the production process for carpentry. Thickness planers cost about $\$ 4,000$, or roughly 18 times average monthly profits. Not surprisingly, less than $10 \%$ of firms own one. Third, the indivisibility of machines is overcome, at least partly, by the presence of an active inter-firm rental market. Back to the example, while less than $10 \%$ of firms own a thickness planer, $50 \%$ rent one. Renting is primarily between firms in the same sector and cluster, and is possible since machine owners have substantial excess capacity that they can rent out to other firms. Fourth, the rental market is plagued by transaction costs - such as transportation and time costs - that could partly undermine its effectiveness. We find that the overall rental market transaction costs $\tau$, as inferred by the relative utilization of machine hours by renters and owners of machines, are approximately $40 \%$ of the direct machine rental price.

Motivated by our data, we develop an equilibrium model to: (i) quantify the aggregate effects of the rental market and the extent to which these are limited by transaction costs; (ii) shed light on the mechanisms through which these effects manifest; and (iii) discuss the lessons for development policy. In the model, individuals draw a managerial ability and a cost of capital and decide how much and how to produce. Managers decide whether to mechanize production and whether to purchase machines or rent them from other firms. If they purchase machines, they also decide how much of their machine's capacity to use for their own production and how much to rent out. The rental market for machines is subject to a transaction $\operatorname{cost} \tau$ : for every dollar earned by a machine owner, the renter pays $1+\tau$ dollars. All managers produce differentiated products and hire workers subject to a firm-specific increasing cost of labor which captures labor market frictions in reduced form.

We characterize the solution analytically, focusing on the role of the rental market. We prove that a rental market with low transaction costs increases the profitability of all active firms and we formalize the two mechanisms through which it operates. The first one is akin to the financial market: by unbundling capital ownership and utilization, a well-functioning rental market improves the allocation of capital since managers with the lowest cost of capital purchase the machine, and the ones with the highest returns use it. The second one is specific to the rental market and conceptualizes the core idea of collective scale: in the presence of strong decreasing returns and high-capacity machines, the equilibrium scale of firms may not be large enough to justify the investment if firms must use all the capacity themselves. The rental market allows firms to share machine capacity, thus overcoming this problem. We estimate the model, targeting the empirical relationships related to the four facts mentioned above.

On the aggregate, eliminating transaction costs in the rental market $(\tau=0)$ increases mechanization by $192 \%$, labor productivity by $12.4 \%$, and output by $17.5 \%$ relative to an economy where renting is not possible. The benchmark economy, where we estimate $\tau=0.430$, 
attains more than half of the possible gains. This shows that the rental market is quite effective despite the documented transaction costs, thus allowing firms to achieve scale collectively.

Turning to the mechanisms, we shed light on why rental markets matter, and when and where they do. We show that all firms benefit from a reduction in transaction costs, as a wellfunctioning rental market allows more firms to access machines, overcoming the indivisibility of machines through collective scale. At the same time, we find that managers with a high cost of capital benefit disproportionally since the rental market unbundles ownership and utilization. Managers operating at relatively lower scale also benefit more since the indivisibility is particularly binding for them. We also clarify that the rental market is prevalent and important in our setting because it creates a workaround for other market imperfections that we estimate to be large, such as frictions in the financial, labor and output markets. Our results imply that we should expect rental markets to become less prevalent as countries develop and market imperfections vanish.

We use the model to perform policy experiments and study how the effectiveness of development policies aimed at increasing mechanization and productivity depends on the rental market. We show that the presence of the rental market reduces the effectiveness of subsidies to purchase machines. We then compare the distributional effects of subsidies to purchase and rent machines, and find that providing a mix of both can be an equitable policy to raise mechanization and productivity for all types of firms. Finally, we show that, in our context, equilibrium effects cannot be ignored: the productivity gains that could be estimated by partial equilibrium randomized experiments offer misleading evidence on the effect of policies at scale.

Related Literature. Our work speaks to three core topics in economic development. First, we contribute to a large literature on the role of fixed costs in production and the potential for poverty traps (Banerjee and Duflo, 2005; Kaboski and Townsend, 2011; Balboni et al., 2021; Banerjee et al., 2021; Bari et al., 2021). Our contribution here is twofold. By exploiting our unique data on capacity utilization, we provide direct evidence that capital indivisibility is an important source of scale economies. In doing so, we also build on a classic literature that studies economies of scale in the early phases of U.S. industrialization (Atack, 1978, 1985; Chandler, 1990; Atack et al., 2008). ${ }^{4}$ Further, we uncover how small firms in informal clusters are able to overcome large fixed costs and to invest in technology through a rental market for machines, and how this limits the productivity costs of small scale and the risk that firms remain stuck in poverty traps.

Second, we bring new perspectives to a broad literature on the role of financial frictions in creating misallocation and impeding entrepreneurship and growth (Greenwood and Jovanovic,

\footnotetext{
${ }^{4}$ In more recent work in developing countries, Foster and Rosenzweig (2017) show the importance of indivisible capital in farming, although they lack data on capacity utilization. Jensen and Miller (2018) also suggest that larger firms use capital more effectively, but cannot show direct evidence due to data limitations.
} 
1990; Midrigan and Xu, 2014; Buera et al., 2011a, 2017). Our contribution is to show how the rental market reduces capital misallocation by reallocating machine capacity across firms. As the rental market provides a workaround for financial frictions, our results imply that the aggregate cost of financial frictions might be, in certain contexts, lower than previously estimated.

Third, our work sheds new light on the well-accepted notion that the firm size distribution in developing countries is dominated by very small firms (Hsieh and Olken, 2014; Hsieh and Klenow, 2014). This classic result hinges on using the managerial span of control to define the boundary of the firm (as in Lucas (1978)). As we estimate limited transaction costs in the rental market, this motivates us to redefine a firm as all the workers using the same machines. Doing so, the firm size distribution changes dramatically in our data: the share of firms with more than 10 employees goes from 5\% to 33\%. Many before us have conceptually challenged the notion that managerial control defines the size of the firm. ${ }^{5}$ Our contribution is to offer a case study that highlights how redrawing the firm boundaries may change our view on the firm size distribution. To our knowledge, we are the first to do so in a low-income country, which is particularly relevant due to the prevalence of small firms.

We are not the first to focus on rental markets for capital or on the role of clusters for productive efficiency. On rental markets, Rampini (2019) discusses the role of renting in a model of financing for durable assets, and Rampini and Townsend (2016) bring evidence from Thai households. In work contemporaneous to ours, Caunedo et al. (2020) and Caunedo and Kala (2021) study the role of rental markets for mechanization in agriculture in India. Our contribution is to focus on the role of the rental market in helping small firms achieve scale collectively, and to offer a simple yet quantifiable model that is grounded in the empirical evidence collected through our detailed surveys.

The role of firm clusters for productivity is an old idea that goes back at least to Marshall (1920). More recent work at the intersection of sociology and economics has provided interesting case studies (Rabellotti, 1995; Schmitz, 1995). Our contribution is to provide the first quantitative assessment of physical firm-to-firm interactions in determining access to modern technology. ${ }^{6}$ In doing so, we also highlight that interactions in the rental market for capital can be an important source of economies of agglomeration, thus providing a useful micro-foundation for the large urban literature on agglomeration (Duranton and Puga, 2004; Ellison et al., 2010).

Structure of the paper. The rest of the paper is organized as follows. Section 2 discusses the sampling strategy and survey design. In Section 3 we present key facts on the organization of production and the rental market. The model is developed in Section 4, and Section 5

\footnotetext{
${ }^{5}$ See Coase (1937); Richardson (1972); Chandler (1977); Grossman and Hart (1986) and Hart and Moore (1990). Empirically, Olmstead and Rhode (1995) describe how cooperative exchanges for reaper services among farmers in the United States contributed to their rapid diffusion.

${ }^{6}$ Cai and Szeidl (2018) and Perla and Tonetti (2014) study firm-to-firm knowledge spillovers.
} 
discusses identification and estimation. Section 6 quantifies the aggregate effects of the rental market, the mechanisms through which these effects arise, and the implications for development policy. Additional results are in the Online Appendix. A Supplemental Appendix not intended for publication can be found on the authors' websites.

\section{The Survey}

The survey took place in late 2018 and early 2019, and was implemented by our partner NGO, BRAC Uganda, in partnership with the Ministry of Trade of Uganda. In this section, we present the key elements of the sampling strategy and the survey instrument in turn. ${ }^{7}$

Sampling. Our survey targeted firms in manufacturing, where output is easier to measure and where both capital and labor are relevant inputs. Within manufacturing, we focused on three prominent sectors: carpentry, metal fabrication and grain milling. As revealed by the latest Census of Business Establishments conducted by the Uganda Bureau of Statistics in 2010, these are sectors that: (i) employ a large share of workers and (ii) are not dominated by micro-enterprises. The first criterion implies that we target sectors that are important for policy, whereas the second criterion allows us to focus on sectors where both small and large firms co-exist. By focusing on three sectors we can examine sectoral heterogeneity in our results.

The survey was implemented in a representative sample of urban and semi-urban areas across three of the four macro-regions of Uganda: Central, Western, and Eastern regions. A sample of 52 sub-counties was randomly extracted, stratifying by population and by whether the sub-county is in the broader Kampala area. ${ }^{8}$ We conducted an in-person door-to-door listing of all the firms in our three sectors in the sampled areas, identifying close to 3,000 firms. We then randomly extracted about 1,000 firms from our listing to be included in the survey, oversampling firms with five or more employees, to ensure coverage of a sufficient number of relatively large firms. In firms selected for the survey, we interviewed the owner and all the employees working on our pre-specified core products, which are discussed below. Across the three sectors we interviewed 1,115 firm owners and 2,883 employees. Compliance with the survey was high at over $90 \%$. All our results are weighted to reflect our sampling strategy. ${ }^{9}$

Survey design. Our objective was to zoom inside the firm, and paint a complete picture of how capital and labor inputs are combined to produce output. Following existing surveys, we

\footnotetext{
${ }^{7}$ Further details are provided in the Supplemental Appendix.

${ }^{8}$ Uganda is divided into 1,382 sub-counties, with the average sub-county spanning 64.4 square miles.

${ }^{9}$ Some of the descriptive evidence on rental markets presented later in the paper was captured in short follow-up surveys conducted with our sample of firms in the months after the initial survey was completed. See the Supplemental Appendix for more details on this additional data collection.
} 
collected a wide range of firm-level information such as revenues, number of employees, wages, owner and employee characteristics (e.g., age, education, experience, and training). Following McKenzie and Woodruff (2017), we also measured the managerial skills of the owner, using a battery of questions about record keeping, marketing, stock control, business performance review and financial planning, which are combined into a continuous index of managerial ability.

We then went beyond related studies and collected information on the entire production process for key products. This allows us to improve on the measurement of capital and labor, and how they are combined. We worked with the Uganda Industrial Research Institute to identify for each sector one "core product" made by most firms. These are: doors in carpentry, windows in metal fabrication, and maize flour in grain milling. We then broke down the production process of these products into a series of steps that firms typically engage in, and collected information on: (i) whether firms produce the pre-specified core product; (ii) whether they perform the pre-specified production steps; and (iii) the combination of capital and labor used in each step. In particular, for each step we know whether this is performed using modern electric-powered machines or with manual tools, which employees work on the step and for how many hours, and the time taken by the employee (or team of employees) to complete it.

For each machine, we collected numerous details, including whether it is owned or rented, the purchase (or rental) cost, and detailed measures of capacity utilization: for both machine owners and machine renters we know how many hours per week they use each machine in production, and machine owners were also asked how many hours they rent out each of their machines to other firms. Finally, for our core products we collected information on: quantities produced and sold, prices, and multiple proxies of quality measured through direct observation by our enumerators. ${ }^{10}$

\section{The Organization of Production in Urban Uganda}

In this section, we describe how production is organized in our three sectors, with a focus on the role of scale and mechanization. In doing so, we highlight a number of key facts and statistical relationships that inform and discipline our model.

\footnotetext{
${ }^{10}$ More specifically, for carpentry firms, all questions related to the core product were asked about two-panel doors. For carpenters not producing two-panel doors, the questions were asked about the main type of door produced by the firm. Firms in metal fabrication were asked about two-shutter sliding windows, and for grainmilling, we asked about maize flour No. 1. If firms did not produce these product varieties, the questions were asked about the main type of windows and maize flour produced, respectively. In the Supplemental Appendix, we show that most firms produce the specific variety of the core products that we asked about in the survey.
} 


\subsection{Descriptives on the Anatomy of Production}

We begin by describing how production is carried out, in terms of the output that is produced, how this is produced, and the extent to which there are differences across firms. To this end, we highlight a number of key descriptive statistics for our sample of firms, reported in Table 1. Additional descriptives can be found in the Online Appendix.

Many small firms operating in informal clusters. Production in these sectors takes place in a large number of small firms. Panel A shows that the average firm is small, employing about 4.5-6 workers across our sectors. However, the average firm operates well beyond subsistence, with monthly revenues between $\$ 1,200-\$ 1,900$. To put these numbers into perspective, per capita GDP in Uganda was $\$ 60$ per month in 2018. We identified close to 3,000 firms in our listing, with hundreds of firms in each sector. We show that these numerous small firms concentrate in clusters. One way to see this is to use our listing to calculate the average number of firms in the same sector within a 500 meter radius from each firm in our survey. These are: 26 firms in carpentry, 9 in metal fabrication and 15 in grain milling, thus confirming that there is substantial spatial clustering. Using the latest available official firm census for Uganda, Figure 1 shows that the geographical proximity of firms is a systematic feature of production in our setting, especially in sectors where firms are small (and our target sectors are not outliers).

Figure 1: Spatial concentration of firms across sectors in Uganda

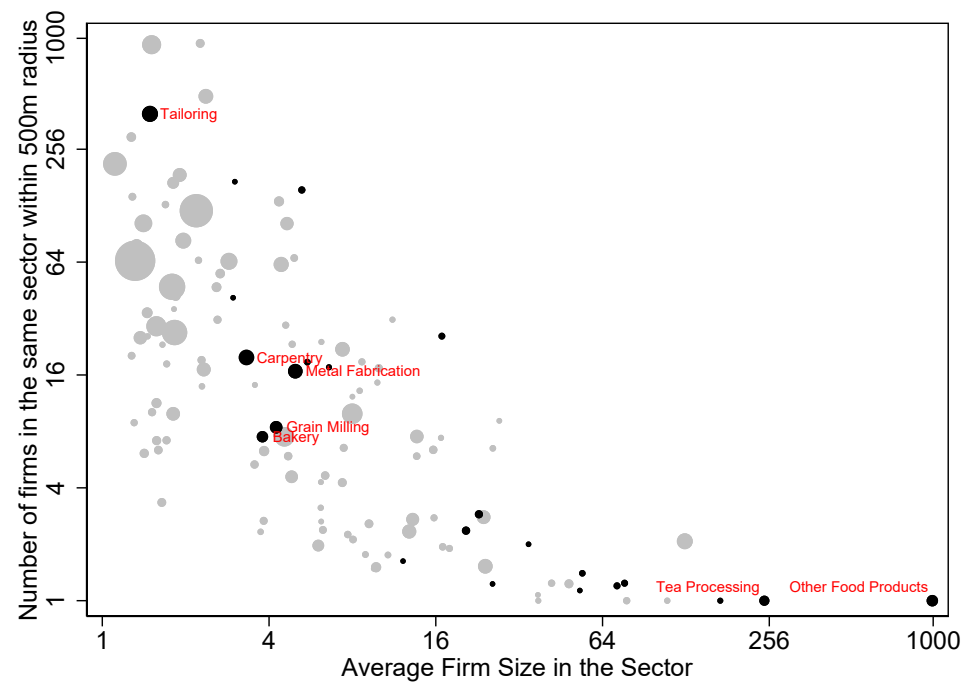

Notes: Data from the Census of Business Establishments (2010) for Uganda. For each firm, we compute the number of other firms in the same 3-digit industry located at a distance below 500 meters. We then plot the within industry average as a function of average firm size. The size of each dot is proportional to the number of workers in the industry. Black dots are industries in manufacturing. We drop sectors that employ less than 1,000 individuals across Uganda, and omit one clear outlier. 
Firms produce similar products. Panel B shows that the large majority of firms engage in the production of the pre-specified core product, and the core product makes up a relatively large share of monthly revenues for the average firm, corresponding to 35\%-66\% across sectors. In addition, firms producing the core product engage in the majority of the pre-specified production steps, with little variation across firms. ${ }^{11}$ In short, firms produce similar products using similar production steps, so that we do not find evidence of significant specialization across firms. The similarity of products and production steps across firms is notable in that it opens up the possibility that firms could share the same machines in production.

Table 1: Descriptives on the anatomy of production in the three sectors

\begin{tabular}{lcccccc}
\hline & \multicolumn{2}{c}{ Carpentry } & \multicolumn{2}{c}{$\begin{array}{c}\text { Metal } \\
\text { fabrication }\end{array}$} & \multicolumn{2}{c}{$\begin{array}{c}\text { Grain } \\
\text { milling }\end{array}$} \\
\hline Number of surveyed firms & \multicolumn{2}{c}{522} & & 433 & 160 \\
\hline & Mean & {$[\mathrm{Q} 20 ; \mathrm{Q} 80]$} & Mean & {$[\mathrm{Q} 20 ; \mathrm{Q} 80]$} & Mean & {$[\mathrm{Q} 20 ; \mathrm{Q} 80]$} \\
\hline & $(1)$ & $(2)$ & $(3)$ & $(4)$ & $(5)$ & $(6)$ \\
\hline Panel A: Basic firm characteristics & & & & & & \\
Number of employees & 4.5 & {$[2.0 ; 6.0]$} & 4.9 & {$[3.0 ; 6.0]$} & 6.0 & {$[3.0 ; 8.0]$} \\
Monthly revenues (USD) & 1,222 & {$[279 ; 1,810]$} & 1,548 & {$[456 ; 2,355]$} & 1,916 & {$[214 ; 3,342]$} \\
Owner years of education & 9.8 & {$[7.0 ; 13.0]$} & 10.0 & {$[7.0 ; 13.0]$} & 10.9 & {$[7.0 ; 16.0]$} \\
Manager ability & 11.2 & {$[6.0 ; 16.0]$} & 10.9 & {$[5.0 ; 16.0]$} & 11.8 & {$[5.0 ; 18.0]$} \\
Number of other firms within 500m & 26.5 & {$[3.0 ; 55.0]$} & 9.1 & {$[3.0 ; 11.0]$} & 15.3 & {$[0 ; 51.0]$} \\
\hline Panel B: Core product and production steps & & & & & \\
Share of firms making core product & 0.68 & - & 0.92 & - & 0.93 & - \\
Revenue share of core product & 0.35 & {$[0.17 ; 0.53]$} & 0.36 & {$[0.22 ; 0.48]$} & 0.66 & {$[0.38 ; 0.97]$} \\
Share of production steps performed & 0.76 & {$[0.60 ; 0.90]$} & 0.89 & {$[0.86 ; 1.00]$} & 0.60 & {$[0.43 ; 0.71]$} \\
\hline Panel C: Machine utilization on core product & & & & & \\
Number of machine types used & 5.4 & {$[2.0 ; 8.0]$} & 3.6 & {$[2.0 ; 5.0]$} & 3.1 & {$[2.0 ; 4.0]$} \\
Total value of machines used (USD) & 2,249 & {$[401 ; 2,674]$} & 526 & {$[136 ; 421]$} & 1,053 & {$[443 ; 1,474]$} \\
Total value of machines rented (USD) & 2,058 & {$[70 ; 2,525]$} & 332 & {$[0 ; 184]$} & 16 & {$[0 ; 0]$} \\
Avg. weekly hours each machine used & 9.1 & {$[1.9 ; 13.0]$} & 17.8 & {$[3.7 ; 30.3]$} & 44.6 & {$[26.5 ; 62.5]$} \\
\hline
\end{tabular}

Notes: Means and 20th-80th quantile ranges. Sample: surveyed firms. For the statistics from row 6 (Revenue share of core product) onwards, the sample is restricted to firms producing the core product (doors, windows, and maize flour, respectively). Monthly revenues: average revenues for each of the three months preceding the survey. Manager ability: index going from -1 to 27 and based on multiple survey questions; see the Supplemental Appendix for details. The number of other firms within a $500 \mathrm{~m}$ radius is calculated using the initial listing and considers firms operating in the same sector. Firms with no machines are assigned a value of zero for the number and monetary value of machines. Average weekly machine hours are conditional on positive hours. Conversion rate: 1 USD $=3,800$ UGX. Revenues, machine values and number of employees are trimmed at the top $1 \%$.

\footnotetext{
${ }^{11}$ The Supplemental Appendix reports a more detailed analysis of the prevalence of product types across firms
} and of the share of firms performing each production step. 
Dispersion in mechanization, size, and productivity. Although firms produce similar products using similar steps, we find substantial heterogeneity in mechanization of the production process for the core product. This is possible because the same production steps can be performed either with modern machines or with manual tools. As shown in Panel C, there is variation across firms both in the number and value of machines used. For instance, in carpentry, while the average firm uses five machines, firms at the 20th (80th) quantile use two (eight) machines. In addition, we document substantial dispersion in size and productivity. For example, while the average carpentry firm has 4.5 employees, the 20-80 quantile range goes from two to six employees. We find similar dispersion in revenues and in managerial ability.

\subsection{Mechanization, Scale, and Rental Markets}

We now describe the importance of mechanization for productivity, the role of scale for mechanization, and the role of the rental market for machines. We organize the discussion around four key facts. While doing so, we produce a set of empirical correlations. We do not argue that these relationships are causal; rather they will provide a set of (endogenous) empirical targets that will be used in the model estimation. Through the model, we will then be able to provide a precise quantitative interpretation of the strength of these correlations. From now on, we focus on carpentry, as that is the sector where the role of scale for mechanization is more striking for technological reasons related to the capacity and cost of production machines. We return to the other sectors in Section 3.5.

\section{Fact 1: Importance of Mechanization for Productivity}

We study the correlation between mechanization and productivity. In the survey, firms were asked to indicate which of 23 pre-specified machine types they use in the production of their core product (doors). For each firm, we construct their "mechanization rate", defined as the share of such machines used. ${ }^{12}$ We regress revenues and revenues per worker on the mechanization rate, using the sample of carpenters who produce the core product. The results are reported in Table 2. Columns 1 and 4 show a strong positive correlation between mechanization and both revenues and revenues per worker. These regressions control for sub-county fixed effects, and so do not just capture the sorting of more productive managers to more productive areas where machines may be more easily accessible.

Mechanization is not the only relevant correlate of revenue productivity. In fact, as shown in columns 2 and 5 of Table 2, there is a strong positive correlation between our managerial ability index and productivity: a one standard deviation increase in the index is associated

\footnotetext{
${ }^{12}$ In constructing the mechanization rate, each machine type is weighted using the share of total machine time it accounts for in the data, so that machines used more heavily in our sample get a higher weight.
} 
with a $29 \%$ increase in revenues and a $14 \%$ increase in revenues per worker. ${ }^{13}$ In columns 3 and 6 we include both the mechanization rate and the managerial ability index at the same time, and find that both remain strong predictors. This indicates that the correlation between mechanization and productivity in column 4 does not just capture the fact that high ability managers are better able to use machines or have easier access to capital. ${ }^{14}$

Table 2: The role of mechanization and managerial ability for revenue productivity

\begin{tabular}{|c|c|c|c|c|c|c|}
\hline & \multicolumn{3}{|c|}{ Log Revenues } & \multicolumn{3}{|c|}{ Log Revenues p.w. } \\
\hline & (1) & $(2)$ & $(3)$ & $(4)$ & $(5)$ & $(6)$ \\
\hline Mechanization Rate (0-1) & $\begin{array}{c}1.693^{* * *} \\
(0.267)\end{array}$ & & $\begin{array}{c}1.530^{* * *} \\
(0.260)\end{array}$ & $\begin{array}{c}1.268^{* * *} \\
(0.255)\end{array}$ & & $\begin{array}{c}1.195^{* * *} \\
(0.261)\end{array}$ \\
\hline Manager Ability (Std.) & & $\begin{array}{c}0.288^{* * *} \\
(0.049)\end{array}$ & $\begin{array}{c}0.250^{* * *} \\
(0.047)\end{array}$ & & $\begin{array}{c}0.144^{* * *} \\
(0.047)\end{array}$ & $\begin{array}{c}0.114^{* *} \\
(0.047)\end{array}$ \\
\hline Sub-county FE & Yes & Yes & Yes & Yes & Yes & Yes \\
\hline Adjusted $R^{2}$ & 0.509 & 0.494 & 0.547 & 0.435 & 0.405 & 0.442 \\
\hline Observations & 378 & 378 & 378 & 378 & 378 & 378 \\
\hline
\end{tabular}

Notes: ${ }^{* * *} p<0.01,{ }^{* *} p<0.05,{ }^{* * *} p<0.1$. OLS regression coefficients, robust standard errors in parentheses. Sample: door producers. Outcomes: Log monthly revenues (columns 1-3) and log monthly revenues per worker (columns 4-6). Mechanization rate: share of pre-specified machine types for the production of core product that are used by the firm. Managerial ability: standardized index based on multiple survey questions; see the Supplemental Appendix for details.

\section{Fact 2: Scale as a Limiting Factor to Investment in Machines}

Figure 2 shows the percentage of firms using each type of machine in the production of doors (our core product), together with their average price. Most machines are expensive: for example, thickness planers cost $\$ 4,000$ on average - about 18 times average monthly profits $(\$ 220) .{ }^{15}$ Machines often also have a capacity that is too high for a single firm. Consequently, even firms that use machines do not use them at full capacity: the average machine is used by a firm for only about 9 hours per week on the core product, and 21 hours per week across all products. Average weekly employee hours are close to 60 , and so this shows the average firm

\footnotetext{
${ }^{13}$ These results are in line with the literature on business practices in developing countries, which tends to find a strong correlation between managerial skills and revenue productivity (McKenzie and Woodruff, 2017).

${ }^{14}$ We further unpack the correlation between mechanization and revenue productivity, and find that this is due to both an increase in physical productivity and output quality. Using data on the time taken to complete a production step, we find that steps in which machines are used can be completed $17 \%$ faster on average (and this result is robust to a large set of controls). We also document a strong positive correlation between mechanization and our direct measures of output quality and prices. However, there is no correlation between mechanization and markups, which confirms that the higher prices reflect higher quality. See the Supplemental Appendix for more details.

${ }^{15} 92 \%$ of the machines used in door production in our data are imported, and the majority of machine owners report typically buying machines from domestic intermediary retailers.
} 
uses machines for only about one third of the time that the firm is open. These results uncover the presence of economies of scale driven by the indivisibility of capital inputs (machines) that increase productivity, but are expensive and have too high capacity relative to the scale of operations of the typical firm.

The fact that firms are small, but productive machines are large and expensive is consistent with two more empirical observations. First, there are low rates of investment in machines (Figure 2). For instance, the thickness planer, a key machine in the production process for doors, is owned by less than $10 \%$ of producers. Aggregating across machines, Panel (a) of Figure 3 reports the CDF of the "investment rate" defined similarly to the mechanization rate, but considering the share of machines that are owned by the firm: about $40 \%$ of door producers own none of the machines needed in production.

Second, firms operating at relatively larger scale are more likely to invest. In Table 3, columns 1 and 2, we regress the investment rate on two proxies for the scale of the firm. The first is the index of managerial ability. This is our preferred measure of firm scale as it captures the production potential of the firm, in line with classic entrepreneurship models where the ability of the manager determines the scale of the firm (e.g., Lucas (1978); Buera et al. (2011b)). The second is the number of workers. This is a standard way of measuring firm size. However, as capital and labor are (imperfectly) substitutable, firms that operate at sufficient scale to invest in machines might partly substitute labor for capital, thus attenuating the correlation between number of workers and investment. With this caveat in mind, we report results using both measures of firm scale. The table shows a strong correlation between firm scale and investment, regardless of which way we measure it.

Figure 2: Usage of machines by ownership vs. rental

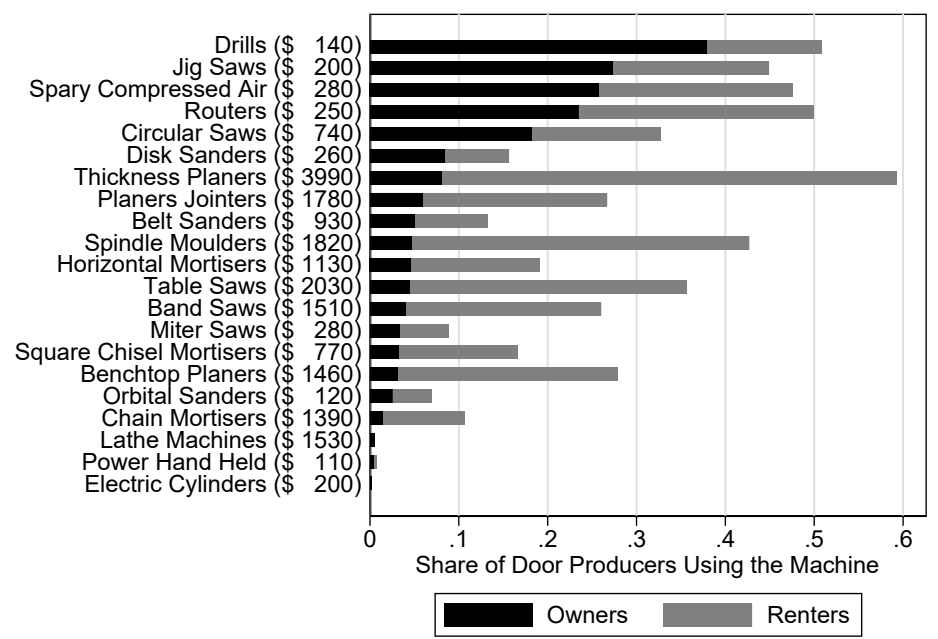

Notes: Sample: door producers. The figure reports the share of firms that use each pre-specified machine by whether they own it or rent it, together with average machine prices. Machine prices are trimmed at the top and bottom $1 \%$. Conversion rate: $1 \mathrm{USD}=3800 \mathrm{UGX}$. 


\section{Fact 3: Rental Markets for Machines Help Overcome the Indivisibility}

As lack of scale creates a barrier to investment, this raises the potential concern that economies of scale might go underexploited in this economy, hindering the mechanization and productivity of small firms. However, we discussed that firms operate in large informal clusters, and they produce similar products using similar production steps. Therefore, firms operating at small scale may be able to share the capacity of large machines. A natural market solution would be to organize a rental market for machines. Using our machine-level data, we show that a rental market has indeed emerged, and that this helps small firms overcome the indivisibility.

On the prevalence of the rental market, Figure 2 shows that while investment rates are low, renting machines is common. For instance, while less than $10 \%$ of firms own a thickness planer, over $50 \%$ rent one. ${ }^{16}$ Aggregating across machines, Panel $\mathrm{C}$ of Table 1 shows that for the average door producer the value of the machines rented in the production of the core product in carpentry is $92 \%$ of the value of all the machines used. Another way to appreciate the extent of the rental market is to compare the CDF of the investment and mechanization rate. We do so in Panel (a) of Figure 3. The contrast is striking: while over $40 \%$ of door producers do not own any of the machines needed for door production, only less than $10 \%$ do not use any such machines, and the difference is completely explained by the rental market.

Table 3: The role of firm scale for investment and mechanization

\begin{tabular}{lcccccc}
\hline & \multicolumn{2}{c}{ Investment Rate } & \multicolumn{2}{c}{ Mechanization Rate } & \multicolumn{2}{c}{$\begin{array}{c}\text { Share of Machine Hours } \\
\text { Rented In }\end{array}$} \\
& $(1)$ & $(2)$ & $(3)$ & $(4)$ & $(5)$ & $(6)$ \\
\hline Manager Ability (Std.) & $0.048^{* * *}$ & & $0.025^{* *}$ & & $-0.122^{* * *}$ \\
& $(0.011)$ & & $(0.011)$ & & $(0.023)$ & $-0.110^{* *}$ \\
Log Num Workers & & $0.069^{* * *}$ & & $0.043^{* *}$ & & $(0.042)$ \\
& & $(0.018)$ & & $(0.021)$ & & 0.645 \\
Mean of Dep. Var. & 0.139 & 0.139 & 0.381 & 0.381 & 0.645 & Yes \\
Sub-county FE & Yes & Yes & Yes & Yes & Yes & 0.199 \\
Adjusted $R^{2}$ & 0.200 & 0.188 & 0.465 & 0.466 & 0.261 & 303 \\
Observations & 381 & 381 & 381 & 381 & 303 & 303 \\
\hline
\end{tabular}

Notes: ${ }^{* * *} p<0.01,{ }^{* *} p<0.05,{ }^{* * *} p<0.1$. OLS regression coefficients, robust standard errors in parentheses. Sample: door producers (columns 1-4) and door producers using at least a machine (columns 5-6). Investment (mechanization) rate: share of pre-specified machine types for the production of core product that are owned (used) by the firm. To compute all outcomes, each machine type is weighted using the share of total machine time it accounts for in the data. Managerial ability: standardized index based on multiple survey questions; see the Supplemental Appendix for details.

\footnotetext{
${ }^{16}$ Figure 2 further shows that the rental market is more common for large and expensive machines, something that we discuss further in the Supplemental Appendix.
} 
The rental market operates primarily between carpenters in the same cluster, with machine owners renting out part of their machine time to other firms. This is possible because machine owners have substantial excess capacity: the average owner uses a machine for 23.9 hours per week, and rents out 10.8 hours of spare machine time to the market. Although other carpentry firms are the primary sources of rentals, about $40 \%$ of carpenters report renting from specialized rental workshops. ${ }^{17}$ We return to this point in the model, where we explicitly model specialized workshops.

Figure 3: Mechanization, firm scale, and rental markets

(a) CDF of investment and mechanization rates

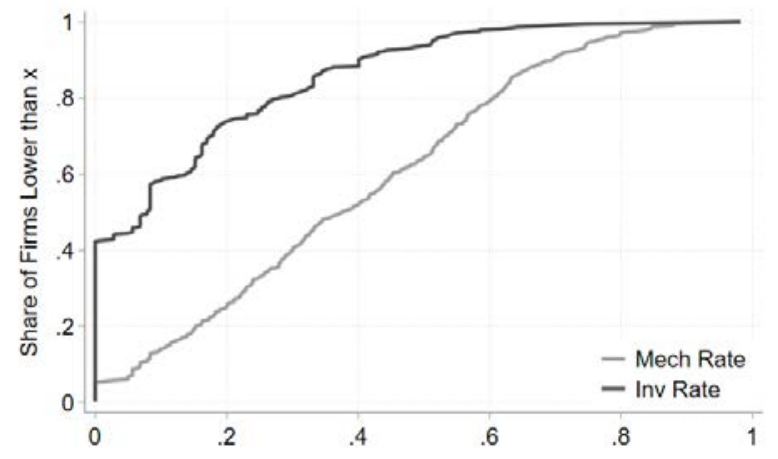

(c) CDF of firm size by ownership vs. rental

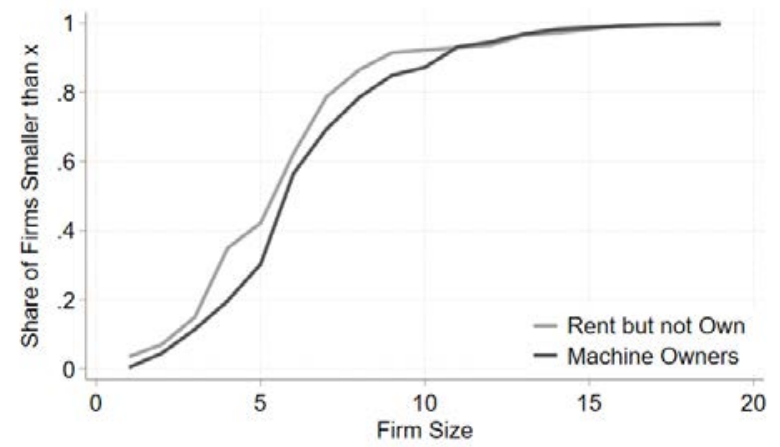

(b) CDF of manager ability by ownership vs. rental

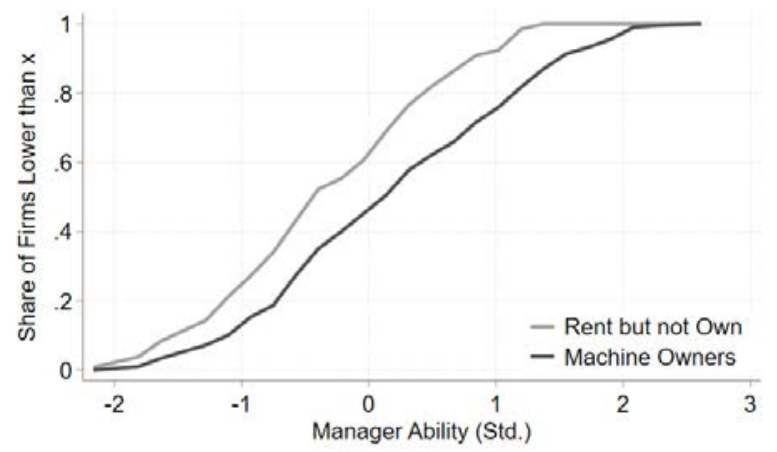

(d) CDF of firm size by definition of a firm

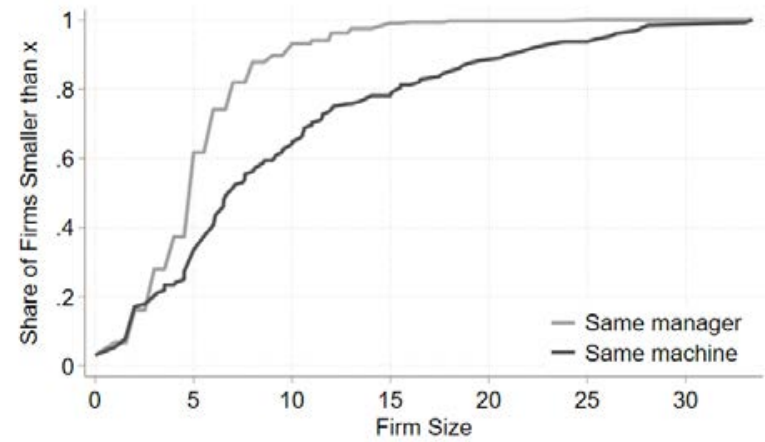

Notes: Sample: door producers. Panel (a): CDF of investment and mechanization rate (see Table 3 for definitions). Panel (b): CDF of standardized manager ability by whether the firm: (i) owns at least a machine; (ii) does not own machines but rents at least one. Panel (c): CDF of number of workers by whether the firm: (i) owns at least a machine; (ii) does not own machines but rents at least one. Panel (d): CDF of number of workers according to two definitions: (i) a firm is a set of workers under the supervision of one manager; (ii) a firm is a set of workers using the same machines. To compute (ii), we follow the procedure described in Section 3.3. Firm size is trimmed at the top $1 \%$ in panels (c) and (d).

Consistent with the fact that the rental market helps small firms overcome the indivisibility, we find that the rental market is particularly important for firms operating at relatively low

\footnotetext{
${ }^{17}$ Our data shows that specialized providers are more common in areas where machine rental prices are higher, and hence where the social value of rentals is higher. See the Supplemental Appendix for details.
} 
scale. Figure 3, panels (b) and (c), show that machine renters operate at smaller scale than machine owners. This is true for both proxies of firm scale, although the difference is more pronounced for managerial ability (that is our preferred measure of firm scale): firms that own at least one machine have a managerial ability 0.46 standard deviations higher than machine renters, while they have about $5 \%$ more employees. In line with this, columns 5 and 6 of Table 3 show that, conditional on using machines, firms operating at smaller scale rent a higher share of the machine hours they use. Hence, through the rental market, firms that operate at insufficient scale to buy machines manage to mechanize. ${ }^{18}$

The Online Appendix further shows that revenues from the rental market are significant, in line with the cost of capital being high in this economy, something that we verify directly and come back to later.

\section{Fact 4: Transaction Costs in the Rental Market for Machines}

We now show that the rental market is plagued by transaction costs that could partly undermine the ability of small firms to overcome the indivisibility of machines. We do so in three steps. First, we use our survey to measure those components of transaction costs that are directly observable, such as travel time. Second, we present evidence consistent with a high degree of competition in the rental market. We then propose a revealed preference approach to identify and estimate the overall size of transaction costs in a manner consistent with our model by exploiting the fact that rental markets are competitive. This yields our preferred estimate of transaction costs, which we show is nonetheless well aligned with the direct measure from the first step.

Rental markets operate subject to transaction costs. As most machines are heavy, the rental market is operationalized by workers carrying intermediate inputs to the firm where the machine is located and paying the machine owner a fee upfront to use their machine. Our survey allows us to directly measure those components of transaction costs related to transportation and time costs for machine access. To give a sense of these costs, the average renter visits machine owners 16 times per month, and every time they go they spend 50 minutes traveling, and about one and a half hours waiting for machine access. Wait times can in part be explained by congestion, as almost a third of renters report visiting machine owners in the early morning. To quantify these transaction costs, we compute for each renter: (i) their monthly value of time spent traveling to the machine owners' premises and waiting for machine access; (ii) their direct monthly transportation costs. Comparing the sum of (i) and (ii) with the monthly expenditures on machine rentals shows that transportation and time costs represent about $24 \%$

\footnotetext{
${ }^{18}$ Consistent with this, Table 3 shows that the correlation between firm scale and mechanization (columns 3 and 4) is much weaker than the correlation between firm scale and investment (columns 1 and 2).
} 
of direct expenditures on rentals, thus revealing that these components of transaction costs are significant. More details on our computation of transaction costs related to transportation and time costs can be found in the Online Appendix.

There may clearly be other transaction costs that we are not able to measure directly in our data (e.g., the risk of missing a sale if customers visit while the manager is at the premises of machine owners). This motivates us to adopt a revealed preference approach to estimate the overall size of transaction costs, which exploits the fact that rental markets are quite competitive, something that we show next.

Competition in the rental market. The rental market is characterized by spot transactions, so contractual frictions (e.g., Macchiavello (2018); Startz (2019)) are unlikely to be a major concern. We provide five pieces of evidence which suggest that the rental market operates competitively: (i) in each sub-county there are typically a number of machine owners of each type of machine, which likely creates competition and limits monopoly power; (ii) there is no correlation between rental prices and the number of machine owners in the sub-county, while we would have expected a negative relationship if machine owners had market power; (iii) larger machines do not generate higher revenues relative to their cost, which suggests that market power among owners of expensive machines is limited; (iv) when asked how they set rental prices, the majority of machine owners report taking into account the prices of other owners in the area; (v) firms do not report lack of information on who owns machines or the quality/reliability of rented machines as a problem, thus showing that information frictions in the rental market are limited. While this evidence is descriptive, it supports the conclusion that rental markets operate competitively. In the Online Appendix, we provide more details on our evidence that the rental market operates subject to transaction costs but is competitive.

Estimating the size of rental market transaction costs. We quantify the size of the overall transaction costs by studying how these distort the utilization of machine hours by renters. Transaction costs increase the effective price paid by renters for machine access. We assume that the rental price of one hour of machine time $p_{r}$ is set competitively, but that each transaction is subject to an additional proportional cost $\tau$. The marginal cost of capital for renters is then $p_{r}(1+\tau)$. For a machine owner instead, the marginal cost of capital is $p_{r}$. This is because, conditional on owning a machine, the opportunity cost of using the machine one extra hour (i.e., the marginal cost) is the price that the firm can earn by renting that hour out to the market. ${ }^{19}$ In a standard cost-minimization problem, the firm sets the ratio of the marginal products of capital and labor equal to the ratio of marginal costs. Since machine renters face a higher marginal cost of capital than machine owners, they will have a lower capital-labor

\footnotetext{
${ }^{19}$ While this is a general insight - that the opportunity cost depends on the market valuation of a good - our interpretation of $\tau$ as a pure transaction cost depends on the assumption of competitive rental markets.
} 
expenditure ratio, as long as $\tau$ is positive. That is, when compared to owners, renters will use relatively more labor and less capital to perform the same task, as capital is more expensive for them on the margin.

Following this logic, we estimate transaction costs focusing on production steps - that are clearly defined tasks in our case - and regress a step-level measure of the capital-labor expenditure ratio on the share of capital in that step that is rented. Specifically, we create a dataset where each observation is a production step $s$ in a firm $j$ in sub-county $c$, and run the following regression on the pooled sample of firms and production steps:

$$
\log \left(\frac{\bar{p}_{s c} K_{s j}}{\bar{w}_{j} L_{s j}}\right)=\beta_{0}+\beta_{1} \operatorname{Rent}_{s j}+\vartheta_{s}+\lambda_{c}+\delta X_{j}+\epsilon_{s j c} .
$$

The left hand side is the capital-labor expenditure ratio: $K_{s j}$ is the total monthly machine hours used by firm $j$ in production step $s ;{ }^{20} \bar{p}_{s c}$ is the average rental price for step $s$ faced by firms in sub-county $c$; $L_{s j}$ is the monthly labor hours used by firm $j$ in step $s$; and $\bar{w}_{j}$ is the predicted average hourly wage at firm $j .{ }^{21} R_{e n t}$ is the share of the machines used by firm $j$ in step $s$ that are rented, and so is our key variable of interest. ${ }^{22}$ A negative $\beta_{1}$ would mean that steps where machines are rented (as opposed to owned) use relatively more labor, which would then indicate the presence of transaction costs. We include step fixed effects $\vartheta_{s}$ (e.g., dummies for planing, thicknessing etc.) since we pool the estimation across steps. As identification of $\beta_{1}$ requires that renters and owners face the same direct rental cost, we include sub-county fixed effects $\lambda_{c}$, so that we compare firms in the same local rental market. Note that once we include sub-county and step fixed effects, the price level $\bar{p}_{s c}$ is subsumed in these fixed effects. ${ }^{23}$ Finally, $X_{j}$ are firm-level controls. Standard errors are clustered at the firm level.

The main concern with the identification of $\beta_{1}$ are omitted firm characteristics correlated with both the capital-labor ratio and the propensity to rent machines. To address this, we leverage our data at the step level and include firm fixed effects in our preferred specification. This allows us to compare the utilization of rented and owned machines across steps within the same firm, thus perfectly controlling for unobserved firm and product characteristics. ${ }^{24}$ As an alternative, we show robustness to controlling for firm-level controls $X_{j}$.

\footnotetext{
${ }^{20}$ In the Supplemental Appendix, we describe how we assign machines to steps and how we aggregate them to create $K_{s j}$.

${ }^{21}$ We prefer to use predicted wages from a regression of worker wages on firm size and individual worker characteristics (rather than actual wages) to alleviate endogeneity concerns. This also more closely maps to the model where differences in wages across firms only depend on firm size.

${ }^{22}$ In creating the shares of rented machines, each machine type in each step is weighted by the share of total machine hours in the step accounted for by that machine type in the data, so that machines used more intensively in a given step get a higher weight for that step.

${ }^{23}$ This is true as long as the step fixed effects are constant across sub-counties, i.e., $\bar{p}_{s c}=\bar{p}_{s} \times \bar{p}_{c}$. Our results are robust to the inclusion of a full set of step by sub-county fixed effects (not reported).

${ }^{24}$ This approach exploits variation coming from firms that partly own and partly rent machines across different steps. The share of such firms in our data is $44 \%$.
} 
Table 4 reports estimates of $\beta_{1}$ from equation 1 . Column 1 reports our preferred specification with firm fixed effects. The estimate of $\beta_{1}$ is -0.358 , with $95 \%$ confidence interval $[-0.088 ;-0.628]$. $\beta_{1}$ is directly related to the magnitude of transaction costs $\tau$ as follows: $\beta_{1}=-\log (1+\tau)$. This implies an estimate of $\tau=e^{0.358}-1=0.430$, which means that in steps where machines are rented, the capital-labor ratio is $43 \%$ lower. In columns 2 and 3 we show that our estimates are robust to excluding firm fixed effects, and adding firm controls instead: column 2 only controls for step fixed effects, and in column 3 we add our full set of controls. ${ }^{25}$ Finally, in column 4 we exclude those machine owners who do not rent out at least some of their machine time, since $p_{r}$ is a better measure of the marginal cost of capital for those machine owners who engage in the rental market. Reassuringly, our results are unaffected by this sample restriction.

Table 4: Estimates of transaction costs in the rental market Dependent variable: Log Capital-Labor Expenditure Ratio

\begin{tabular}{lcccc}
\hline & Firm FE & Step FE & Firm & $\begin{array}{c}\text { Exclude } \\
\text { Non-Renters } \\
\end{array}$ \\
& $(1)$ & $(2)$ & $(3)$ & $(4)$ \\
\hline Share of Rented Machines $(0-1)$ & $-0.358^{* *}$ & $-0.279^{* *}$ & $-0.226^{* *}$ & $-0.357^{* *}$ \\
& $(0.138)$ & $(0.123)$ & $(0.109)$ & $(0.165)$ \\
\hline Sub-county FE & No & No & Yes & No \\
Step FE & Yes & Yes & Yes & Yes \\
Firm Controls & No & No & Yes & No \\
Firm FE & Yes & No & No & Yes \\
Adjusted $R^{2}$ & 0.484 & 0.046 & 0.219 & 0.474 \\
Observations & 1,137 & 1,137 & 1,137 & 940 \\
\hline
\end{tabular}

Notes: ${ }^{* * *} p<0.01,{ }^{* *} p<0.05,{ }^{*} p<0.1$. OLS regression coefficients, standard errors clustered at the firm level in parentheses. Sample: door producers. Level of observation: production steps. Firm controls: managerial ability and dummies for types of doors produced. The numerator of the capital-labor ratio is the total monthly machine hours used by firm $j$ in production step $s$. We restrict attention to the seven most common steps out of the pre-specified ten steps for the production of doors, that is steps 3-9. All specifications control for the number of machines used in each production step. The capital-labor ratios are trimmed at the 1st and 99th percentiles. See the Supplemental Appendix for more details on: (i) how we assign machines to steps and how we aggregate machines within step; (ii) the specific production steps corresponding to steps 3-9.

Our estimate of $\tau$ is robust to a number of additional specification checks reported in the Online Appendix. In particular, we check robustness to: (i) estimating a more flexible specification that includes capital utilization (rather than the capital-labor ratio) on the left hand side, and controls for labor utilization on the right hand side; (ii) running a version of equation 1 at the machine level rather than aggregating machines at the step level.

Our results indicate that the overall rental market transaction costs $\tau$ are approximately $40 \%$ of the direct machine rental price. This shows that while transaction costs are significant,

\footnotetext{
${ }^{25}$ In column 2 we are implicitly assuming that machine rental prices do not vary across sub-counties.
} 
they are not prohibitively large. Comparing this estimate to the direct measure of transaction costs from our survey discussed above shows that transportation and time costs can account for about $60 \%$ of the overall estimated transaction costs. This reassures us about the validity of our estimate of $\tau$. Finally, as shown in the Online Appendix, our estimates of $\beta_{1}$ from equation 1 are lower (in absolute value) in sub-counties with higher firm density, while the scale of the firm is not a significant source of heterogeneity. This further confirms that our estimates of $\tau$ primarily capture transaction costs related to the time and physical costs of travel, as we would expect these to be smaller in areas with higher firm density, while firm scale should not matter for the size of these transaction costs. As discussed in more detail in the next section, our model will deliver the transaction costs $\tau$ as a structural parameter.

\subsection{Achieving Scale Collectively?}

We documented sizable economies of scale, driven by the large capacity and cost of modern machines, and discussed the concern that these may go largely unexploited due to the small scale of most firms. However, we also uncovered an active rental market, which allows small firms to mechanize, but operates under significant transaction costs. The key question that emerges then is to what extent the rental market allows small firms to achieve scale collectively and overcome the indivisibility of machines. In the rest of the paper, we answer this question.

We do so in two ways. First, we summarize empirically the prevalence of the rental market in our setting, by studying its implications for the firm size distribution. This provides an illustration of the extent to which the rental market allows firms to share machines. In the next sections, we then write down and estimate a model to precisely quantify which fraction of the potential gains from scale are reaped collectively through the rental market, to study the distributional effects of the rental market, and to perform policy counterfactuals.

Implications of the rental market for the firm size distribution. Firm size is typically measured by the number of workers under the supervision of the firm manager. However, our data shows that firms are deeply intertwined through a rental market for machines. This suggests that redefining the firm boundary as the workers utilizing the same production machines is an insightful way to summarize the extent to which the rental market helps firms achieve scale collectively. ${ }^{26}$ We thus compare how the firm size distribution changes as we redefine the boundary of the firm. Specifically, Panel (d) of Figure 3 reports: (i) the size distribution when a firm is defined by the number of employees under one manager, and (ii) the size distribution when a firm is defined by all employees operating the same machines, which we create by reas-

\footnotetext{
${ }^{26}$ This alternative definition of the firm boundary is in line with a classic literature in organizational economics which views the firm as being defined by the ownership of production assets (Grossman and Hart, 1986; Hart and Moore, 1990).
} 
signing the employees of machine renters to machine owners. ${ }^{27}$ The results are striking: once we account for rental market interactions, the average firm size increases by $77 \%$, from 5 to 8.8 employees, and the share of firms with more than 10 employees increases from $5 \%$ to $33 \%$. This is especially notable, given that in developing countries firm size distributions based on the typical definition are known to be characterized by a large mass of small firms, with "missing" medium and large firms (Hsieh and Olken, 2014).

The rental market reduces the gains from consolidation. Finally, we note that it remains a puzzle why more profitable firms do not formally take over smaller and less productive firms, and instead engage in rental relationships with them. There could be many constraints leading to this, such as contracting frictions or a limited span of control (Bloom et al., 2010; Akcigit et al., 2021). While our survey (and our model) is not designed to answer these important questions, we note that through the rental market, firms de facto already exploit at least some of the productivity benefits of consolidation, which substantially limits the impact of any such constraints on productive efficiency.

\subsection{Labor and Output Markets}

We present additional descriptive results to inform our modeling choices. First, we find evidence of diseconomies of scale in labor due to labor market frictions, motivating a convex cost of labor in the model. Second, we uncover substantial product differentiation and limited competition in the output market, leading us to write a model with monopolistic competition. We summarize these additional results here, and leave a more detailed discussion to the Online Appendix.

Labor market frictions and diseconomies of scale in labor. We find that firms operate in a labor market with significant search frictions due to lack of information on workers. In short, our data reveals that: (i) most workers are hired through referrals; (ii) it takes on average over a month to replace workers who leave; (iii) in about a third of cases, the manager would be willing to raise the workers' wages if they threatened to leave; (iv) turnover is low despite the absence of any firing or hiring laws. When asked about the sources of labor market frictions, managers indicate difficulties in screening workers at recruitment as their primary concern.

This evidence suggests that there are diseconomies of scale in labor. For instance, since networks are such an important recruitment channel, we can expect the cost of recruitment to

\footnotetext{
${ }^{27}$ To compute (ii), we identify firms that only rent machines, and we reassign their labor to machine owners as follows: all the workers of each machine renter are first reassigned to the machine types they rent, proportionally to the time that they use each machine type. We then sum across renters to create a "pool" of workers to be redistributed to machine owners for each machine type. We exclude from this pool those workers using machines rented from specialized workshops. Finally, for each machine type, we divide this pool of labor equally among all machine owners, and report the CDF of machine owners as the dark solid line in Panel (d). We only consider machines worth on average at least two months of profits for this exercise.
} 
increase exponentially as the manager needs to extend beyond her network of contacts in order to hire more employees (Chandrasekar et al., 2020).

It is worth highlighting the contrast with the rental market on this point: as discussed in Section 3.2, managers report knowing who owns machines and the quality/reliability of rented machines is not perceived as a problem, so that in the rental market we do not find evidence of information frictions. This contrast can be explained by the different nature of the capital and labor inputs: the productivity and reliability of rented machines can be easily assessed by managers as firms use similar machines and these are simple to test, while learning about workers' abilities and whether they can be trusted is more costly due to the lack of skills certification in these contexts. ${ }^{28}$ In line with this, managers report substantial investment in training and supervision of their workers: for instance, the average worker needs more than two months of training/supervision from the time of hiring until they are able to work independently. ${ }^{29}$

We also study how labor specialization, teamwork and hours worked vary across the firm size distribution, to check whether a more efficient or intense use of labor could create economies of scale in the labor input. In short, we find only limited evidence of this channel.

Demand and competition in the output market. As described above, the rental market takes place within clusters of firms in the same sector. That is, firms rent out their machines to other firms they are potentially competing with. Since an active rental market exists, any loss of revenues for machine owners from the increased productivity of surrounding firms must be more than offset by the profits from renting out their machines. Limited competition in the output market would explain the sustainability of this arrangement. We provide two pieces of evidence that suggest that competition is low.

First, we find substantial variation in both prices and quality for our core product (doors) even within sub-counties, which indicates that firms produce differentiated products. Second, our data shows that: (i) the majority of customers originate from within the local urban area; (ii) firm owners engage in extensive interactions with customers, e.g., they try to persuade customers of the quality of their products, and there is price variation across customers for the same product driven by bargaining; and (iii) firms have few customers and cite lack of demand as a very serious problem. This evidence suggests that demand is geographically segmented and that relationships with customers are important, which are both factors that can limit competition. ${ }^{30}$ In line with limited competition due to product differentiation and output

\footnotetext{
${ }^{28}$ See Alfonsi et al. (2020); Bassi and Nansamba (2021); Abebe et al. (2020) and Carranza et al. (2020).

${ }^{29}$ We further notice that since rented machines are operated either directly by the employees of machine renters (in a third of cases) or by those of machine owners (in the remaining cases), workers operating the machines have in any case already been screened, so that information frictions on workers are not relevant at the time of using rented machines. This further justifies why the degree of frictions (and competition) in the labor and rental market can in principle be different.

${ }^{30}$ Another potential reason for limited competition in firm clusters would be collusive behavior on prices.
} 
market frictions, we estimate markups of $23 \%$ for the carpentry sector.

\subsection{The Other Sectors}

We can now return to the reasons why we focused on carpentry in the previous sub-sections. Panel $\mathrm{C}$ of Table 1 shows that the rental market is much less prevalent in metal fabrication and grain-milling: while in carpentry the share of rented machines (in terms of value) is $92 \%$, this is $63 \%$ in metal fabrication and only $2 \%$ in grain milling.

Interestingly, we document that in these other sectors the rental market is less needed for technological reasons. In metal fabrication, machines are substantially cheaper than in carpentry. Therefore, lack of scale does not create a substantial barrier to investment, even though machines are not used at full capacity, as shown in Panel C of Table 1. In grain milling instead, the production process requires only few machines and these are used much more intensively by each firm: as shown in Panel $\mathrm{C}$ of Table 1, the average firm in grain milling uses only 3.1 machines on the core product, but uses each for 44.6 hours per week (the same numbers for carpentry are 5.4 machines and 9.1 hours). Therefore, even though machines are almost as expensive as in carpentry, the lack of scale plays a more limited role in impeding investment as each firm uses machines closer to full capacity. ${ }^{31}$

Given these considerations, we focus on carpentry in the model.

\section{Model}

We develop a model to quantify the aggregate and distributional effects of the rental market. The assumptions implicit in the model's design are motivated by the empirical results and find support in the data, as we discuss in Section 5.3.

\subsection{Setup}

We consider a one-period economy, inhabited by a continuum of agents.

Agents. The economy is inhabited by workers and carpentry managers. Workers are homogeneous, have an exogenous yearly income equal to $\Psi$, which they use to finance consumption, and supply (some of) their labor to the carpentry sector. Carpentry managers, in mass 1, are heterogeneous and each identified by a unique index $\omega \in \Omega$. They differ along two dimensions: (i) the shadow cost of capital, $x(\omega)$, which captures the fact that some individuals might have

Brooks et al. (2018) document the importance of this channel in Chinese manufacturing.

${ }^{31}$ In the Supplemental Appendix we report direct evidence on machine prices and the prevalence of the rental market for each machine type in metal fabrication and grain milling. 
more assets for self-financing and/or easier access to credit; (ii) a skill term, $z(\omega)$, which determines the manager's productivity. We omit the index $\omega$ when not strictly necessary. The cost of capital and managerial skills are jointly distributed with density $g(x, z)$.

Preferences. Individuals consume a general consumption good $Y$, and a composite carpentry good $Y_{C}$, which aggregates the quantities produced by each manager $\omega, y(\omega)$. Defining $\hat{\Omega} \subseteq \Omega$ to be the set of active managers producing positive output, the utility function is

$$
\begin{aligned}
U\left(Y, Y_{C}\right) & =\left[(1-\lambda) Y^{1-\iota}+\lambda Y_{C}^{1-\iota}\right]^{\frac{1}{1-\iota}} \\
Y_{C} & =\left[\int_{\omega \in \hat{\Omega}} y(\omega)^{1-\eta} d \omega\right]^{\frac{1}{1-\eta}},
\end{aligned}
$$

where $\frac{1}{\iota}$ and $\frac{1}{\eta}$ are the two elasticities of substitution.

The consumers' problem. The representative household chooses how much to consume of each good to maximize utility subject to the budget constraint

$$
\begin{array}{cc} 
& \max _{\{y(\omega)\}_{\omega \in \hat{\Omega}}, Y}\left[(1-\lambda) Y^{1-\iota}+\lambda Y_{C}^{1-\iota}\right]^{\frac{1}{1-\iota}} \\
\text { s.t. } & \int_{\omega \in \Omega} p(\omega) y(\omega) d \omega+Y \leq \Psi
\end{array}
$$

where the outside good $Y$ is the numeraire. The assumption of CES demand, see Melitz (2003), implies that the price of the variety produced by manager $\omega$ is

$$
p(\omega)=\left(\frac{\lambda}{1-\lambda}\right)\left(\frac{y(\omega)}{Y_{C}}\right)^{-\eta}\left(\frac{Y_{C}}{Y}\right)^{-\iota} .
$$

We define $P \equiv\left(\frac{\lambda}{1-\lambda}\right) Y_{C}^{\eta-\iota} Y^{\iota}$ so that each manager $\omega$ faces a price schedule decreasing in its own output, given by $p(\omega)=y(\omega)^{-\eta} P$.

Production function. Each manager $\omega$ has access to two production processes to make the good $y(\omega)$ : a non-mechanized one, which uses only labor, and a mechanized one, which uses a combination of labor and capital. If the firm uses the non-mechanized process, output is produced according to

$$
y(\omega)=z(\omega) A_{L} L(\omega)
$$

where $L$ is labor, and $A_{L}$ is a productivity term for the non-mechanized process, identical for all managers. If the firm uses the mechanized process, output is produced according to

$$
y(\omega)=z(\omega) A_{M} K(\omega)^{\alpha} L(\omega)^{1-\alpha}
$$


where $K$ is capital, $A_{M}$ is productivity specific to the mechanized process, and $\alpha$ is the capital share in production.

The outside good $Y$ is in fixed supply.

Machines and capital market. Capital is supplied by machines. There is only one type of machine in the market, which should be interpreted as an aggregate of the different machines documented in the previous section. Machines can be purchased at price $p_{b}$, depreciate at rate $\delta$, and have a convex operating cost given by $\chi(C)=\frac{\chi}{1+\xi} C^{1+\xi}$, where $C$ is the machine capacity utilization, which can be at most 1 . Machines are indivisible and each firm can purchase either one or zero machines.

Rental market for machines. A manager $\omega$ that purchases a machine, chooses to operate it at capacity $C(\omega)$, and uses $K(\omega)$ units of capital in production, has excess capacity equal to $C(\omega)-K(\omega){ }^{32}$ Excess machine capacity is rented out to other firms in a competitive rental market at equilibrium price $p_{r}$. The market is subject to a transaction cost $\tau$, or rental market wedge, that renters have to pay for each unit of machine time. The total effective price paid by a renter to use one unit of machine time is $(1+\tau) p_{r}$, while the machine owner receives the price $p_{r}$. The wedge $\tau$ captures the transaction costs documented in Section 3.2, such as transportation and time costs to use the rental market. All costs are expressed in units of output.

Labor market. Labor is hired in a partial equilibrium market subject to frictions. We model frictions in reduced form as a convex cost of labor: manager $\omega$ hiring labor $L(\omega)$ faces total labor cost equal to $W L(\omega)^{1+\nu}$ where $W$ is the wage level and $\nu \geq 0$ modulates the extent of the frictions. If $\nu=0$, each manager can hire as much labor as she wishes at the equilibrium wage. Instead, if $\nu$ is positive, the manager faces an increasing labor supply curve and needs to pay a higher wage to grow the firm size. As a result, there is wage dispersion across firms, and a size-wage premium - as in frictional labor models such as Burdett and Mortensen (1998).

The managers' problem. First, given her managerial ability $z$, but before observing her cost of capital $x$, each manager $\omega$ decides whether to enter the market and start producing or take an exogenous outside value $\pi_{N}(z)$. The ex-ante profits for a manager $\omega$ are thus given by

$$
\Pi(\omega)=\max \{\underbrace{\pi_{N}(z(\omega))}_{\text {Outside Option }} ; E_{x} \underbrace{[\pi(x(\omega), z(\omega))]}_{\text {Production Profits }}\}
$$

where $\pi(x, z)$ is the profit of a manager with traits $(x, z) . E_{x}[\cdot]$ is the expectation taken with respect to the distribution of the random variable $x$ conditional on the managerial ability $z$. We

\footnotetext{
${ }^{32}$ The excess capacity is trivially $C(\omega)$ if the manager purchases the machine but uses the non-mechanized process, hence $K(\omega)=0$. Also, the excess capacity can be negative if a manager both owns and rents capital.
} 
use this notation throughout the model. The expected profits do not depend on the identity of the manager, or her name $\omega$, but only on her characteristics $(x, z)$. Therefore, we omit $\omega$. We define a dummy $\mathbb{I}_{E}(\omega)$ equal to 1 if manager $\omega$ decides to enter the market. The set of active managers is then $\hat{\Omega} \equiv\left\{\omega \in \Omega\right.$ s.t. $\left.\mathbb{I}_{E}(\omega)=1\right\}$.

If the manager enters the market, she observes her cost of capital $x$ and then chooses labor, capital, and machine capacity to maximize her profits. She thus solves

$$
\begin{gathered}
\pi(x, z)=\max _{L \geq 0, K \geq 0, C \geq 0} \underbrace{y^{1-\eta} P}_{\text {Revenues }}-\underbrace{W L(\omega)^{1+\nu}}_{\text {Labor Cost }}-\underbrace{\left(1-\mathbb{I}_{C}\right)}_{\text {Renters }} \times \underbrace{\left[p_{r}(1+\tau) K\right]}_{\text {Capital Cost for Renters }} \\
+\underbrace{\mathbb{I}_{C}}_{\text {Owners }} \times[\underbrace{p_{r} \max \{0, C-K\}}_{\text {Revenues from Renting Out }}-\underbrace{\frac{\chi}{1+\xi} C^{1+\xi}-(x+\delta) p_{b}-p_{r}(1+\tau) \max \{0, K-C\}}_{\text {Capital Cost for Owners }}] \\
\text { s.t } \\
y=\left\{\begin{array}{lll}
z A_{L} L & \text { if } \mathbb{I}_{K}=0 \quad \text { [Non-Mechanized Production Process] } \\
z A_{M} K^{\alpha} L^{1-\alpha} & \text { if } \mathbb{I}_{K}=1 & \text { [Mechanized Production Process] }
\end{array}\right.
\end{gathered}
$$

where $\mathbb{I}_{C}$ and $\mathbb{I}_{K}$ are dummies equal to 1 if the manager chooses to buy the production machine, and to use capital in production, respectively. The max operators within the revenues from renting out and cost of capital for machine owners allow for the possibility that excess capacity is negative, that is, that some machine owners also rent in capital from the rental market.

Definition of the competitive equilibrium. The competitive equilibrium is given by a vector of entry choice, capital, labor, capacity, output, and output price for each manager $\omega$, $\left\{\mathbb{I}_{E}(\omega), K(\omega), L(\omega), C(\omega), y(\omega), p(\omega)\right\}_{\omega \in \Omega}$, the rental price for machines $p_{r}$, and the aggregate price level $P$, such that:

1. the rental market clears: $\int_{\omega \in \hat{\Omega}} C(\omega) d \omega=\int_{\omega \in \hat{\Omega}} K(\omega) d \omega$;

2. the goods' markets clear: $Y_{C}=\left[\int_{\omega \in \hat{\Omega}} y(\omega)^{1-\eta} d \omega\right]^{\frac{1}{1-\eta}}$;

3. each potential manager maximizes profits - i.e., solves problems 3 and 4;

4. the representative consumer maximizes utility - i.e., solves problem 2.

\subsection{Characterization}

We study the role of the rental market in shaping economic activity and productivity. The main objects of interest are the managers' choices of whether to mechanize the production process - i.e., use positive capital $\left(\mathbb{I}_{K}=1\right)$ - and whether to invest - i.e., purchase the production 
machines and thus choose positive capacity $\left(\mathbb{I}_{C}=1\right)$ - and how these depend on the rental market wedge $\tau$. To simplify the analytical characterization, we work under the following empirically motivated assumption, which we will relax in the quantification. ${ }^{33}$

Assumption 1. The excess capacity is weakly positive, i.e., $C(\omega) \geq K(\omega)$, for all managers.

We summarize the results in a Lemma that describes the equilibrium structure and how it changes as a function of the rental market wedge $\tau$, and a Proposition that illustrates the aggregate impact of the rental market and the two mechanisms through which it operates.

Lemma 1. There exist two weakly increasing functions $\hat{x}(z)$ and $\hat{z}(x)$ such that: (i) managers invest if and only if $x<\hat{x}(z)$ and (ii) they mechanize if and only if $z \geq \hat{z}(x)$. Furthermore, if $\tau=0$, then $\hat{x}(z)=\hat{x}$ for all $z$ and $\hat{z}(x)=\hat{z}$ for all $x$, while if $\tau \rightarrow \infty$, then $\hat{x}(z)=\hat{z}^{-1}(x)$.

Figure 4: Equilibrium investment and mechanization choices

(a) No transaction costs $(\tau=0)$

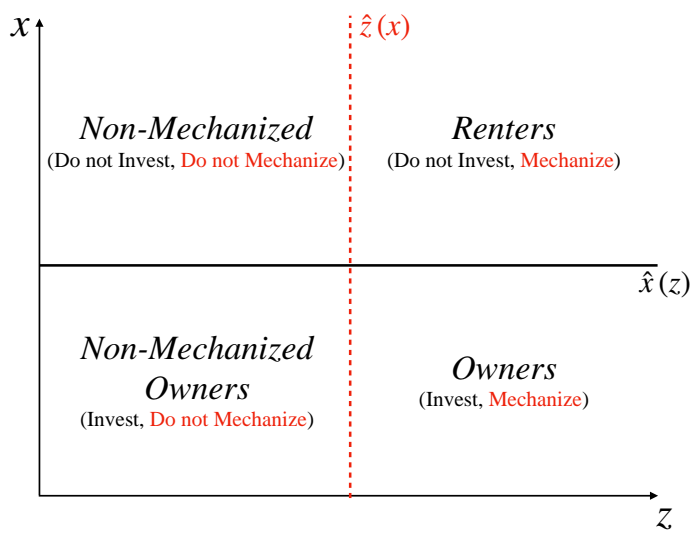

(c) Large transaction costs (high $\tau$ )

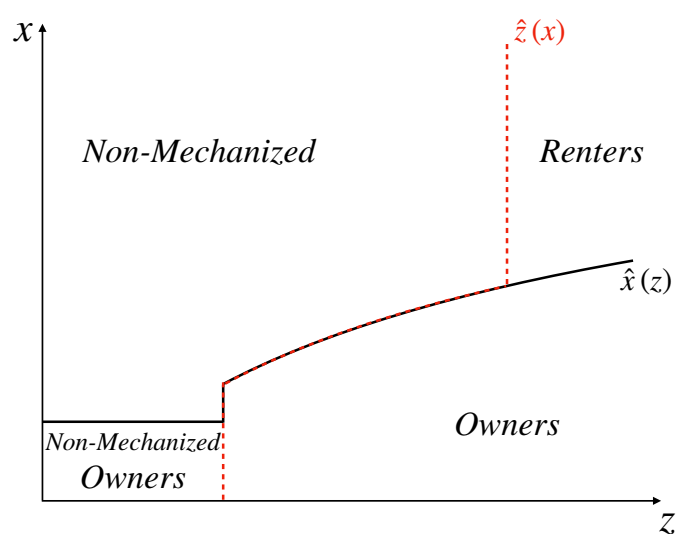

(b) Small transaction costs (low $\tau$ )

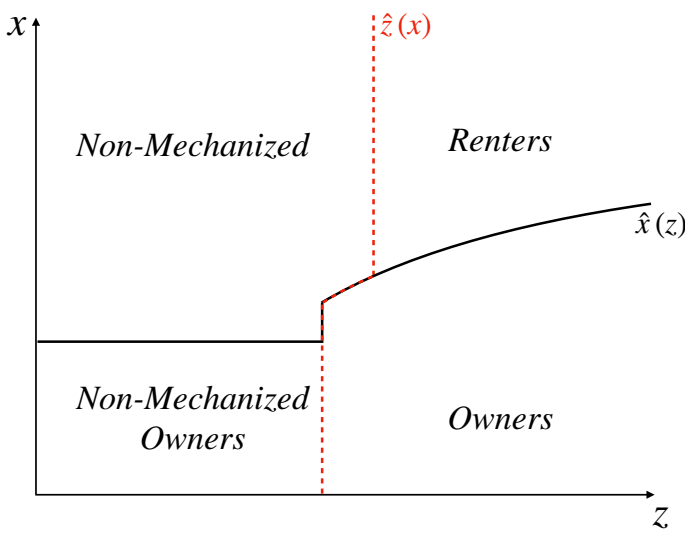

(d) No rentals $(\tau \rightarrow \infty)$

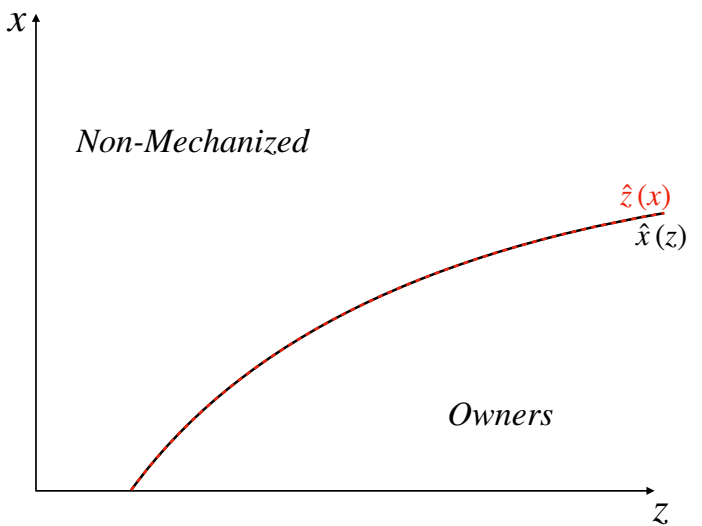

Notes: The figure shows the partitions of the $(x, z)$ space into four compact groups of managers: (i) renters, that do not invest but mechanize; (ii) owners, that invest and mechanize; (iii) non-mechanized owners, that invest but do not mechanize and thus rent out all their machine's capacity; and (iv) non-mechanized firms, that do not invest nor mechanize. We show these partitions for different values of the rental market wedge $\tau$.

\footnotetext{
${ }^{33}$ In our data, over $70 \%$ of carpenters who own machines also rent out their machines to others.
} 
Lemma 1, illustrated in Figure 4, shows that managers are partitioned into four groups with different production choices depending on their ability $z$ and cost of capital $x$, and that the shape of the partitioning depends on the rental market wedge $\tau$. When transaction costs are zero (Figure 4a), the choice to mechanize and invest are not related, as mechanization only depends on the return from using capital $z$, while investment depends only on the cost of capital $x$. The return from capital increases in $z$ due to the capital-skill complementarity in the production function. Transaction costs in the rental market instead bundle together capital ownership and utilization (Figures $4 \mathrm{~b}$ and $4 \mathrm{c}$ ) as they make capital more expensive to use for renters, and less profitable to rent out for machine owners. This creates misallocation of resources relative to the benchmark without transaction costs. In the extreme case when $\tau \rightarrow \infty$ (Figure $4 \mathrm{~d}$ ), mechanization is possible only through investment in machines.

Proposition 1. For a fixed set of managers $\hat{\Omega}$ and output price $P$, a decrease in $\tau$ yields

1. Higher profits for all managers: $\pi(x, z)$ weakly increases for all $(x, z)$.

2. A higher engagement in the capital market: the mass of firms that either invest or mechanize, $\int \mathbb{I}_{C}(\omega) d \omega+\int\left(1-\mathbb{I}_{C}(\omega)\right) \mathbb{I}_{K}(\omega) d \omega$, increases since the revenues from renting out each unit of machine time - $p_{r}$ - increase, while the cost of renting in $-(1+\tau) p_{r}-$ decreases;

3. An improvement in the allocation of capital: for a constant price $p_{r}$, the correlation between mechanization and investment choices decreases;

4. A higher ability to overcome the indivisibility through collective scale: let $x(\omega)=\bar{x}$ for all $\omega$, then the average mechanization increases.

In a well-functioning (low $\tau$ ) rental market, capital is more valuable, as its equilibrium price $p_{r}$ increases, but also cheaper to access for renters, as the increase in $p_{r}$ is not large enough to compensate the decline in $\tau$. As a result, as long as the aggregate output price $P$ is constant, all managers weakly benefit, irrespective of their production choices (1.). Furthermore, the relative returns from both owning and using capital increase, which increases the overall engagement of firms in the capital markets (2.). ${ }^{34}$

The overall effects are the result of two distinct mechanisms through which the rental market operates. The first one (3.) is akin to a financial market. By unbundling capital ownership and utilization, a well-functioning rental market improves the allocation of capital since managers with the lowest cost of capital (low $x$ ) purchase the machine, and the ones with the highest returns from using capital (high $z$ ) mechanize. ${ }^{35}$ The second one (4.) is specific to the rental

\footnotetext{
${ }^{34}$ Notice that, nonetheless, neither mechanization nor investment must necessarily increase. An improvement in the allocation of capital could decrease overall investment as firms more effectively rely on renting to mechanize. Similarly, mechanization may decrease since when $\tau$ is low, the high market value of capital may induce some machine owners to rent out all their capital rather than mechanize.

${ }^{35}$ We keep the price $p_{r}$ constant in the Proposition to avoid that changes in the value of capital may indirectly affect the allocation by influencing the share of managers willing to invest and mechanize.
} 
market and at the core of the idea of achieving scale collectively. In the presence of strong decreasing returns and high-capacity machines, the optimal firm size may not be large enough to justify the investment if the firm must use all the capacity by itself. The rental market allows firms to share the machines' capacity, thus overcoming this problem. The result is that, even when all managers have identical cost of capital $x(\omega)=\bar{x}$ so that the rental market has no allocative role by construction, a well-functioning rental market increases mechanization by allowing more firms to access the same machines.

\section{Estimation}

Next, we estimate the model. First, we describe how we parameterize it and calibrate the several parameters that have a direct empirical counterpart in our data and can be computed outside of the model. Then, we show how the remaining 15 parameters are jointly estimated targeting 38 empirical moments and provide a heuristic identification argument. Finally, we show the estimation results and discuss a few key model's assumptions and their implications for identification.

\subsection{Parametrization and Calibrated Parameters}

First of all, to make the model amenable to a quantitative empirical analysis, we introduce two minor extensions: (i) extreme value shocks to smooth out the discrete choice of managers of whether to enter, mechanize, and invest in machines; (ii) an external sector that specializes in renting out machines, to capture the empirical evidence of Section 3 showing that a sizable share of the overall market capacity is supplied by specialized workshops.

Extreme value shocks. Each manager $\omega$ draws two vectors of preference shocks: (i) $\left\{\varepsilon_{N} ; \varepsilon_{E}\right\}$ where $\varepsilon_{N}$ is for exit, and $\varepsilon_{E}$ for entry; (ii) $\left\{\varepsilon_{m}(\omega)\right\}_{m \in \mathbb{M}}$, where $\mathbb{M}$ is the set of four possible production methods, or the combination of the investment and mechanization choices. The shocks are distributed according to independent Type II Extreme Value Distribution with shape parameters $\tilde{\theta}^{-1}$ and $\theta^{-1}$. Given the realization of the first vector of shocks, the manager decides whether to enter, taking into account the expected value of production which depends on the realization of the second vector of shocks:

$$
\Pi(\omega)=\max \left\{\varepsilon_{N}(\omega) \pi_{N}(\omega) ; \varepsilon_{E}(\omega) \pi_{E}(\omega)\right\}
$$

where

$$
\pi_{E}(\omega)=\mathrm{E}_{x, \varepsilon}\left[\max _{m \in \mathbb{M}} \varepsilon_{m}(\omega) \pi_{m}(x(\omega), z(\omega))\right]
$$


and $\pi_{m}(x(\omega), z(\omega))$ is the solution to problem (4), imposing as an additional constraint that the manager must follow the production method $m .{ }^{36}$

Frechet-distributed taste shocks smooth out discrete choices and provide analytical expressions for the probability that each option is chosen. The parameter $\theta$ modulates the relative roles of shocks and individual characteristics in determining production choices. The higher is $\theta$, the closer the equilibrium resembles the partitions shown in Figure 4. If $\theta \rightarrow 0$, all managers are equally likely to adopt any production method, irrespective of their skills and cost of capital.

Specialized rental providers. Specialized machine providers, in fixed mass $\phi$, do not produce carpentry good themselves, but own capital that they rent out to carpenters. They face the same cost of capacity utilization as carpentry firms. We do not need to take a stand on their interest rate $x$ because they are in fixed supply and their profits are not included in the sector GDP. Each specialized machine provider solves the capacity maximization problem

$$
\max _{C} p_{r} C-\chi(C)
$$

The solution to the problem yields an additional supply of capital in the market equal to $\phi \chi^{-\frac{1}{\xi}} p_{r}^{\frac{1}{\xi}}$, where $\chi$ and $\xi$ are the same parameters as in the carpentry problem, and $p_{r}$ is the rental market price.

Next, we turn to describing the chosen parameterization and the calibrated parameters.

Outside option. We assume that the outside option of a manager $\omega$ is

$$
\pi_{N}(\omega)=\tilde{\pi}_{N}\left(E_{\omega}\left[\pi_{E}(\omega)\right]\right)^{1-\psi}\left(\pi_{E}(\omega)\right)^{\psi}
$$

where $\tilde{\pi}_{N}$ is a constant term that captures the overall value of the outside option, while $\psi$ captures how sensitive this is to managers' ability.

Calibrated parameters. We assume that the joint distribution of $(x, z)$ is given by two correlated log-normals, yielding five free parameters: $\{\mathrm{E}(x), \operatorname{Var}(x), \mathrm{E}(z), \operatorname{Var}(z), \operatorname{Cov}(x, z)\}$. We normalize $A_{L}=1$. With these restrictions, the model entails 22 parameters. As we describe next, 7 of these can be directly computed in the data, while we jointly estimate the remaining 15 in the next section. All parameters are shown in the Online Appendix, which also includes references to the specific tables where we compute each parameter and show robustness.

The rental market wedge $\tau$ can be estimated examining the relative capital intensity of machine owners and renters. In fact, the model yields the exact empirical specification run in

\footnotetext{
${ }^{36}$ For example, for a renter, $m=\left\{\mathbb{I}_{K}=1 ; \mathbb{I}_{C}=0\right\}$, we would add to the problem that $K>0$ and $C=0$.
} 
Section 3.2 since the following relationship holds for all managers that mechanize

$$
\log \left(\frac{p_{r} K(\omega)}{w(\omega) L(\omega)}\right)=\gamma_{0}-\left(1-\mathbb{I}_{C}(\omega)\right) \log (1+\tau)
$$

As shown in Section 3.2, our preferred estimate of transaction costs yields $\tau=0.43$.

Due to the Cobb-Douglas production, the capital share $\alpha$ is pinned down by the ratio of the capital and labor expenditures, which we compute in the data for each mechanized step. We focus on machine owners since their marginal cost of capital is not affected by the rental market wedge and we find that the capital-labor ratios are very similar across steps. We compute the average, weighted by the share of labor expenditures in each step, and find $\alpha=0.50$.

We compute the rental and purchase prices, $p_{r}$ and $p_{b}$, directly from our machine-level data, by calculating a weighted average of the reported prices across all the machines in our dataset. The weights are given by the overall number of hours that each type of machine is used in our data. The representative machine costs $\$ 776.2$ and is rented at $\$ 0.514$ cents per hour.

We can calculate depreciation directly in our data by computing, for each machine, the relationship between value and age. We aggregate across machine types using the same weights as for prices and find that the representative machine depreciates at a yearly rate of $6.9 \%$.

Using the same aggregation described above, we calculate the share of total machine capacity supplied from specialized providers. We find that this share is $49.4 \%$, which leads to $\phi=0.976$ when we normalize the mass of active managers to be equal to 1 .

Finally, for the elasticity of substitution for the composite carpentry good, $\frac{1}{\iota}$, we pick 2.2 , which is the estimate for "Wood Manufactures, N.E.S." from Broda and Weinstein (2006), who estimate the elasticities of substitution for 3 digit industries using U.S. data. ${ }^{37}$

\subsection{Targeted Moments and Identification}

To estimate the 15 remaining parameters, we target 38 empirical moments. These include all the empirical relationships presented in Section 3.2 and shown in Tables 2 and 3 and Figure 3, as well as additional moments computed from our data. All the 38 moments are reported in the Online Appendix, which also links to the tables where each moment is constructed.

We follow the standard indirect inference approach and run the same regressions using both our survey data and the model-generated data. While the approach is straightforward, the model-generated data requires two small intermediate steps before running the empirical specifications. First, we need to smooth out the discrete mechanization and investment choices. In the data, we compute mechanization rates, investment rates and share of machine hours rented in, aggregating across all the used machines, as explained in details in Section 3.2.

\footnotetext{
${ }^{37}$ Notice that $\iota$ does not affect the estimation but is necessary to compute general equilibrium counterfactuals. Nonetheless, given the possible uncertainty around this parameter, we consider 1 and 4 for robustness.
} 
In the model, each manager makes a discrete choice of whether to mechanize and invest in a machine. To transform the discrete choices into rates, we project all the individual firm outcomes on the distribution of managerial characteristics. For example, the mechanization rate for the type $(x, z)$ would be the share of managers with characteristics $(x, z)$ that choose to mechanize. ${ }^{38}$ Second, we need to transform the primitive ability $z$ to make it comparable to our empirical index of managerial ability. In practice, we create a standardized measure of managerial ability, $\log \hat{z}$, which normalizes $\log z$ to have mean 0 and standard deviation 1 , and we then use this measure to run the regressions with the model-generated data. ${ }^{39}$

All parameters are jointly identified, but we next provide a heuristic argument for how each block of targeted moments pins down certain parameters of interest.

Mechanization, investment, and renting. We match the mechanization and investment rates, and the share of total machine hours that are rented in. Given the cost of machines, the mechanization rate increases in the relative productivity of mechanizing, hence in $A_{M}$. The investment rate decreases in the average investment cost, which is given by the average interest rate $E[\log x]$. The share of machine hours rented in decreases in the average firm productivity $E[\log z]$ : the higher is the average productivity, the more each machine owner would want to use the machine capacity for her own use, and thus the lower the excess capacity available for renters.

Production choice, firm size, and managerial ability. We target eight moments on the relationships between the production choices and two key measures of firm scale, one endogenous - the number of workers - and the other exogenous - the managerial ability. Specifically, we target the coefficients from the regressions of mechanization rate, investment rate, and the share of machine hours rented in, on either the number of workers or managerial ability (six moments), and the gap in average size and managerial ability between machine owners and renters (two moments). The moments pertaining to the number of workers help to pin down the primitive parameters that modulate the returns to scale: the labor market frictions $\nu$, and the inverse elasticity of substitution within the carpentry sector $\eta$. A large $\nu$ or a small $\eta$ limit the ability of firms to expand, thus compressing the size distribution. The moments on managerial ability, instead, discipline the variance of the Frechet shocks, modulated by $\theta$, and the correlation between managerial ability and the cost of capital. If $\theta$ is low, the mechanization

\footnotetext{
${ }^{38}$ Running the regressions with the raw model-generated data yields very similar results, as our procedure simply takes one additional average, for each firm-level outcome, before running the regressions.

${ }^{39}$ Reassuringly, we find that the (standardized) distribution of the managerial ability index in the raw data follows a distribution close to a normal, which is the one assumed in the model. Notice also that, since the units of the empirical index of managerial ability are not directly interpretable within the model, we do not directly match the distribution of the empirical index to estimate the distribution of $\log z$, and instead we target the moments described below. See the Supplemental Appendix for details.
} 
choice is mostly driven by the random shocks rather than by manager characteristics, generating a flat relationship between production choices and managerial ability. If $\operatorname{Corr}(\log x, \log z)$ is negative and large, the probability of investing would increase steeply with managerial ability, due both to larger returns and lower costs.

Machine rental prices and capacity. Recall that the cost of machine utilization is given by $\frac{\chi}{1+\xi} C^{1+\xi}$. The larger is $\xi$, given the observed capacity utilization, the higher the profitability of renting out machines, hence the more managers choose to invest. The market clearing conditions thus pin down $\xi$. The overall capacity utilization of each machine is tightly linked to $\chi{ }^{40}$ The lower is $\chi$, relative to the rental price, the more machines will be used close to capacity. The relative number of hours of machine capacity used by owners and renters, and the share of overall capacity that each owner rents out, are instead affected by all the primitive parameters determining the joint distributions of production choices and managerial ability.

Observed returns to mechanization and managerial ability. We target eight moments on the empirical relationships between mechanization, managerial ability and firm revenues. Specifically, we target the coefficients from the regression of log revenues and log revenues per worker on managerial ability, mechanization rate, and both variables included together. Of course, both in the model and data, these cannot be interpreted as causal relationships since they are correlations capturing different mechanisms. Nonetheless, they offer useful targets to discipline primitive parameters. In particular, the observed returns to managerial ability are crucial to pin down the standard deviation of managerial ability, $\operatorname{Std}(\log z)$. As mentioned, we normalize $\log z$ before running the regression. As a result, the larger is $\operatorname{Std}(\log z)$, the steeper would be the relationship between log revenues and managerial ability since $S t d(\log z)$ affects the variance of revenues and not, by construction, the variance of standardized managerial ability. The observed returns to mechanization, instead, help to discipline the relative productivity of the mechanized process, $A_{M}$. Finally, within each set of regressions, the difference between the coefficients on overall revenues and revenues per worker disciplines the returns to scale, as modulated by $\eta$ and $\nu$.

Managers' selection. The share of individuals that choose to be managers is directly related to the value of the outside option $\left(\tilde{\pi}_{N}\right)$. The sensitivity of the outside option to managers' ability $(\psi)$, and the scale parameter for the distribution of the entry taste shocks $(\tilde{\theta})$ determine how selected on ability managers are, and the likelihood that an individual with low returns from starting a firm becomes a manager due to a large entry shock. To discipline them, we target

\footnotetext{
${ }^{40}$ In the data, we observe the average number of hours that each machine is used in the market (by both the machine owner and firms that rent out the machine), which we use to compute the capacity utilization of the representative machine, assuming 60 hours per week as full capacity.
} 
four moments on the relative skill distributions of managers and workers since our data suggests that, for most managers, the outside option is to be a worker in the same industry. ${ }^{41}$ Specifically, we target: the workers-managers gap in managerial ability; the ratios of the standard deviations of their income and managerial ability; and the coefficient of a regression of the probability of becoming a manager on relative managerial ability (ranked from 0 to 1 ). ${ }^{42}$

Labor, output, and capital markets. Finally, we target eight moments to guarantee that our model matches core statistics of the labor, output, and capital markets. The average markup is directly tied to the elasticity of substitution across varieties $\frac{1}{\eta}$. The stronger are labor market frictions - i.e., the larger is $\nu$ - the more wages are increasing with firm size. In the model, firm size is itself increasing in managerial ability, but this relationship is mediated by labor market frictions: the larger is $\nu$, the more high ability managers will rely on capital rather than labor to scale up. Therefore, we target the relationship of wages with firm size and of wages, capital, and labor with managerial ability. ${ }^{43}$ Last, the average wage is directly related to the wage level $W$, and the mean and standard deviation of the interest rate among managers who borrow discipline $\mathrm{E}(\log x)$ and $\operatorname{Std}(\log x)$.

\subsection{Estimation Results and Discussion}

We solve for the set of parameters $\varphi$ that satisfies $\varphi^{*}=\arg \min _{\varphi \in \mathbb{F}} \mathcal{L}(\varphi)$, where $\mathcal{L}(\varphi) \equiv$ $\sum_{r}\left[\left(m_{r}(\varphi)-\hat{m}_{r}\right)^{2}\right], m_{r}(\varphi)$ is the value of moment $r$ in our model given parameters $\varphi$, and $\hat{m}_{r}$ is the vector of moments computed in the data. The empirical targets $\hat{m}_{r}$ and the model computed moments $m_{r}\left(\varphi^{*}\right)$ are shown in the Online Appendix. ${ }^{44}$

Results. Overall, the model offers a good fit of the data, especially considering that it is fairly parsimonious, with 15 parameters being used to target 38 moments. At the same time, the fit of the model is, as possibly expected, not perfect. Mainly, the model has a hard time to replicate the strong direct effect of mechanization on revenues once we condition on managerial ability. We notice, however, that managerial ability is likely measured with error in the data, hence the large empirical coefficient that we target might be overestimated due to mechanization being correlated with true managerial ability.

\footnotetext{
${ }^{41}$ In our data, $86 \%$ of managers report having worked as employees at some point in the past.

${ }^{42}$ To construct the moments on managers' selection, we use the predicted managerial ability of employees, as our index of managerial ability was collected only for managers. See the Online Appendix for details.

${ }^{43}$ The wage of a firm of size $L$ is given by $W L^{\nu}$. As a result, a regression of log wage on log size exactly identifies $\nu$. Nonetheless, we choose to target a bundle of moments rather than rely uniquely on the regression of wage on size, which might suffer from omitted variable bias, as we further discuss in the Online Appendix.

${ }^{44}$ In the Supplemental Appendix, we describe our estimation procedure and we show that the likelihood function $\mathcal{L}(\varphi)$ is single peaked around the estimated value $\varphi^{*}$, which suggests that the model is tightly identified, at least locally.
} 
The ability of the model to replicate all the core patterns documented in Section 3.2 on the relationships between scale, mechanization, and the rental market builds confidence in our estimated parameters. These are all reported in the Online Appendix. We next discuss a few key ones. We estimate moderate decreasing returns to scale coming from product differentiation $(\eta=0.078)$. The elasticity of substitution across doors is roughly 13, consistent with the fact that we are looking at a narrow sector, where product differentiation is present, but limited. ${ }^{45}$ We estimate the labor market friction to be almost identical $(\nu=0.153)$ to what would be pinned down from a regression of wage on size, although several other moments help us to identify $\nu$ in the estimation. The labor market frictions are sizable: one way to interpret their size is to notice that the markup, which is inversely related to firm size, would decrease by approximately $50 \%$ in their absence. We find that the cost of capital is negatively correlated with managers' ability (Corr $(\log x, \log z)=-0.227)$, consistent with evidence in the literature (see Banerjee (2003)) and from our context, as discussed further in the Online Appendix. ${ }^{46}$

Discussion of model's assumptions. In the next section, we are going to use the estimated model for a quantitative analysis. As usual, our results will hinge on the assumptions made in the model, which we here discuss. Four of them are particularly relevant.

First, our model is static and thus ignores consumption/savings decisions and asset accumulation. This choice is driven by the nature of our data, which is made of one cross-section. Nonetheless, we allow individuals to have different cost of capital $x$. We estimate the cost of capital to be negatively correlated with managerial ability, which may be capturing, in reduced form, the fact that more successful managers are able to accumulate more capital (Moll, 2014). Since the distribution of $x$ is exogenous, our counterfactuals should be interpret as keeping the distribution of access to capital constant, while - in practice - it may change in dynamic models, as in Cavalcanti et al. (2021). Our analysis abstracts from this additional feedback effect.

Second, we have assumed that, despite the transaction cost, there is perfect competition in the rental market, while the labor market is frictional and firms have monopsony power. These assumptions are relevant. The perfect competition in the rental market is used to estimate the size of the rental wedge $\tau$. The frictions in the labor market limit the ability of firms to grow by hiring labor, thus increasing the importance of the rental market for capital, as we further explore quantitatively below. Given the importance of these assumptions, we presented extensive evidence to justify them in Sections 3.2 and 3.4.

Third, firms can only purchase one machine, which prevents the firms with low capital cost

\footnotetext{
${ }^{45}$ In this setting, the parameter $\eta$ may also capture frictions in the output market.

${ }^{46} \mathrm{We}$ provide further evidence that conditional on managerial ability, managers with lower cost of capital are more likely to invest, which is a key model prediction. In particular, we verify that: (i) conditional on managerial ability, managers with easier access to capital, as proxied by various survey measures, are more likely to invest; and (ii) conditional on managerial ability, mechanization and investment rates are higher in areas with easier bank access. See the Supplemental Appendix for details.
} 
from essentially taking over the rental market. This assumption is motivated by our setting, in which we show that less than $7 \%$ of firms use more than one machine of each type. However, it also reminds us that the model is intended for a low-income country and should not be used, in its current form, to study countries in which firms produce at large scale and with multiple machines of the same type.

Fourth, we model the labor market in partial equilibrium, as captured by the fixed wage level $W$. We made this assumption to reflect that we are studying only one sector within Uganda which is unlikely to affect the overall wage level, especially since the training to become a carpentry worker is quite moderate so that an increase in demand for labor would simply lead to reallocation from other sectors.

Finally, we have assumed that mechanization only affects the quantity of output produced, but not its quality. In practice, while of course mechanization also affects product quality, given the CES demand system, distinguishing between productivity and quality is irrelevant. ${ }^{47}$

\section{Quantifying the Importance of the Rental Market}

We use the estimated model to study the role of rental markets for economic development, focusing on their aggregate effects, on the mechanisms through which these effects manifest, and on the lessons for development policy.

\subsection{Aggregate Effects of the Rental Market}

We calculate the equilibrium of an economy that keeps all primitive parameters constant at their estimated values but varies the rental market wedge $\tau$. Managers are allowed to switch their entry decisions and production methods, and the prices of output and rented machines are allowed to vary, in response.

Figure 5 shows the results. We consider values of the rental market wedge $\tau \in[0, \bar{\tau}]$, where $\bar{\tau}$ is a value sufficiently large to shut down the rental market. We plot mechanization, labor productivity and total output, normalized relative to an economy with no rental markets, as a function of $\tau$. We also consider 1 and 4 as alternative values of $\frac{1}{\iota}$ (2.2. is the benchmark value). To highlight the aggregate gains that could be achieved by reducing the rental market wedge, we plot in red the estimated value of $\tau$ from our revealed preference approach, and in blue the value of $\tau$ that we could assign to transportation and time costs based on our direct survey evidence described in Section 3.2.

\footnotetext{
${ }^{47}$ In a previous version of the paper we were allowing the mechanized process to affect quality, and we estimated the quality gains using data on price. We found that mechanization had a similar impact on quality and productivity - consistent with direct empirical evidence presented in the Supplemental Appendix.
} 
Figure 5: Aggregate effects of changing the rental market transaction costs $\tau$
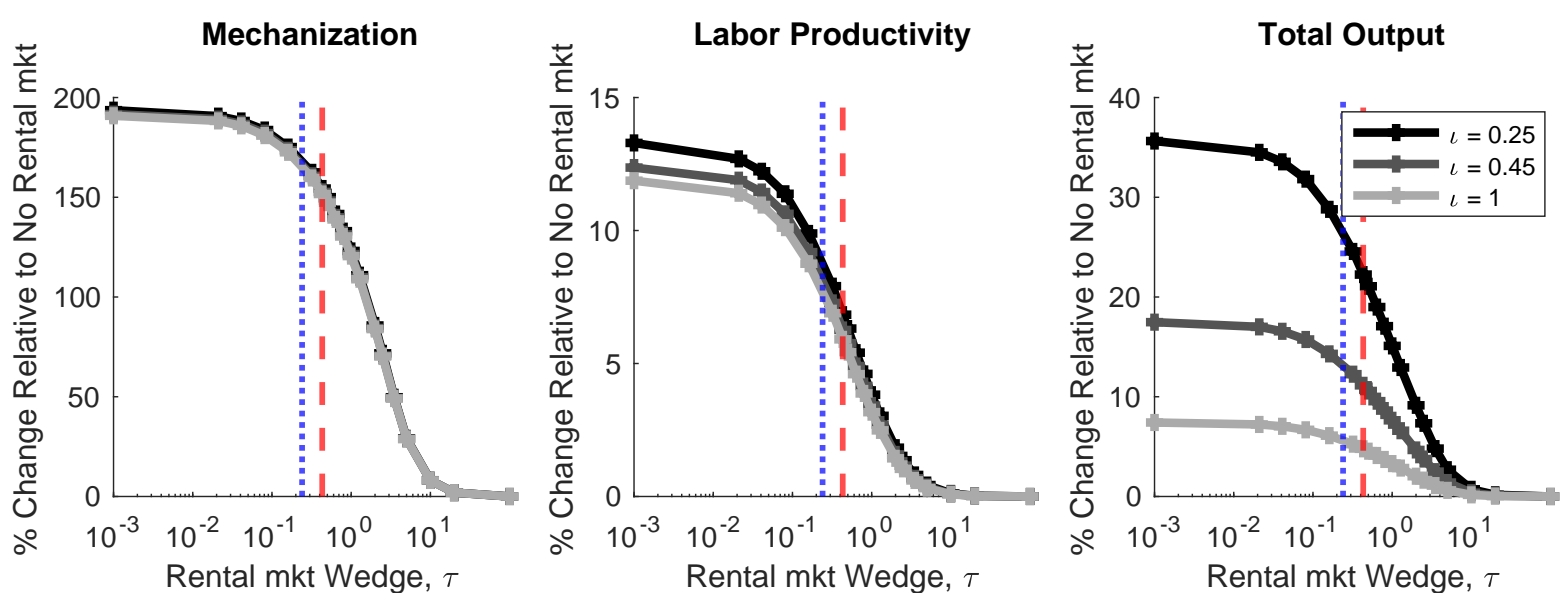

Notes: The figure shows the impact of changing the rental market wedge $\tau$ on aggregate outcomes. Each panel shows, for a different statistic of interest, the percentage change relative to an economy without a rental market. The red dotted line highlights the level of the rental market wedge estimated in our data, while the blue dotted line shows the value that we could directly assign to transportation and time costs. We show the results for three values of the elasticity of substitution between aggregate GDP and the composite carpentry good, $\iota$.

The rental market has large aggregate effects. Transitioning from an economy without a rental market to one with no transaction costs increases aggregate output by $17.5 \%$, average labor productivity by $12.4 \%$, and the share of firms that are mechanized by $192 \%$. Importantly, our benchmark economy with $\tau=0.430$ achieves more than half of the total possible gains. In this sense, the rental market in urban Uganda is a key determinant of aggregate productivity and allows firms to reap a large share of the benefits of scale, or to achieve scale collectively.

The rental market has a larger effect on mechanization and output than on labor productivity. There are two reasons for this result: (i) the rental market primarily allows access to machines for the less productive managers, which account for only a small share of overall output; (ii) with a well-functioning rental market, more low ability managers enter the sector, diluting the average productivity.

The impact of the rental market on aggregate output is mediated by the size of the elasticity of substitution $\frac{1}{\iota}$. When $\iota$ is large, the scope for the carpentry sector to expand is limited and thus a reduction in $\tau$ would lead to a decrease in employment, as firms substitute labor for the relatively cheaper capital.

\subsection{How and Why the Rental Market Shapes the Economy}

Next, we use the model to zoom into how and why the rental market affects the economy. In Figure 6a, we study how the rental market affects which managers mechanize and invest, focusing on the comparison of the benchmark economy with the two polar cases with $\tau=0$ 
(no transaction costs) and $\tau=\bar{\tau}$ (no rental market). Our objective is to illuminate the two core benefits of the rental market described in Proposition 1: (i) to allow more firms to access machines, overcoming the cost of indivisibility through collective scale, and (ii) to improve the allocation of capital by unbundling ownership and utilization. In Figure 6b, instead, we quantify how the prevalence of the rental market in our setting is affected by the large estimated imperfections in other markets. Our goal is to highlight the characteristics of our setting that make rental markets important, and to discuss the prevalence of the rental market in other contexts.

Figure 6: Understanding how and why the rental market shapes the economy

(a) Impact of the rental market on mechanization, as a function of manager characteristics
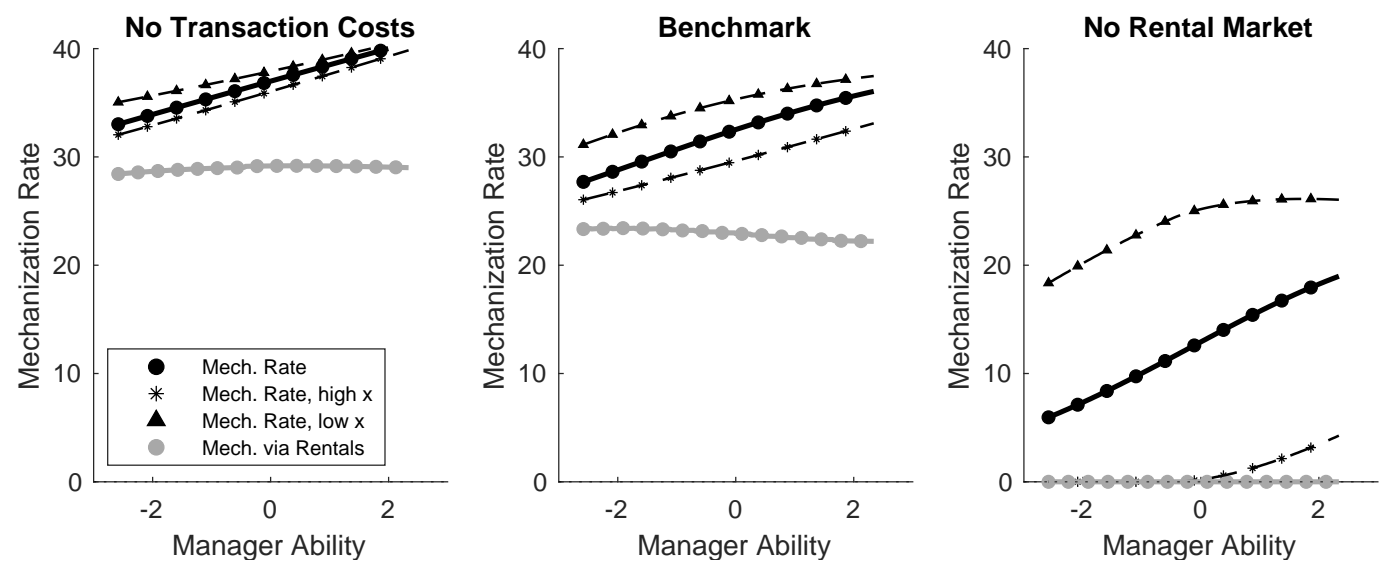

(b) Prevalence of rental markets in different economies
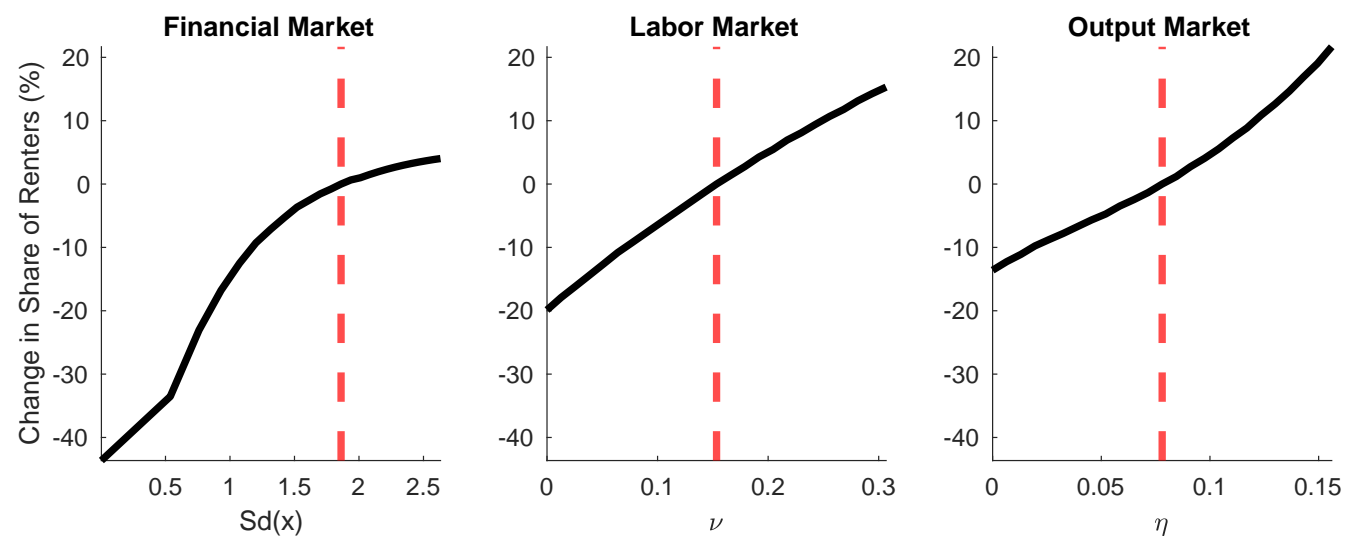

Notes: The sub-figure (a) shows the mechanization rate as a function of managerial ability, and separately for managers that have cost of capital above or below the median. In gray, we show the share of managers that access machines through the rental market. The left panel shows an economy with $\tau=0$, the middle one the benchmark with $\tau=0.43$, and the right one the case with $\tau=\bar{\tau}$. The sub-figure (b) shows how the share of managers that rent machines changes as we vary the imperfections in the financial, labor and output markets, as captured by the dispersion of the cost of capital across managers $(S d(x))$, the labor market frictions $(\nu)$, and the firm-level decreasing returns to scale $(\eta)$. The red dotted lines highlight the benchmark levels of each parameter. 
The rental market allows firms to achieve scale collectively. The solid black line with round markers in Figure 6a shows that, as in the data, mechanization increases in managerial ability. Comparing across panels, we notice that: (i) the level of mechanization increases for all managers as we reduce the size of $\tau$; (ii) it increases disproportionally more for the relatively low ability ones. ${ }^{48}$ The rental market allows firms, especially the ones operating at lowest scale, to access capital by breaking the indivisible machines into divisible time units, which small firms can afford without having to pay prohibitive fixed costs. At the same time, it also benefits the relatively large firms, due to the fact that, even for them, machine capacity is too large relative to their scale of production: all firms thus benefit from collective scale.

The gray line is the share of managers that mechanize accessing machines through the rental market. This relationship is not increasing with managerial ability since, conditional on mechanizing, high skilled managers are more likely to invest, due to both their larger scale and lower cost of capital (recall that we estimate a negative correlation between $z$ and $x$ ). Corroborating the discussion above, all managers rely extensively on the rental market to mechanize, especially when $\tau$ is low, but relatively low skilled managers do so even more.

The rental market unbundles capital ownership and utilization. Next, we focus on the average mechanization rates for managers with cost of capital below and above the median. The managers with lower cost of capital are always more likely to mechanize, but the gap in mechanization rate between high and low cost of capital managers decreases steeply as a function of $\tau$. By unbundling capital ownership and utilization, the rental market allows access to machines even for managers with a prohibitively high cost of capital, thus effectively working as a substitute for the financial market. Through this channel, the rental market reduces the misallocation induced by the dispersion in the cost of capital. ${ }^{49}$

The rental market attenuates other market imperfections. In Figure 6b, we recompute the model as we vary three parameters that capture the extent of frictions in the financial, labor, and output markets. The left panel shows that the rental market becomes less prevalent as the dispersion of the cost of capital is reduced. ${ }^{50}$ The rental market facilitates the reallocation of capital across firms and thus it shrinks if banks can do that task. The middle panel shows that fewer managers need to rely on the rental market if we reduce labor market frictions. Labor market frictions keep firms small, thus preventing them to reach sufficient scale for investing.

\footnotetext{
${ }^{48}$ For instance, for managers at the $90^{t h}$ percentile of ability, going from $\tau=\bar{\tau}$ to $\tau=0$ doubles their mechanization rate, while for managers at the $10^{t h}$ percentile, the mechanization rate increases by more than six times.

${ }^{49}$ For the high skilled managers, the overall average mechanization rate is closer to the one of managers with below median interest rate. This is due to the estimated negative correlation between $z$ and $x$.

${ }^{50}$ While reducing the dispersion of $x$, we also change its mean to keep constant the average cost of capital of managers that invest.
} 
Lastly, the third panel shows that increasing the elasticity of substitution across managers reduces the mass of renters in equilibrium. ${ }^{51}$ When $\eta$ is large - that is, when the ability of productive firms to expand at the cost of the unproductive ones is limited - many low ability managers enter the market, operate at a small scale, and rely on the rental market to mechanize.

Overall, we learn that the rental market is important in our context because it creates a workaround for other imperfections. These results show that we expect rental markets to become less relevant as countries develop, the average firm size increases, and market imperfections vanish. ${ }^{52}$ Using data from the World Bank Enterprise Surveys, we find that the prevalence of rental markets for capital is indeed lower in higher income countries (see the Online Appendix for details).

\subsection{Rental Markets Shape the Effectiveness of Development Policies}

Finally, we show that taking into account the presence and functioning of the rental market has sharp implications for development policies. Our main exercise uses the model to analyze the effectiveness of different policies aimed at increasing mechanization, and how this depends on the rental market. In doing so, we also highlight the role of general equilibrium effects.

The rental market reduces the benefits of subsidies to purchase machines. We first consider a subsidy to purchase a machine equal to the median monthly profit (136\$). This subsidy, which is of similar size to typical capital grants for firms studied in the literature (Banerjee et al., 2019; Janes et al., 2019), translates in our setting to a reduction of $17.5 \%$ of the estimated cost of the representative machine.

Row (1) of Table 5 shows the effects of the subsidy comparing the equilibrium outcomes of two economies where rental markets operate as in our baseline economy (i.e., with $\tau=0.430$ ) and that are identical in all parameters, but for the fact that in one all firms receive a voucher that decreases the price of the machine. The subsidy increases mechanization, productivity and output. The effects are sizable if compared with the direct cost of the policy: column (4) shows that each dollar spent on subsidies generates $\$ 1.24$ in increased GDP, or a net benefit of 24 cents on a dollar. Yet, as we next show, the effectiveness of this policy is limited by the presence of the rental market.

In row (2), we compute the effects of an identical policy, but starting from an economy without a rental market. To keep the comparison budget neutral, we adjust the size of the

\footnotetext{
${ }^{51}$ While a high $\eta$ may be due to product differentiation, it also likely captures imperfections in the output market, as discussed in Section 3.

${ }^{52}$ For example, using data from Hornbeck and Rotemberg (2019) and from the 2017 County Business Patterns of the US Census respectively, we document that the average size of carpentry firms in the US increased from 7.5 in 1860 to either 25.4 or 49.5 in 2017, depending on whether we use NAICS codes 337 or 321911 , respectively, to identify carpenters in the County Business Patterns data.
} 
subsidy so that, given the endogenous take-up, the total expenditure in machine vouchers is identical in the two scenarios. We learn that the subsidy is much more effective in the economy without the rental market, generating six times as large effects on mechanization and three times the net benefit. Given our estimated parameters, in the absence of a rental market the relatively high price of machines prevents most firms from investing, hence from accessing technology. Thus, the subsidy affects all managers in this case, as investing is the only viable mechanism to access capital when rental markets are not available.

This comparison shows that the effectiveness of subsidies to purchase machines, such as import subsidies for capital equipment, is expected to be larger in economies or sectors were rental markets are less prevalent.

Table 5: Impacts of eliminating the rental market wedge: importance of equilibrium effects

\begin{tabular}{|c|c|c|c|c|c|c|c|}
\hline & & $\begin{array}{c}\Delta \mathbb{I}_{K} \\
\text { Mechanization } \\
(1)\end{array}$ & $\begin{array}{c}\Delta \frac{P Y_{C}}{L} \\
\text { Productivity } \\
(2)\end{array}$ & $\begin{array}{c}\Delta P Y_{C} \\
\text { Output } \\
(3)\end{array}$ & $\begin{array}{c}\frac{\Delta P Y_{C}}{\text { Cost }} \\
\text { Return on } 1 \$ \\
(4)\end{array}$ & $\begin{array}{c}\Delta E_{\underline{x}}\left[\pi_{N}(\omega)\right] \\
\text { Profit, low } x \\
\quad(5)\end{array}$ & $\begin{array}{c}\Delta E_{\bar{x}}\left[\pi_{N}(\omega)\right] \\
\text { Profit, high } x \\
\quad(6)\end{array}$ \\
\hline & Subsidies: & \multicolumn{6}{|c|}{ Rental Market and Policy Effectiveness } \\
\hline (1) & to buy & $+4.98 \%$ & $+1.4 \%$ & $+1.44 \%$ & $1.24 \$$ & $+2.25 \%$ & $+0.14 \%$ \\
\hline \multirow[t]{2}{*}{$(2)$} & to buy $(\tau=\bar{\tau})$ & $+29.89 \%$ & $+1.65 \%$ & $+2.25 \%$ & $1.74 \$$ & $+3.16 \%$ & $+2.24 \%$ \\
\hline & & \multicolumn{6}{|c|}{ Comparing Policies } \\
\hline$(3)$ & to rent & $+4.44 \%$ & $+1.37 \%$ & $+1.44 \%$ & $1.82 \$$ & $+0.88 \%$ & $+1.71 \%$ \\
\hline \multirow[t]{2}{*}{ (4) } & to buy \& rent & $+4.75 \%$ & $+1.39 \%$ & $+1.44 \%$ & $1.5 \$$ & $+1.5 \%$ & $+1.01 \%$ \\
\hline & & \multicolumn{6}{|c|}{ Equilibrium Effects } \\
\hline$(5)$ & to buy $(\mathrm{PE})$ & $+3.54 \%$ & $+0.8 \%$ & $-0.72 \%$ & $-0.62 \$$ & $+3.27 \%$ & $+0.31 \%$ \\
\hline (6) & to rent $(\mathrm{PE})$ & $+15.25 \%$ & $+4.69 \%$ & $+2.77 \%$ & $3.5 \$$ & $+6.99 \%$ & $+13.48 \%$ \\
\hline
\end{tabular}

Notes: Each cell shows the percentage difference relative to the benchmark economy. Each column corresponds to a different aggregate statistic, while each row to a different policy counterfactual, as described in the text.

Rental vouchers can improve the equity of subsidies. We next consider rental vouchers, along the lines of the policy studied in the agricultural context by Caunedo and Kala (2021). We consider vouchers that reduce the price paid by renters for each unit of capital and solve for the amount that provides the same overall increase in GDP as the purchase subsidies considered above, which turns out to be $15.5 \%$. The two policies provide, by construction, identical aggregate effects. ${ }^{53}$ However, they have very different distributional consequences. The purchase

\footnotetext{
${ }^{53}$ The two policies have different costs. However, the two are not directly comparable since the purchase subsidy increases the overall stock of capital in the economy, thus having longer lasting effects. To compare the two, we compute the internal rate of return, taking into account depreciation, that would generate the same return on a dollar for the two policies over one year. We find this rate to be $61.2 \%$, showing that rental subsidies are the most effective alternative only if the opportunity cost of capital is large enough.
} 
subsidy increases mainly the profits of managers with low cost of capital (row (1), columns 5 and 6) since few of those with a high cost of capital invest even with the subsidy. High cost of capital managers are mostly affected through the general equilibrium effects, that is, through the reduction in the rental price, which favors them, and the reduction in the output price, which hurts them. The rental vouchers, instead, benefit disproportionally those with a high cost of capital, as they are more likely to rent (row (3), columns 5 and 6). Managers that invest still benefit, due to the increased demand for rentals and the resulting hike in the rental price.

Depending on which firms policy-makers wish to help the most, they might prefer to use purchase or rental vouchers, or both. For example, in row (4) we show that a policy that assigns an equal subsidy to purchase and rent can be more equitable, while still achieving by construction the same impact on GDP.

Results from partial equilibrium RCTs could mislead policy makers. While RCTs can usually identify the impact of policies in partial equilibrium, policy-makers are primarily interested in the impact of policies at scale, hence taking into account general equilibrium effects. Motivated by this observation, we next use our model to study, for our two discussed policies, how the partial equilibrium evidence that could be gathered through an RCT relates to the aggregate results computed with the model.

In rows (5) and (6), we compute the average effects of the two types of subsidies while keeping constant the entry choice, aggregate output and rental prices, thus essentially evaluating the average treatment effects of interventions that target a small number of firms. In order to make the results comparable with rows (1) and (3), we create the aggregate effects by assigning to all firms in the economy the average treatment effects from this hypothetical RCT.

The comparison between the general and partial equilibrium effects differs widely across policies. The rental vouchers (row (6)) have a much larger effect in partial equilibrium since three types of equilibrium effects dampen the aggregate results: the rental subsidy (i) leads marginal, lower ability managers to enter; (ii) increases the price of machines in the rental market; and (iii) decreases the price of output. The opposite, instead, is true for the purchase subsidy (row (5)), which in partial equilibrium would lead to smaller effects on mechanization and productivity, and even to a negative effect on GDP due to managers shifting from production to investing, attracted by the high returns from renting out capital, and reducing their labor and output as a result. In this case, the general equilibrium effects are larger since the reduced rental cost of capital, generated by the increased supply of machines, leads more firms to mechanize and enter the market.

Overall, our results offer a concrete example that highlights the challenge of extrapolating from partial equilibrium reduced form estimates to aggregate predictions on the impact of policies at scale (Bergquist et al., 2019; Egger et al., 2019). 
Industrial parks and urban planning. Finally, we notice that the rental market provides an additional, and often overlooked, benefit to industrial parks. While most of the discussion in the literature concerns the returns from shared infrastructure, such as roads and electricity access (Steenbergen and Javorcik, 2017), our results suggest that industrial parks could also generate large returns from capital pooling, as locating many firms in close proximity to one another is likely to reduce the transaction costs in the rental market. ${ }^{54}$ Further, as we have shown that smaller firms are more likely to rent, while larger ones to own machines, our work implies that properly designed industrial parks should include both relatively larger and smaller firms. The former would benefit from accessing customers in the rental market, while the latter from being in close proximity to firms that are more likely to be machine owners.

\section{Conclusion}

As well known, small firms in developing countries are often organized in large informal clusters. In this paper, we show that this feature of the organization of production limits the costs of small scale by allowing firms to achieve scale collectively: while machines are indivisible, their capacity is divisible and can be shared among firms located near each other.

We combine a novel firm survey in urban Uganda with an equilibrium model of firm behavior. The data provides direct evidence of economies of scale driven by the indivisibility of modern machines, but also reveals that their capacity is traded between small firms in an active rental market. The model allows us to quantify the large aggregate effects of the rental market on technology adoption and productivity, to show that these effects are due to the size of other frictions that keep firms small, and to explain that taking rental markets into account has important implications for the design of development policies.

Our work offers a case study that highlights the importance of the rental market for understanding productivity in one (large) sector in one developing country. While the narrow focus was necessary to gain a deep knowledge of the institutional setting and properly measure how firms produce output, our overarching goal is to draw general lessons for economic development. Three takeaways strike us as particularly important. First, rental markets can be a powerful workaround for other market imperfections, thus limiting the aggregate costs of frictions that could keep firms small. Second, to understand technology adoption in low income countries, it is important to take into account firm-to-firm interactions within informal clusters, while focusing on the small scale of firms in isolation might be misleading. Third, in settings with large and indivisible production machines, rental vouchers can be an effective and equitable policy tool to increase overall mechanization and boost productivity.

\footnotetext{
${ }^{54}$ Corroborating this idea, we show in the Online Appendix that the estimated rental market wedge is smaller in areas with higher firm density.
} 


\section{References}

Abebe, Girum, Stefano Caria, Marcel Fafchamps, Paolo Falco, Simon Franklin, and Simon Quinn, "Anonymity or Distance? Job Search and Labor Market Exclusion in a Growing African City," Review of Economic Studies, 2020, forthcoming.

Akcigit, Ufuk, Harun Alp, and Michael Peters, "Lack of selection and limits to delegation: firm dynamics in developing countries," American Economic Review, 2021, 111 (1), 231-275.

Alfonsi, Livia, Oriana Bandiera, Vittorio Bassi, Robin Burgess, Imran Rasul, Mushi Sulaiman, and Anna Vitali, "Tackling Youth Unemployment: Evidence from a Labor Market Experiment in Uganda," Econometrica, 2020, 88 (6), 2369-2414.

Atack, Jeremy, "Estimation of Economies of Scale in Nineteenth-Century United States Manufacturing and the Form of the Production Function," The Journal of Economic History, 1978, 38 (1), 268-270.

_ , Estimation of economies of scale in nineteenth century United States manufacturing, New York: Garland Publishing, 1985.

_ , Fred Bateman, and Robert A. Margo, "Steam power, establishment size, and labor productivity growth in nineteenth century American manufacturing," Explorations in Economic History, 2008, 45, 185-198.

Atkin, David, Azam Chaudhry, Shamyla Chaudry, Amit K. Khandelwal, and Eric Verhoogen, "Organizational barriers to technology adoption: Evidence from soccer-ball producers in Pakistan," The Quarterly Journal of Economics, 2017, 132 (3), 1101-1164.

Balboni, C., O. Bandiera, R. Burgess, M. Ghatak, and A. Heil, "Why do people stay poor?," mimeo, 2021.

Banerjee, A. V., E. Breza, E. Duflo, and C. Kinnan, "Do credit constraints limit entrepreneurship? Heterogeneity in the returns to microfinance.," mimeo, 2019.

Banerjee, Abhijit, Emily Breza, Esther Duflo, and Cynthia Kinnan, "Can microfinance unlock a poverty trap for some entrepreneurs?," Technical Report, mimeo 2021.

Banerjee, Abhijit V., "Contracting constraints, credit markets, and economic development," in "Econometric Society Monographs," Vol. 37 2003, pp. 1-46.

_ and Esther Duflo, "Growth Theory through the Lens of Development Economics," in Philippe Aghion and Steven N. Durlauf, eds., Handbook of Economic Growth, Vol. 1A, Amsterdam: Elsevier, 2005, pp. 473-552.

Banerjee, Abhijit V and Esther Duflo, "Do Firms Want to Borrow More? Testing Credit Constraints Using a Directed Lending Program," The Review of Economic Studies, 2014, 81 (2), 572-607.

Bari, Faisal, Kashif Malik, Muhammad Meki, and Simon Quinn, "Asset-based microfinance for microenterprises: Evidence from Pakistan," 2021.

Bassi, Vittorio and Aisha Nansamba, "Screening and Signaling Non-Cognitive Skills: Experimental Evidence from Uganda," USC-INET Research Paper, 2021.

Bergquist, Lauren, Benjamin Faber, Thibault Fally, Matthias Hoelzlein, Edward Miguel, and Andres Rodriguez-Clare, "Scaling Agricultural Policy Interventions: Theory and Evidence from Uganda," Mimeo, 2019.

Bloom, Nicholas, Aprajit Mahajan, David McKenzie, and John Roberts, "Why do firms in developing countries have low productivity?," American Economic Review, 2010, 100 (2), 619-23.

Broda, Christian and David Weinstein, "Globalization and the Gains from Variety," The Quarterly journal of economics, 2006, 121 (2), 541-585.

Brooks, Wyatt, Joseph P. Kaboski, and Yao A. Lee, "Growth policy, agglomeration, and (the lack of) competition," mimeo, 2018.

Buera, Francisco J, Joseph P. Kaboski, and Yongseok Shin, "Finance and development: A 
tale of two sectors," American economic review, 2011, 101 (5), 1964-2002.

_ , Joseph P Kaboski, and Yongseok Shin, "Finance and development: A tale of two sectors," American economic review, 2011, 101 (5), 1964-2002.

Buera, Francisco J., Joseph P. Kaboski, and Yongseok Shin, "The Macroeconomics of Microfinance," mimeo, 2017.

Burdett, Kenneth and Dale T. Mortensen, "Wage Differentials, Employment Size, and Unemployment," International Economic Review, 1998, 39 (2), 257-273.

Cai, Jing and Adam Szeidl, "Interfirm Relationships and Business Performance," The Quarterly Journal of Economics, 2018, 133 (3), 1229-1282.

Carranza, Eliana, Robert Garlick, Kate Orkin, and Neil Rankin, "Job Search and Hiring with Two-sided Limited Information about Workseeker's Skills," mimeo, 2020.

Caselli, Francesco, "Accounting for Cross-Country Income Differences," Handbook of Economic Growth, 2005, 1, 679-741.

Caunedo, J and E. Keller, "Capital Obsolence and Agricultural Productivity," The Quarterly Journal of Economics, 2021, 136 (1), 505-561.

Caunedo, Julieta and Namrata Kala, "Mechanizing Agriculture Impacts on Labor and Productivity," 2021.

_ , _ , and Haimeng Zhang, "Economies of Density in Capital Rental Markets," mimeo, 2020.

Cavalcanti, Tiago V, Joseph P Kaboski, Bruno S Martins, and Cezar Santos, "Dispersion in financing costs and development," Technical Report, National Bureau of Economic Research 2021.

Chandler, Alfred D. Jr., The Visible Hand: The Managerial Revolution in American Business, Cambridge, Mass.: Harvard University Press, 1977.

_, Scale and Scope: The Dynamics of Industrial Capitalism, Harvard University Press, 1990.

Chandrasekar, Arun, Melanie Morten, and Alessandra Peter, "Network-based Hiring: Local Benefits; Global Costs," Mimeo, 2020.

Coase, R. H., "The Nature of the Firm," Economica, 1937, 4 (16), 386-405.

Duranton, Gilles and Diego Puga, "Micro-foundations of urban agglomeration economies," in "Handbook of regional and urban economics," Elsevier, 2004.

Egger, Dennis, Johannes Haushofer, Edward Miguel, Paul Niehaus, and Michael Walker, "General Equilibrium Effects of Cash Transfers: Experimental Evidence from Kenya," Mimeo, 2019.

Ellison, Glenn, Edward L. Glaeser, and William R. Kerr, "What causes industry agglomeration? Evidence from coagglomeration patterns," American Economic Review, 2010, 100 (3), $1195-1213$.

Foster, Andrew D and Mark R Rosenzweig, "Are there too many farms in the world? Labormarket transaction costs, machine capacities and optimal farm size," Technical Report, National Bureau of Economic Research 2017.

Greenwood, Jeremy and Boyan Jovanovic, "Financial development, growth, and the distribution of income," Journal of Political Economy, 1990, 98 (5), 1076-1107.

Griliches, Z., "Issues in Assessing the Contribution of Research and Development to Productivity Growth," Bell Journal of Economics, 1997, 10 (1), 92.

Grossman, Sanford J. and Oliver D. Hart, "The Costs and Benefits of Ownership: A Theory of Vertical and Lateral Integration," Journal of Political Economy, 1986, 94 (4), 691-719.

Hall, Robert E. and Charles I. Jones, "Why Do Some Countries Produce so Much More Output per Worker than Others?," The Quarterly Journal of Economics, 1999, 114 (1), 83-116.

Hardy, Morgan and Jamie McCasland, "Are Small Firms Labor Constrained? Experimental Evidence from Ghana," 2020, mimeo.

Hart, Oliver and John Moore, "Property Rights and the Nature of the Firm," Journal of Political 
Economy, 1990, 98 (6), 1119-1158.

Hornbeck, Richard and Martin Rotemberg, "Railroads, Reallocation, and the Rise of American Manufacturing," mimeo, 2019.

Hsieh, Chang-Tai and Benjamin A Olken, "The Missing "Missing Middle"," The Journal of Economic Perspectives, 2014, 28 (3), 89-108.

- and Peter J Klenow, "The life cycle of plants in India and Mexico," The Quarterly Journal of Economics, 2014, 129 (3), 1035-1084.

Janes, L., M. Koelle, and S. Quinn, "Do capital grants improve microenterprise productivity?," CSAE Working Paper WPS/2019-13-v2, 2019.

Jensen, Robert and Nolan H. Miller, "Market Integration, Demand, and the Growth of Firms: Evidence from a Natural Experiment in India," American Economic Review, 2018, 108 (12), 35833625 .

Kaboski, Joseph $\mathbf{P}$ and Robert M. Townsend, "A structural evaluation of a large-scale quasiexperimental microfinance initiative," Econometrica, 2011, 79 (5), 1357-1406.

Lucas, Robert E, "On the size distribution of business firms," The Bell Journal of Economics, 1978, pp. 508-523.

Macchiavello, Rocco, "A Mutually Beneficial Relationship: Relational Contracts in Developing Countries," in "A Research Agenda for New Institutional Economics," Edward Elgar Publishing, 2018.

Marshall, A, Principle of Economics, 8th edition ed., London: MacMillan, 1920.

McKenzie, David and Christopher Woodruff, "Business Practices in Small Firms in Developing Countries," Management Science, 2017, 63 (9), 2967-81.

Mel, Suresh De, David McKenzie, and Christopher Woodruff, "Returns to Capital in Microenterprises: Evidence from a Field Experiment," The Quarterly Journal of Economics, 2008, 123, $1329-1372$.

_ , _ and _, "Labor Drops: Experimental Evidence on the Return to Additional Labor in Microenterprises," American Economic Journal: Applied Economics, 2019, 11 (1), 202-35.

Melitz, Marc J., "The Impact of Trade on Intra-Industry Reallocations and Aggregate Industry Productivity," Econometrica, 2003, 71 (6), 1695-1725.

Midrigan, Virgiliu and Daniel Yi Xu, "Finance and misallocation: Evidence from plant-level data," American economic review, 2014, 104 (2), 422-58.

Moll, Benjamin, "Productivity losses from financial frictions: Can self-financing undo capital misallocation?," American Economic Review, 2014, 104 (10), 3186-3221.

Olmstead, Alan L and Paul W Rhode, "Beyond the threshold: an analysis of the characteristics and behavior of early reaper adopters," The Journal of Economic History, 1995, 55 (1), 27-57.

Perla, J and C Tonetti, "Equilibrium Imitation and Growth," Journal of Political Economy, 2014, 122 (1), 52-76.

Rabellotti, Roberta, "Is there an "industrial district model"? Footwear districts in Italy and Mexico compared.," World Development, 1995, 23 (1), 29-41.

Rampini, Adriano, "Financing Durable Assets," American Economic Review, 2019, 109 (2), 664-701.

_ and Robert Townsend, "Renting for Development," in "2016 Meeting Papers" number 1296 Society for Economic Dynamics 2016.

Richardson, George B, "The organisation of industry," The economic journal, 1972, 82 (327), 883896.

Schmitz, Hubert, "Collective efficiency: Growth path for small scale industry," The journal of development studies, 1995, 31 (4), 529-566.

Shapiro, Jeremy, Chaning Jang, and Matthew Spitzer, "Evaluating the impact of physical and 
human capiral augmentation to drive small business growth in Kenya," mimeo, 2020.

Startz, Meredith, "The Value of Face-to-Face: Search and Contracting Problems in Nigerian Trade," mimeo, 2019.

Steenbergen, V. and B. Javorcik, "Analyzing the Impact of the Kigali Special Economic Zone on Firm Behavior," Technical Report F-38419-RWA-1, International Growth Center Policy Working Paper 2017. 


\section{Online Appendix}

The Online Appendix is divided into four sections: Appendix A reports additional empirical results that expand on evidence presented in Section 3. Appendix B includes proofs and details on the model solution. In Appendix C, we describe the computation of calibrated parameters and moments that are not already described in the paper. Finally, in Appendix D we study the prevalence of the rental market across countries. A Supplemental Appendix not intended for publication can be found on the authors' websites.

\section{A Additional Results on the Organization of Production}

\section{A.1 Additional Firm Descriptives}

Table A1: Additional firm descriptives

\begin{tabular}{|c|c|c|c|c|}
\hline & $\begin{array}{l}\text { All sectors } \\
\text { (1) }\end{array}$ & $\begin{array}{c}\text { Carpentry } \\
(2)\end{array}$ & $\begin{array}{c}\text { Metal } \\
\text { fabrication } \\
(3)\end{array}$ & $\begin{array}{l}\text { Grain } \\
\text { milling } \\
(4)\end{array}$ \\
\hline \multicolumn{5}{|l|}{ Panel A: Firm characteristics } \\
\hline Monthly profits (USD) & 236.9 & 219.5 & 257.2 & 244.9 \\
\hline Monthly profits per worker (USD) & 42.6 & 42.3 & 46.7 & 32.6 \\
\hline Markup & 0.22 & 0.23 & 0.21 & 0.24 \\
\hline Firm age (years) & 10.1 & 10.4 & 8.9 & 12.0 \\
\hline Firm has trading license $(\%)$ & 82.2 & 76.4 & 85.7 & 91.3 \\
\hline \multicolumn{5}{|l|}{ Panel B: Owner characteristics } \\
\hline Owner is male (\%) & 96.3 & 97.9 & 99.2 & 83.0 \\
\hline Owner age (years) & 40.2 & 39.2 & 37.9 & 50.1 \\
\hline Hours usually worked per day for the firm & 9.1 & 9.8 & 9.3 & 6.7 \\
\hline \multicolumn{5}{|l|}{ Panel C: Employee characteristics } \\
\hline Employee is male (\%) & 98.0 & 97.7 & 99.5 & 95.2 \\
\hline Employee age (years) & 28.4 & 29.0 & 26.6 & 30.7 \\
\hline Employee years of education & 9.3 & 8.9 & 10.2 & 7.9 \\
\hline Employee tenure (years) & 3.5 & 3.5 & 3.3 & 3.9 \\
\hline Hours usually worked per day for the firm & 9.9 & 9.7 & 10.0 & 10.0 \\
\hline Employee monthly wage (USD) & 69.6 & 73.8 & 71.6 & 52.3 \\
\hline Employee hourly wage (USD) & 0.29 & 0.33 & 0.29 & 0.19 \\
\hline
\end{tabular}

Notes: Means are reported. 1 USD $=3,800$ UGX for monetary amounts. Monthly profits: average of profits reported by managers for each of three months preceding the survey. Markups: average revenues over variable costs minus one (see Section C.4). Profits, profits per worker and markups are trimmed at the 99th percentile. 
Table A1 provides additional descriptive evidence to suggest that our surveyed firms are established and operate regular business activities, in spite of their small scale. The average firm has been in business for 10 years, and a majority of them are registered with the local authority (Panel A). The average owner works 9 hours per day for the firm, so this is the primary job for most of them (Panel B). The average employee has 3.5 years of tenure, works 9.9 hours per day for the firm, and makes about $\$ 70$ per month (Panel $\mathrm{C}$ ). Taken together, the evidence shows that our sample is composed of established and profitable firms that employ workers who hold stable, regular, and well-paying jobs by Ugandan standards. There is no substantial heterogeneity across sectors along these dimensions.

\section{A.2 Additional Results on the Rental Market in Carpentry}

Figure A1: Rental income as a function of machine price

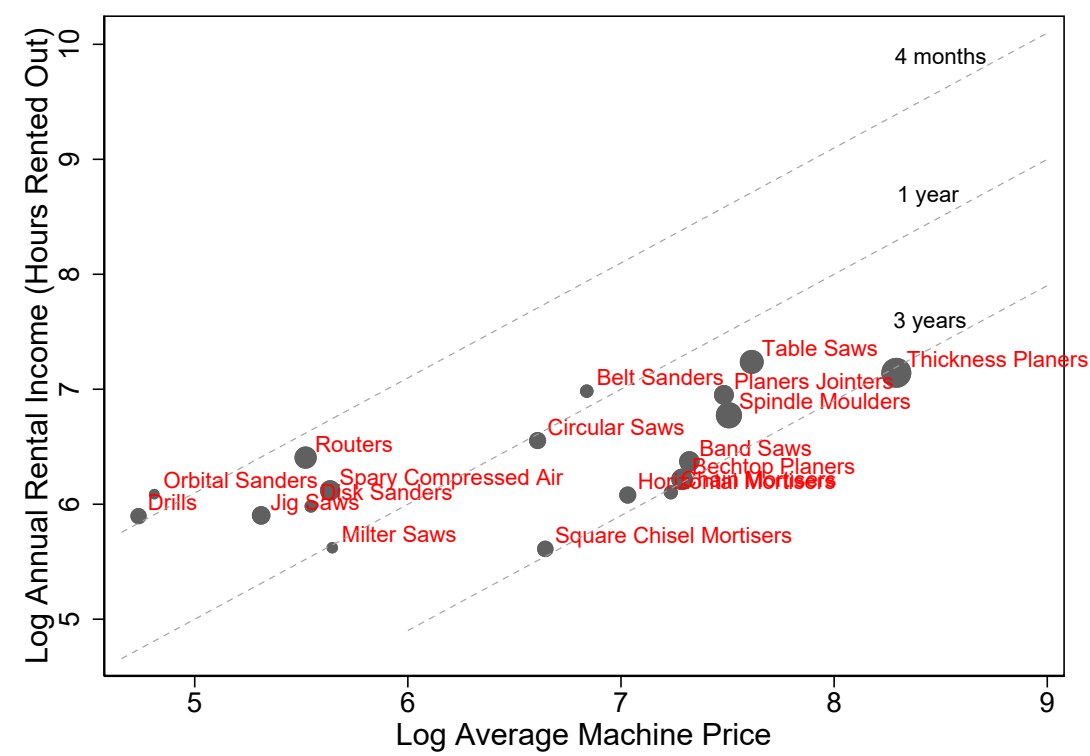

Notes: The figure reports the log of annual rental income from renting out machines against log purchase prices, conditional on renting out machines in carpentry. Machines are weighted by the share of firms who report renting in the machine, so that larger dots correspond to machines rented out more intensively in the data. Diagonal lines depict the time taken to recuperate the purchase price of a machine by renting it out. Machine prices and rental income are both trimmed at the top and bottom $1 \%$.

Revenues from the rental market. Figure A1 plots average machine prices against average annual income from renting out machines. The figure shows that managers clearly benefit from renting our their excess capacity: machine owners can recover the cost of the typical machine with about one year of revenues from the rental market. This is in line with evidence presented in Section 5 that the cost of capital faced by managers is high on average. In addition, the figure 
shows that revenues from renting out machines are relatively higher for the cheapest ones. ${ }^{55}$

Evidence on competition in the rental market. We provide five pieces of evidence which suggest that the rental market operates competitively, though subject to transaction costs. First, the concentration of machines is limited: focusing on the three most commonly rented machines (i.e., thickness planers, spindle moulders, and table saws) we find that there are typically more than two machine owners of each machine type in each sub-county, conditional on there being at least one owner. This likely creates competition and limits the monopoly power of machine owners. ${ }^{56}$ Second, Table A2 regresses hourly rental prices on the number of machine owners in the sub-county. If machine owners have market power, we would expect prices to decrease as the number of owners increases, due to higher competition. Instead, we fail to find a negative coefficient in any of the specifications. Third, if machine owners have market power, we would expect rental prices to be relatively higher for more expensive machines, as there is a higher entry cost in supplying them. However, as discussed above, Figure A1 shows that this is not the case. In fact, revenues from the rental market are higher for relatively smaller machines.

Fourth, firms that rent out their machines were asked how they decide what price to charge machine renters, and two thirds explicitly say that they take into account the price charged by other carpenters, as shown in Table A3. In line with this, when asked how they choose machine providers, renters do not mention prices as an important determinant of their choice, while distance from the rental place and quality of machines are reported as important reasons. Finally, we find limited evidence of search frictions due to lack of information in the rental market. In particular, Table A3 shows: (i) the limited role of social networks and referrals in rental market interactions, as only $30 \%$ of renters already knew someone working at the place where they rent machines, and prior personal connections are not cited as an important reason for choosing a particular machine provider; (ii) lack of information on where to rent machines is not reported as an important reason for not using certain machines or for owning instead of renting; (iii) lack of quality/reliability of rented machines is not reported as an important reason for owning rather than renting. ${ }^{57}$ Taken together, this evidence shows that there is a substantial degree of competition in the rental market, and that search frictions are limited.

\section{Direct evidence on transaction costs in the rental market. Panel A of Table A4} presents descriptive evidence on transaction costs related to transportation and time costs in

\footnotetext{
${ }^{55}$ This result suggests that renting out cheaper machines, which can be easily moved around/stolen, may lead to relatively large costs for machine owners, possibly due to larger monitoring costs.

${ }^{56}$ See the Supplemental Appendix for more details on this point.

${ }^{57}$ Table A3 uses data from a follow-up survey conducted in three of our sampled sub-counties about four months after the end of the main survey. See the Supplemental Appendix for more details.
} 
the rental market in carpentry. ${ }^{58}$ The table shows that renters typically visit machine owners 16 times per month, and every time they go: (i) they spend around 50 minutes traveling (and do so primarily using motorcycle taxis); (ii) they spend almost three hours at the premises of machine owners and about half of this time is spent idle, waiting for machine access. In line with wait times being important, our survey further reveals that $70 \%$ of machine owners report avoiding wait times as a primary reason for owning instead of renting, and that wait times can in part be explained by congestion as more than one fourth of renters report visiting machine owners in the early morning.

Table A2: Relationship between rental market price and machine concentration

Dependent variable: Log Hourly Rental Price

\begin{tabular}{lcccc}
\hline & Baseline & No Subcounty & Baseline & Baseline \\
& & FE & $(3)$ & $(4)$ \\
\hline Number of Machine Owners & 0.000933 & $0.00324^{* * *}$ & & \\
& $(0.00101)$ & $(0.00111)$ & & \\
Number of Machines Owned & & & 0.00115 & \\
& & & $(0.000846)$ & 0.00185 \\
Number of Machine Owners & & & & $(0.0100)$ \\
(no weight) & Yes & Yes & Yes \\
Machine FE & Yes & No & Yes & Yes \\
Subcounty FE & 29 & 43 & 29 & 29 \\
Number of Subcounties & 0.343 & 0.064 & 0.346 & 0.341 \\
Adjusted $R^{2}$ & 192 & 192 & 192 & 192 \\
Observations & & & & \\
\hline
\end{tabular}

Notes: ${ }^{* * *} p<0.01,{ }^{* *} p<0.05,{ }^{*} p<0.1$. OLS regression coefficients, robust standard errors in parentheses. Sample: door producers; data aggregated to machine-types per subcounty. Explanatory variables: number of machine owners in a subcounty (columns 1-2); number of machines owned in a subcounty (column 3); number of machine owners in a subcounty (column 4).

To quantify these transaction costs, in Panel B of Table A4, we compute for each renter: (i) their monthly value of time spent traveling to the machine owners' premises and waiting for machine access; (ii) their direct monthly transportation costs from using motorcycle taxis. We present two alternative measures of the value of time. The first (Panel B, row 1) is calculated as the sum of the total travel time and the time spent idle at the premises of the rental place, valued at the average wage. The second measure (Panel B, row 2) is the same total time, but valued reflecting the average income of managers and employees, respectively. ${ }^{59}$ This second measure

\footnotetext{
${ }^{58}$ The data comes from a short follow-up phone survey conducted four months after the end of the main survey in three of our sampled sub-counties.

${ }^{59}$ That is, when employees travel to the rental place, we value their time at the average wage; instead, when
} 
is our preferred estimate since it accounts for the difference in value of time between managers and employees. ${ }^{60}$ If renters travel by motorcycle taxis, we compute their direct transportation cost (Panel B, row 3) using typical motorcycle fares that we collected in Kampala. The direct transportation cost is set to zero if renters report walking or using a bicycle. In $22 \%$ of cases, renters report to mainly use other means of transport such as buses, cars, or vans. We value those at zero direct cost, since we do not have reliable information on the cost of such means of transport per trip.

Table A3: Descriptives on the rental market for machines

Questions $(\%)$

(a) When setting rental prices, machine owner compares own prices to 65.2 those of other carpenters

(b) Renter had prior connection to the rental place

(c) Main reason for choosing the specific rental place Quality of machines 23.7 Skill of machine operators $\quad 7.6$ $\begin{array}{ll}\text { Distance (Travel time) } & 37.8\end{array}$

Prices

They have machines that are otherwise hard to find

Prior connection or friendly atmosphere

Accessibility to timber in location

Many types of machines available

Short waiting time

No other rental places nearby

Other

(d) Reasons for owning rather than renting machines

Do not know where to rent

Rented machines are not reliable

Rented machines are of lower quality

(e) Reasons for not using certain machines in carpentry

Do not know where to rent

Do not know where to buy

Notes: Panel (a) reports the share of machine owners who compare their price to that charged by other carpenters in the area (firms could choose among a list of 7 options selecting multiple responses). Panel (b): for each rental source, renters were asked if they knew someone working there before they started going there for business. Panel (c): renters were asked the reasons for going to each of their current rental locations (each firm could choose a maximum of 3 reasons and we report the top-ranked reason). Panel (d): each machine owner was asked why they own rather than rent machines (firms could select among a list of 8 options and could select multiple responses). Panel (e): firms neither using nor owning certain machines were asked the reasons for that (firms could choose 3 among a list of 11 reasons and we report the distribution of relevant reasons, that is, of reasons included in the top 3 most relevant).

managers are the ones who go, we value their time at the average hourly profit (see Table A1).

${ }^{60}$ Panel A shows that this distinction is important, as in $56 \%$ of cases the managers themselves are the ones who travel to the premises of machine owners to use rented machines. 
Comparing the sum of the monthly transportation costs (Panel B, row 3) and the value of time from our preferred measure (Panel B, row 2) with the monthly expenditures on machine rentals (Panel B, row 5) shows that transportation and time costs represent $\$ 45.5 / \$ 180.1=$ $24.4 \%$ of direct expenditures on rentals. That is, we are able to explain about $60 \%$ of the estimated rental market transaction costs from Table 4 through transportation and time costs.

Table A4: Descriptives on rental market transaction costs

Panel A: Descriptive statistics on rental market transaction costs

Number of different rental places the firm goes to

Number of machines rented from each rental place on average

Total number of visits per month to all rental places the firm goes to

Share of renters staying at the premises of rental place while machine is operated

$61.3 \%$

Time from arrival to rental place to job completion for average visit (minutes)

162.7

Time spent idle at premises of rental place for average visit (minutes)

73.3

Total travel time for the average completed visit to the rental place (minutes)

48.1

Share of renters traveling to the rental place by motorcycle taxi

$53.1 \%$

Share of managers who travel themselves to rental place

$56.5 \%$

Panel B: Calculated monthly transaction costs for renters

Value of time to access machines (USD, valued at average wage)

10.5

Value of time to access machines (USD, valued at average opportunity cost, A)

Direct transportation cost (USD, B)

Total cost of time and transportation (USD, A+B)

45.5

Total direct expenditure on machine rentals (USD)

180.1

Notes: Panel A shows average statistics regarding rental market transaction costs. The total number of visits (Panel A, row 3) is defined as the number of separate times the firm reports going to all rental places to use their machines per month. The first four rows of Panel B show average monthly costs for renters calculated from Panel A. The final row in Panel B reports the total direct expenditure on machine rentals at the firm level, valued at median machine prices (see Table A12), which was collected in a subsequent phone survey of our sample of carpenters 7 months after the main survey. See the Supplemental Appendix for additional evidence on wait times at the premises of machine owners.

Robustness of estimation of rental market transaction costs. Figure A2 reports a battery of 27 robustness checks on our estimate of the coefficient $\beta_{1}$ from equation 1. Each circle inside the plot area corresponds to a point estimate, and we show both $90 \%$ and $95 \%$ confidence intervals. The bottom panel displays features of each regression specification: a dark circle implies that the specification includes that feature; red circles highlight features in our preferred specification.

Features labeled "Hours", "Exp", "H_Firm", "E_Firm" refer to alternative ways of aggregating machine hours within steps to calculate the dependent variable. "Hours" denotes that the aggregation uses weights based on machine utilization in the data, so that machines that are used more heavily in a given step get a higher weight in that step. "Exp" implies that the 
aggregation uses weights based on aggregate expenditure in the data, using the relative price of each machine type, so that machines that represent a higher share of expenditure in a given step get a higher weight in that step. "H_Firm" and "E_Firm" are similar to "Hours" and "Exp" respectively, but use firm-level hours and expenditure instead. "Ratio" indicates whether the left hand side is the capital-labor expenditure ratio (Ratio $=1$ ) or if we include only capital utilization on the left hand side and control for labor utilization on the right hand side $($ Ratio $=0)$. The latter option relies less heavily on the firm cost-minimization problem. "Xs" denote that firm controls including sub-county fixed effects, managerial ability, and dummies for door types produced are included in the regression (step fixed effects are included in all specifications). "FE" indicates whether firm fixed effects are used instead. "NR" shows whether the sample excludes machine owners who do not rent out their machines. "Step" indicates if the regression is at the step-level versus at the machine-level.

Figure A2: Estimates of transaction costs in the rental market - robustness

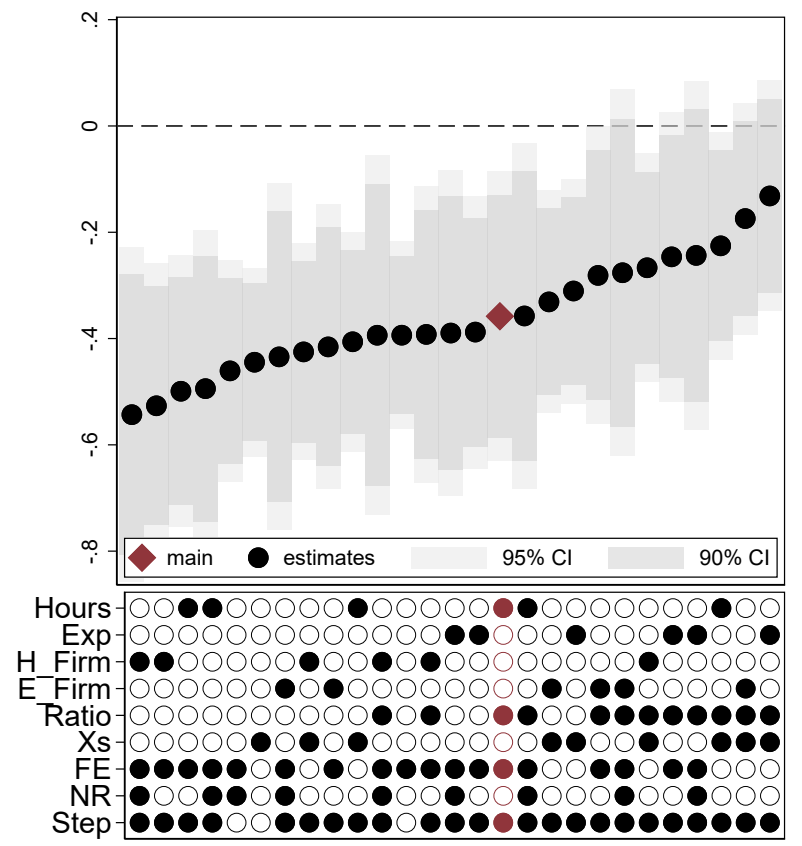

Notes: Standard errors are clustered at the firm level throughout. Sample: door producers. We use predicted wages from a regression of worker wages on firm size and individual worker characteristics (Table A7) to alleviate endogeneity concerns. When Ratio $=0$, the appropriate standard errors would require bootstrapping as labor utilization (on the right-hand side) is a generated regressor. The figure was constructed with the STATA package speccurve. Due to the limited flexibility of the package, we do not report bootstrap standard errors, but note that these are very similar.

Across all specifications the Figure shows that: (i) estimates of $\beta_{1}$ are negative, and (ii) the great majority are between -0.2 and -0.5 ; with our preferred estimate of -0.358 roughly in the middle of the range. In the Supplemental Appendix we verify that estimates of $\beta_{1}$ are mostly negative when the estimation is carried out separately for each of production steps 3-9 (i.e., the seven most common steps), justifying our use of a pooled specification. We also show 
that machine-level controls (e.g., machine value, age, expected remaining life, and dummy for manufacture abroad) are not predictive of the capital-labor ratio for machine owners or renters.

Table A5: Heterogeneity in estimates of transaction costs in the rental market Dependent variable: Log Capital-Labor Expenditure Ratio

\begin{tabular}{lccc}
\hline & $(1)$ & $(2)$ & $(3)$ \\
\hline Share of Rented Machines (0-1) & $-0.346^{* *}$ & $-0.639^{* * *}$ & $-0.528^{* * *}$ \\
& $(0.144)$ & $(0.188)$ & $(0.175)$ \\
Interaction with: & & & \\
Manager Ability (Std.) & -0.057 & & \\
& $(0.135)$ & & \\
Avg. Firms within 500m above Med. & & $0.477^{* *}$ & \\
& & $(0.239)$ & 0.328 \\
Firms per $k m^{2}$ above Med. & & & $(0.245)$ \\
\hline Sub-county FE & No & No & No \\
Step and Firm FE & Yes & Yes & Yes \\
Adjusted $R^{2}$ & 0.483 & 0.487 & 0.485 \\
Observations & 1,137 & 1,137 & 1,137 \\
\hline
\end{tabular}

Notes: ${ }^{* *} p<0.01,{ }^{* *} p<0.05,{ }^{* * *} p<0.1$. OLS regression coefficients, standard errors clustered at the firm level in parentheses. Sample: door producers. Level of observation: production steps. We restrict attention to the seven most common steps for the production of doors, that is steps 3-9. All specifications control for the number of machines used in each production step. For the definition of the dependent variable and the Share of rented machines, see Table 4. The variable Avg. Firms within 500m above Med. is a dummy equal to one if the average number of carpentry firms within a $500 \mathrm{~m}$ radius of each surveyed firm in a sub-county is above the median. The variable Firms per $\mathrm{km}^{2}$ above Med. is similarly defined. To maintain a balanced number of observations above/below the median, the median is defined across all observations in the data used for estimation (rather than across sub-counties).

Heterogeneity in rental market transaction costs. Table A5 reports estimates of our preferred specification from equation 1, but where we add interactions between the share of rented machines in a production step and different firm and sub-county level characteristics. This allows us to test for heterogeneity in transaction costs. Column 1 shows that there is no evidence of significant heterogeneity by manager ability: the estimated interaction is small in magnitude and far from significant. In columns 2 and 4 we consider two measures of firm density, one based on the number of other firms operating within a 500 meter radius from each firm in our data (column 2), and one based on the number of firms per square kilometer in the sub-county (column 3). In both cases we find that the estimated transaction costs are lower in areas with higher firm density. Column 2 shows that the interaction term is 0.477 with $95 \%$ confidence interval $[0.009 ; 0.945]$, indicating that transaction costs are $e^{(0.639-0.477)}-1=0.176$ in areas with above median firm density (while they are 0.430 in the average sub-county). Column 3 shows similar results: the estimated interaction term is 0.328 , although not precisely 
estimated. These results further confirm that our estimates primarily capture transaction costs related to the time and physical costs of travel, as we would expect these to be smaller in areas with higher firm density, while firm scale should not matter for the size of these costs.

\section{A.3 Additional Results on Labor and Output Markets in Carpentry}

Labor market frictions. Table A6 reports descriptive evidence on the labor market in carpentry. The table presents a number of facts that are consistent with the presence of substantial search frictions driven by lack of information on workers, as summarized in the main text.

Table A6: Descriptives on the labor market

\begin{tabular}{ll}
\hline Questions & \\
\hline Lack of employees with the right skills is a serious problem (\%) & 26.1 \\
Finding workers with the right skills is a serious problem (\%) & 30.0 \\
Screening workers at recruitment is a serious problem (\%) & 33.2 \\
Number of employees who left in the last six months & 0.57 \\
Share of firms with no workers leaving in the last six months (\%) & 75.2 \\
Share of workers hired through referrals (\%) & 57.5 \\
Would offer wage rise to keep current workers from leaving (\%) & 32.9 \\
Employees received any on-the-job training in the firm (\%) & 49.8 \\
$\quad$ If received) Average duration of the on-the-job training (months) & 7.6 \\
Time until an employee is able to work under minimal/no supervision (days) & 64.7 \\
Expected time taken for finding a replacement for an employee (days) & 38.8 \\
\hline
\end{tabular}

Notes: This table shows descriptives on the labor market in carpentry. Each row corresponds to a different question asked to firm owners/managers. Rows 1-5 report averages across firms. Rows 6-11, instead, report averages across all employees, since the manager answered the associated questions separately for each employee in the firm.

To quantify the size of labor market frictions, Table A7 shows the results of Mincerian regressions of worker monthly earnings in carpentry. In columns 1-3 the key independent variable is our standardized index of managerial ability; in columns 4-6 it is the log of firm size. All regressions control for monthly hours worked and sub-county fixed effects. In columns 2 and 5 we additionally control for worker education, age, tenure and a dummy for whether the worker received vocational training. Columns 3 and 6 additionally control for cognitive and noncognitive skills, and so are our preferred specifications. Focusing on column 6, the coefficient on $\log$ number of workers is 0.146 , indicating that a $1 \%$ increase in firm size is associated with a $0.15 \%$ increase in wages. As shown in column 3, we find similar results using our standardized index of managerial ability as a measure of firm scale.

The main identification concern in these regressions is sorting on unobservables: if more able workers are more likely to sort into higher ability/larger firms, then the coefficient on our key 
independent variables of interest would be upward biased. The inclusion of sub-county fixed effects limits concerns related to sorting across locations. Our rich set of controls for worker skills also limit concerns related to sorting on unobserved ability. Still, we cannot claim that these results are causal. Therefore, we prefer to target a bundle of moments to identify the parameter $\nu$, rather than relying solely on the regressions in Table A7.

Table A7: Relationship between wage and firm size

Dependent Variable: Log Employee Monthly Earnings

\begin{tabular}{|c|c|c|c|c|c|c|}
\hline & (1) & $(2)$ & $(3)$ & (4) & $(5)$ & (6) \\
\hline Manager Ability (Std.) & $\begin{array}{c}0.088^{* *} \\
(0.037)\end{array}$ & $\begin{array}{c}0.073^{* *} \\
(0.036)\end{array}$ & $\begin{array}{c}0.060 \\
(0.037)\end{array}$ & & & \\
\hline Log Num Workers & & & & $\begin{array}{c}0.166^{* *} \\
(0.067)\end{array}$ & $\begin{array}{c}0.142^{* *} \\
(0.066)\end{array}$ & $\begin{array}{c}0.146^{* *} \\
(0.065)\end{array}$ \\
\hline Years of Schooling & & $\begin{array}{c}0.029^{* * *} \\
(0.008)\end{array}$ & $\begin{array}{c}0.029^{* * *} \\
(0.008)\end{array}$ & & $\begin{array}{c}0.027^{* * *} \\
(0.008)\end{array}$ & $\begin{array}{c}0.027^{* * *} \\
(0.008)\end{array}$ \\
\hline Age & & $\begin{array}{c}0.048^{* * *} \\
(0.007)\end{array}$ & $\begin{array}{c}0.046^{* * *} \\
(0.008)\end{array}$ & & $\begin{array}{c}0.048^{* * *} \\
(0.007)\end{array}$ & $\begin{array}{c}0.046^{* * *} \\
(0.008)\end{array}$ \\
\hline Age Squared & & $\begin{array}{c}-0.000 * * * \\
(0.000)\end{array}$ & $\begin{array}{c}-0.000^{* * *} \\
(0.000)\end{array}$ & & $\begin{array}{c}-0.000^{* * *} \\
(0.000)\end{array}$ & $\begin{array}{c}-0.000^{* * *} \\
(0.000)\end{array}$ \\
\hline Tenure at the Firm (Yrs) & & $\begin{array}{c}0.013^{* *} \\
(0.006)\end{array}$ & $\begin{array}{c}0.013^{* *} \\
(0.006)\end{array}$ & & $\begin{array}{c}0.013^{* *} \\
(0.006)\end{array}$ & $\begin{array}{c}0.012^{* *} \\
(0.006)\end{array}$ \\
\hline Vocational Training $(0 / 1)$ & & $\begin{array}{l}0.039 \\
(0.063)\end{array}$ & $\begin{array}{l}0.049 \\
(0.062)\end{array}$ & & $\begin{array}{l}0.052 \\
(0.064)\end{array}$ & $\begin{array}{l}0.060 \\
(0.062)\end{array}$ \\
\hline Log hours worked & $\begin{array}{c}0.320^{* * *} \\
(0.075)\end{array}$ & $\begin{array}{c}0.330^{* * *} \\
(0.073)\end{array}$ & $\begin{array}{c}0.321^{* * *} \\
(0.072)\end{array}$ & $\begin{array}{c}0.333^{* * *} \\
(0.080)\end{array}$ & $\begin{array}{c}0.340^{* * *} \\
(0.077)\end{array}$ & $\begin{array}{c}0.324^{* * *} \\
(0.075)\end{array}$ \\
\hline $\begin{array}{l}\text { Skills Controls } \\
\text { (Joint } p \text {-value) }\end{array}$ & No & No & $\begin{array}{c}\text { Yes } \\
0.013\end{array}$ & No & No & $\begin{array}{c}\text { Yes } \\
0.001\end{array}$ \\
\hline Subcounty FE & Yes & Yes & Yes & Yes & Yes & Yes \\
\hline Adjusted $R^{2}$ & 0.201 & 0.267 & 0.274 & 0.198 & 0.264 & 0.274 \\
\hline Observations & 1,062 & 1,062 & 1,062 & 1,062 & 1,062 & 1,062 \\
\hline
\end{tabular}

Notes: ${ }^{* * *} p<0.01,{ }^{* *} p<0.05, * p<0.1$. OLS regression coefficients, standard errors clustered at the firm level in parentheses. Sample: carpentry sector; regressions are at the employee level. Dependent variable: log monthly earnings. All independent variables refer to the employee, except Managerial Ability (standardized index based on multiple survey questions - see the Supplemental Appendix for details). Worker skills controls (Columns 3 and 6): cognitive ability (4-item Raven matrices test), agreeableness, conscientiousness, extraversion, neuroticism and openness (10-item Big Five test). The Joint $p$-values in columns 3 and 6 are from a joint F-test that the additional skills controls are jointly insignificant in predicting wages.

Organization of labor across the size distribution. We study how labor specialization, teamwork and hours worked vary across the size distribution. Figure A3 reports the results for carpentry, and shows that: (i) while we do see some evidence that specialization increases with firm size, this is not strong: the average employee works on half of the production steps even in large firms, which is far from full specialization; (ii) there is little evidence that team-work increases with firm size, except at the very top of the distribution; and, (iii) we do not find that 
larger firms use labor more intensively: workers spend close to three hours per day idle, and this does not vary much by firm size. In short, a more efficient organization of labor or a more intense use of labor are unlikely to drive economies of scale in labor.

Figure A3: Organization of labor across the size distribution
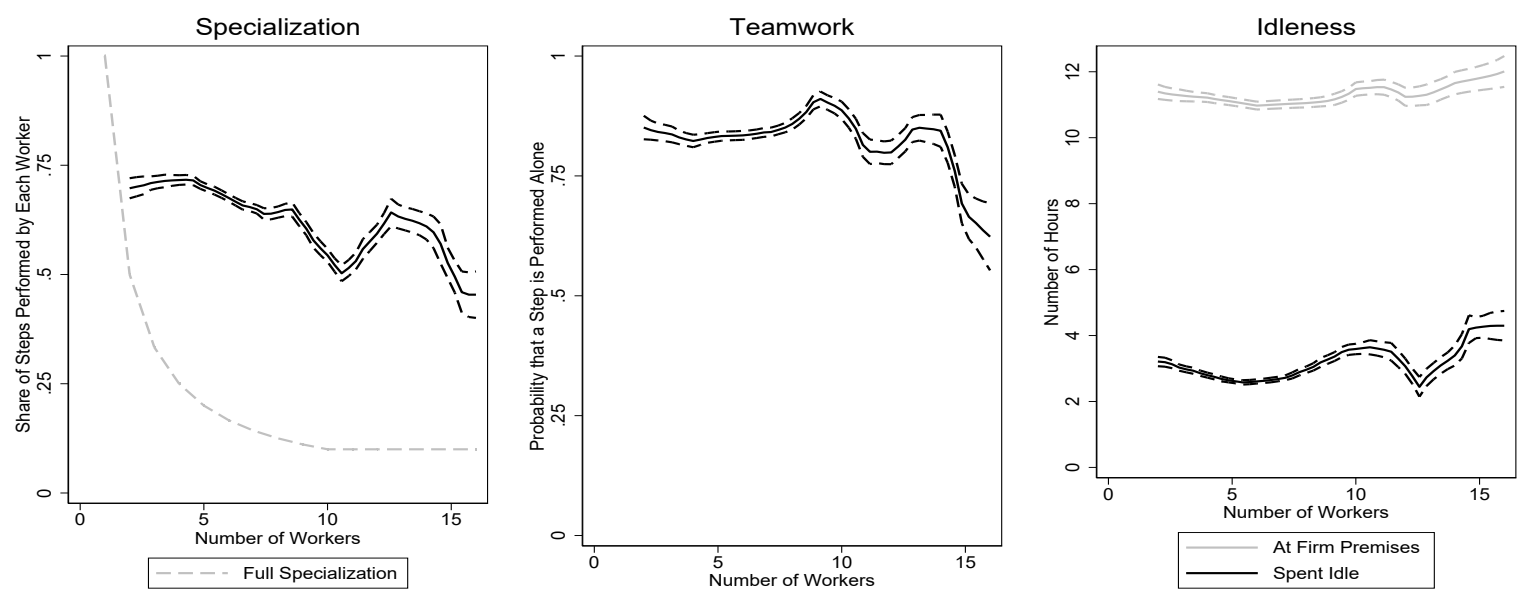

Notes: Sample: carpentry. The left panel compares the mean share of production steps performed by each worker (solid black curve) with the minimum share of steps that each worker would have to complete under full specialization, given the total number of steps performed by the firm (gray dotted curve). The middle panel plots the probability that a production step is performed alone rather than in teams (solid black curve). The right-hand panel shows the average number of daily hours spent by workers at the firm premises in total (solid gray curve) and spent idle at the firm premises (solid black curve). Mean functions are estimated conditional on number of workers (x-axis) throughout, and dotted lines depict $95 \%$ confidence intervals.

Demand and competition in the output market. To document the extent of product differentiation in carpentry, we focus on firms producing 2-panel doors, and compute the residual variation in price and in a standardized index of output quality, controlling for sub-county fixed effects. ${ }^{61}$ We find substantial residual dispersion in both prices and quality even within subcounties. For instance, the ratio of the 75 th to the 25 th percentile of the quality distribution is more than 2. This confirms that there is differentiation even within narrowly defined products. ${ }^{62}$

On output market frictions, Table A8 reports descriptive evidence on access to demand and relationships with customers in carpentry. As discussed in the main text, the table presents a number of statistics that are consistent with demand being geographically segmented, and with customer relationships being important, which are both factors that can lower competition. ${ }^{63}$

\footnotetext{
${ }^{61}$ The index of output quality is constructed using multiple measures of product quality recorded through direct observation by our enumerators.

${ }^{62}$ See the Supplemental Appendix for more details on residual dispersion in product prices and quality.

${ }^{63}$ In addition, the Supplemental Appendix reports: the share of customers originating from (i) outside the parish but within the district, and (ii) outside the district; the breakdown of: (i) the share of sales to other types of customers such as subsidiaries, wholesalers and government agencies; (ii) the share of other routes through which orders are placed (e.g., besides walk-ins); the breakdown of: (i) the share of firms citing other reasons (besides bargaining) as main reason for price variation; (ii) the share of firms that communicate the
} 
For the estimation of markups, see Section C.

Table A8: Descriptives on demand

Panel A: Location of customers

$\%$ of firms reporting that most customers come from within the LC1

$20.1 \%$

$\%$ of firms reporting that most customers come from outside the LC1

$34.0 \%$

but within the parish

Panel B: Location of transactions

$\%$ of sales to final customers

$94.8 \%$

$\%$ of firms that sold to final customers at the business premises

$96.9 \%$

$\%$ of firms that sold to final customers through shipping in Uganda

$15.6 \%$

$\%$ of firms that sold to final customers through shipping outside Uganda

$0.6 \%$

$\%$ of firms where orders are placed in person through walk-ins

$79.6 \%$

Panel C: Customer relations

Average number of customers coming to the business per day

Average ratio of highest to lowest selling price for the same product to final customers

$\%$ firms citing Bargaining as main reason for price variation for the same product

$43.2 \%$

$\%$ of firms that communicate the quality of their products

by directly talking to customers

$\%$ of firms citing being close to customers as main reason

$28.5 \%$

for locating the business premises

$\%$ of firms indicating lack of demand as a main constraint to growth

$54.3 \%$

Notes: The table reports descriptive statistics on demand in the carpentry sector. Panel A shows the share of firms reporting that most customers come from within the LC1 or within the parish. LC1 stands for the lowest level of administrative unit, which corresponds to a village for rural areas and to a neighborhood for a town or a city. Panel B shows the share of sales in the last three months to final customers, the location of deliveries and the share of customers placing orders at the firm premises. Panel $\mathrm{C}$ shows the descriptives on customer relations.

\section{B Proofs of the Theoretical Results}

In this section, we include the main steps of the proofs of the theoretical results of Section 4. Details on the quantitative extension of Section 5 and further details on the algebra are included in the Supplemental Appendix.

\section{Profit Functions and Comparative Statics}

We first solve the optimal variable inputs for each one of the four possible combinations of mechanization $\left(\mathbb{I}_{K}\right)$ and ownership $\left(\mathbb{I}_{C}\right)$. Through simple algebra, left to Supplemental Appendix,

quality of their products through other means; (iii) the share of firms that cite other reasons as main reason for locating the business premises (beyond proximity to customers); (iv) the share of firms that indicate other reasons (besides lack of demand) as a main constraint to growth. 
we can show that the profit function is given by

$$
\pi(x, z)=\max \{\underbrace{\tilde{A}_{L} z^{\tilde{\gamma}_{L}}}_{\text {Non-Mechanized }\left(\pi_{L}\right)} ; \underbrace{\tilde{A}_{L} z^{\tilde{\gamma}_{L}}+\tilde{m}(x)}_{\text {Non-Mechanized Owners }\left(\pi_{L, b}\right)} ; \underbrace{\tilde{A}_{M, r} \tilde{\gamma}_{M}}_{\text {Renters }\left(\pi_{M}\right)} ; \underbrace{\tilde{A}_{M, b} z^{\tilde{\gamma}_{M}}+\tilde{m}(x)}_{\text {Owners }\left(\pi_{M, b}\right)}\}
$$

where

$$
\begin{aligned}
\tilde{\gamma}_{L} & =\frac{(1+\nu)(1-\eta)}{\nu+\eta} \\
\tilde{\gamma}_{M} & =\frac{(1+\nu)(1-\eta)}{\nu+\eta-(1-\eta) \nu \alpha} \\
\tilde{A}_{L} & =\left[A_{L}^{1-\eta} P W^{-\frac{1-\eta}{1+\nu}}(1-\eta)^{\frac{1-\eta}{1+\nu}}\right]^{\frac{1+\nu}{\eta+\nu}}\left(\frac{\nu+\eta}{1+\nu}\right) \\
\tilde{A}_{M, r} & =\left(\frac{\nu+\eta-(1-\eta) \nu \alpha}{1+\nu}\right)\left[\frac{A_{M}^{1-\eta} P(1-\eta)^{(1-\eta)\left(\frac{1+\nu \alpha}{1+\nu}\right)}}{\left((1+\tau)^{\frac{p_{r}}{\alpha}}\right)^{\alpha(1-\eta)}\left(\frac{W}{1-\alpha}\right)^{\frac{(1-\alpha)(1-\eta)}{1+\nu}}}\right]^{\frac{1+\nu}{v+\eta(1-\eta) \nu \alpha}} \\
\tilde{A}_{M, b} & =(1+\tau)^{\frac{\alpha(1-\eta)(1+\nu)}{v+\eta-(1-\eta) \nu \alpha}} \tilde{A}_{M, r} . \\
\tilde{m}(x) & =\left(\frac{\xi}{1+\xi}\right) \chi^{-\frac{1}{\xi}} p_{r}^{\frac{1+\xi}{\xi}}-(\delta+x) p_{b}
\end{aligned}
$$

Equipped with these expressions, we notice a few comparative statics that are useful throughout this section: i) $\pi_{L}(x, z)$ does not depend on either $\tau$ or $p_{r}$; ii) $\pi_{L, b}(x, z)$ does not depend on $\tau$, but it increases in $p_{r}$; iii) $\pi_{K}(x, z)$ decreases in $(1+\tau) p_{r}$; iv) $\pi_{K, b}(x, z)$ does not depend on $\tau$, and it increases in $p_{r}$.

Notice that we used Assumption 1 in the solution of $\pi_{M, b}$. In the Supplemental Appendix, we include the general solution which holds also if Assumption 1 is violated.

\section{Equilibrium Rental Price}

As a preliminary result, we characterize the relationship between $p_{r}$ and $\tau$ and prove that, as stated in Proposition 1, part 3: $p_{r}$ decreases, while the cost of renting in, $(1+\tau) p_{r}$, increases in $\tau$.

First, consider the demand for capital in the rental market. It is decreasing in $\tau$ and in $p_{r}$ for two reasons: i) each renter decreases capital utilization due to higher marginal cost; ii) the share of renters in the economy reduces since $\pi_{M}(x, z)$ decreases, while all other options either increase or stay constant (see previous subsection).

Second, consider the supply for capital in the rental market. It is increasing in $\tau$ and $p_{r}$ for two reasons: i) a higher $p_{r}$ leads each machine owner to increase machine capacity and decrease utilization, thus increasing rented capital $C-K$; ii) the share of individuals that invest increases since $\pi_{L, b}(x, z)$ and $\pi_{M, b}(x, z)$ increase relative to $\pi_{M}(x, z)$ and $\pi_{L}(x, z)$.

Finally, let's prove the result by contradiction. Consider an increase in $\tau$, but keeping $p_{r}$ 
constant. Total demand for rented capital drops, while supply is unaffected. As a result, price $p_{r}$ must fall for the rental market to reach back the equilibrium. The fall in price $p_{r}$ cannot more than compensate the increase in $\tau$ so that $(1+\tau) p_{r}$ also falls; otherwise, the demand for rented capital would increase, thus implying that $p_{r}$ should increase, and reaching a contradiction. We have thus proved that $p_{r}$ decreases in $\tau$ and $(1+\tau) p_{r}$ increases in $\tau$.

\section{Proof of Lemma 1}

To prove the Lemma, we solve for the investment and mechanization decisions and show that they follow cutoff policies as stated.

Investment. Consider managers that do not mechanize. Since $\pi_{L, b}(x, z)$ decreases in $x$, there will be a cutoff $\hat{x}$ such that if and only if $x<\hat{x}$ the manager invests. Moreover, notice that if a manager $z$ does not mechanize, the investment cutoff does not depend on $z$, and it is in fact given by $\tilde{x}$ such that $\tilde{m}(\tilde{x})=0$ :

$$
\tilde{x}=\frac{p_{r}^{\frac{\xi+1}{\xi}}}{p_{b}} \chi^{-\frac{1}{\xi}}\left(\frac{\xi}{1+\xi}\right)-\delta .
$$

Next, consider a manager that mechanizes. She invests if and only if $\pi_{M, b}(x, z) \geq \pi_{M}(z)$, which gives

$$
x \leq \hat{x}(z) \equiv\left((1+\tau)^{\frac{\alpha(1-\eta)(1+\nu)}{\nu+\eta-(1-\eta) \nu \alpha}}-1\right) \frac{\pi_{M}(z)}{p_{b}}+\frac{p_{r}^{\frac{\xi+1}{\xi}}}{p_{b}} \chi^{-\frac{1}{\xi}}\left(\frac{\xi}{1+\xi}\right)-\delta
$$

where $\hat{x}(z)$ is an increasing function of $z$ if $\tau>0$, while it does not depend on $z$ if $\tau=0$. Also, notice that $\hat{x}(z) \geq \tilde{x}$ and that if and only if $\tau=0$, then $\hat{x}(z)=\tilde{x}$.

Mechanization. Consider managers that do not invest. They mechanize if and only if $\pi_{M}(z) \geq \pi_{L}(z)$. Since $\pi_{M}(z)$ is more convex in $z$ (because $\tilde{\gamma}_{M}>\tilde{\gamma}_{L}$ as long as $\nu>0$ ), we know that there must exist a value $\tilde{z}_{a}$ such that if and only if $z \geq \tilde{z}_{a}$, then the manager mechanizes.

Next, consider managers that invest. They mechanize if and only if

$$
\begin{aligned}
\pi_{M, b}(x, z) & \geq \pi_{L, b}(x, z) \\
(1+\tau)^{\frac{\alpha(1-\eta)(1+\nu)}{\nu+\eta-(1-\eta) \nu \alpha}} \pi_{M}(z) & \geq \pi_{L}(z) .
\end{aligned}
$$

Therefore, also among the managers that invest, the choice to mechanize does not depend on $x$ and it is given by a cutoff $\hat{z}_{b}$ such that a manager mechanizes if and only if $z \geq \hat{z}_{b}$. Importantly, 
we notice that $\hat{z}_{b}>\hat{z}_{a}$ if $\tau>0$, while $\hat{z}_{b}=\hat{z}_{a}$ if $\tau=0$. Finally, notice that $\hat{z}_{a}$ is decreasing in $\tau$, while $\hat{z}_{b}$ does not depend on it directly (but only through the price $p_{r}$ ). As a result, when $\tau \rightarrow \infty$, only the managers that invest will mechanize, which then implies that $\hat{x}(z)=\hat{z}^{-1}(x)$.

\section{Proof of Proposition 1}

Part 1: higher profits for all managers. Since we have proved that $p_{r}$ decreases in $\tau$, while $(1+\tau) p_{r}$ increases in $\tau$, the comparative statics discussed above immediately imply that profits must be weakly decreasing in $\tau$ for each production choice. As a result, their $\max -$ i.e., $\pi(x, z)$ - must decrease as well.

Part 2: higher engagement in the capital market. Similarly to part 1, this result is directly implied by the comparative statics just discussed: $\pi_{L}(x, z)$, which is the only production choice not engaged in the capital market, is also the only function that does not depend on $\tau$, while $\pi_{L, b}(x, z), \pi_{M}(x, z)$, and $\pi_{M, b}(x, z)$ all decrease in $\tau$. As a result, the lower is $\tau$, the fewer managers will decide to not mechanize nor invest.

Part 3: an improvement in the allocation of capital. Since we are keeping $p_{r}$ constant by assumption, only $\pi_{M}(x, z)$ is affected by the decrease in $\tau$. As $\pi_{M}(x, z)$ increases, some managers will shift their choices and the overall number of renters must increase, while all the other groups must weakly decrease. Recall that renters are managers that mechanize but do not invest. As long as not all the new renters were non-mechanized owners absent the decrease in $\tau$, the correlation between mechanization and investment would strictly decline. Notice that this must not be true if we let $p_{r}$ increase. In this case, we could observe a net increase of other groups of managers, which could affect the overall correlation.

\section{Part 4: a higher ability to overcome the indivisibility through collective scale.} First notice that, if all managers have identical cost of capital $-x(\omega)=\bar{x}$ - there cannot be any non-mechanized owners in equilibrium, as otherwise everyone would invest. The reason is that, for a given cost of capital, mechanized owners have more to gain from a machine investment (rental income, cost savings on own use) than non mechanized owners (rental income). The equilibrium thus has the lowest productivity managers being non-mechanized, the medium productivity ones being renters, and the most productive ones being owners. A decrease in $\tau$, as we have seen, increases $\pi_{M}(x, z)$ and $\pi_{M, b}(x, z)$ relative to $\pi_{L}(x, z)$. As a result, mechanization must decrease in $\tau$, proving the result. 


\section{Calibrated and Estimated Parameters, and Moments}

In this section, we first report each model parameter, indicating whether they are calibrated from our data or estimated using simulated method of moments. Then, we show all the 38 moments used in estimation, and compare the data-generated and model-generated moments. Finally, we provide more details on each calibrated parameter, and on the computation of each moment used in estimation.

\section{C.1 Calibrated and Estimated Parameters}

Table A9 reports all 22 model parameters, with corresponding source tables. The rental market wedge in row (1) is estimated following the procedure described in Section 3.2. The parameters in rows (2) to (7) are calibrated from our data. Those in rows (8) to (22) are jointly estimated.

Table A9: Model calibrated and estimated parameters

\begin{tabular}{|c|c|c|c|c|c|c|c|}
\hline & Parameter & Value & Source & & Parameter & Value & Source \\
\hline$(1)$ & $\tau$ & 0.430 & T. 4, c. 1 & $(12)$ & $\chi$ & 1.495 & \\
\hline$(2)$ & $\alpha$ & 0.50 & T.A11, c.4 & (13) & $\xi$ & 1.157 & \\
\hline$(3)$ & $p_{b}$ & 776.2 & T.A12, c.1 & (14) & $\mathrm{E}(\log x)$ & 1.715 & \\
\hline$(4)$ & $p_{r}$ & 0.514 & T.A12, c.1 & $(15)$ & $\operatorname{Std}(\log x)$ & 1.861 & \\
\hline$(5)$ & $\delta$ & 0.069 & T.A12, c.1 & (16) & $\operatorname{Corr}(\log x, \log z)$ & -0.227 & \\
\hline$(6)$ & $\iota$ & 0.450 & BW (2006) & (17) & $\eta$ & 0.078 & Jointly Est. \\
\hline$(7)$ & $\phi$ & 0.976 & T.A12, с.1 & (18) & $\nu$ & 0.153 & \\
\hline$(8)$ & $A_{M}$ & 2.447 & Jointly Est. & (19) & $W$ & 0.291 & \\
\hline$(9)$ & $\theta$ & 0.659 & Jointly Est. & $(20)$ & $\tilde{\pi}_{X}$ & 1.611 & \\
\hline (10) & $\mathrm{E}(\log z)$ & -1.012 & Jointly Est. & $(21)$ & $\psi$ & 0.801 & \\
\hline (11) & $\operatorname{Std}(\log z)$ & 0.055 & Jointly Est. & $(22)$ & $\tilde{\theta}$ & 2.881 & \\
\hline
\end{tabular}

Notes: This table reports the calibrated and estimated parameters. See the respective source tables and corresponding sections for more details. BW (2006) stands for Broda and Weinstein (2006). The parameters in rows (8) to (22) are jointly estimated using simulated method of moments.

\section{C.2 Moments}

Table A10 shows all 38 moments used for the model estimation. For each moment, the second column includes links to the tables $(\mathrm{T})$ and figures $(\mathrm{F})$ where the moment is computed, with corresponding columns (c) and panels (p). The third and fourth columns then show the parameters' values in the data and in the model. Finally, the last column shows the key parameters that each moment helps identify. 
Table A10: Targeted moments and model fit

\begin{tabular}{|c|c|c|c|c|c|}
\hline & Moment & Source & Data & Model & Key Param. \\
\hline (1) & Mechanization Rate & Т.3, c.3 & 0.381 & 0.326 & $A_{M}$ \\
\hline$(2)$ & Investment Rate & Т.3, c.1 & 0.139 & 0.169 & $\mathrm{E}[\log x]$ \\
\hline$(3)$ & Share of Machine Hours Rented In & Т.3, c.5 & 0.645 & 0.708 & $\mathrm{E}[\log z]$ \\
\hline$(4)$ & Mech. Rate on Number of Workers & Т.3, c.4 & 0.043 & 0.070 & \multirow{4}{*}{$\nu, \eta$} \\
\hline$(5)$ & Inv. Rate on Number of Workers & Т.3, c.2 & 0.069 & 0.079 & \\
\hline (6) & Share of Mach. Hrs Rented on Num. of Workers & Т.3, c.6 & -0.110 & -0.145 & \\
\hline$(7)$ & Ratio of Size of Machine Owners vs. Renters & F.3, p.(c) & 0.057 & 0.034 & \\
\hline$(8)$ & Mech. Rate on Managerial Ability & Т.3, c.3 & 0.025 & 0.017 & \multirow{4}{*}{$\begin{array}{c}\theta, \\
\operatorname{Corr}[\log x, \log z\end{array}$} \\
\hline (9) & Inv. Rate on Managerial Ability & Т.3, c.1 & 0.048 & 0.036 & \\
\hline (10) & Share of Mach. Hours Rented on Man. Ability & Т.3, c.5 & -0.122 & -0.051 & \\
\hline (11) & Owners-Renters Managerial Ability Gap & F.3, p.(b) & 0.457 & 0.365 & \\
\hline$(12)$ & Median Hourly Machine Rental Price & T.A12, c.1 & 0.514 & 0.514 & $\xi$ \\
\hline$(13)$ & Average Machine-Level Capacity Utilization & T.A12, c.1 & 0.531 & 0.585 & $\chi$ \\
\hline (14) & Average Firm-Level Capacity Utilization & T.A12, c.1 & 0.356 & 0.310 & $\mathrm{E}[\log z]$ \\
\hline (15) & Average Firm-Level Cap. Utilization, Owners & T.A12, c.1 & 0.380 & 0.415 & \multirow{3}{*}{$\begin{array}{c}\nu, \eta, \theta \\
\operatorname{Corr}[\log x, \log z\end{array}$} \\
\hline (16) & Average Firm-Level Cap. Utilization, Renters & T.A12, c.1 & 0.338 & 0.284 & \\
\hline (17) & Average Firm-Level Cap. Rented Out & T.A12, c.1 & 0.151 & 0.170 & \\
\hline (18) & Log Revenues on Man. Ability & Т.2, c.2 & 0.288 & 0.231 & \multirow{4}{*}{$\operatorname{Std}[\log z], \nu, \eta$} \\
\hline (19) & Log Revenues p.w. on Man. Ability & Т.2, c.5 & 0.144 & 0.044 & \\
\hline (20) & Log Rev. on Man. Ability (and Mech. Rate) & T.2, с.3 & 0.250 & 0.226 & \\
\hline (21) & Log Rev. p.w on Man. Ability (and Mech. Rate) & T.2, c.6 & 0.114 & 0.031 & \\
\hline$(22)$ & Log Revenues on Mech. Rate & T.2, c.1 & 1.693 & 2.421 & \multirow{4}{*}{$A_{M}, \nu, \eta$} \\
\hline (23) & Log Revenues p.w. on Mech. Rate & Т.2, c.4 & 1.268 & 1.076 & \\
\hline$(24)$ & Log Rev. on Mech. Rate (and Man. Ability) & Т.2, c.3 & 1.530 & 0.249 & \\
\hline$(25)$ & Log Rev. p.w. on Mech. Rate (and Man. Ability) & T.2, c.6 & 1.195 & 0.782 & \\
\hline$(26)$ & Ratio of Number of Managers to Workers & T.1, c.1 & 0.222 & 0.200 & \multirow{5}{*}{$\pi_{X}, \psi, \tilde{\theta}$} \\
\hline$(27)$ & Workers-Managers Managerial Ability Gap & T.A16, c.1 & -0.285 & -0.329 & \\
\hline$(28)$ & Ratio of Std of Income of Workers vs. Managers & T.A17, c.1 & 0.898 & 0.804 & \\
\hline$(29)$ & Ratio of Std of Man. Ability of Workers vs. Man. & T.A17, c.1 & 0.970 & 0.994 & \\
\hline$(30)$ & Entry Choice on Man. Ability (Normalized) & T.A16, c.3 & 0.275 & 0.241 & \\
\hline$(31)$ & Average Markup & T.A1, c.2 & 0.229 & 0.235 & $\eta$ \\
\hline$(32)$ & Log Hourly Wage on Number of Workers & T.A7, c.6 & 0.146 & 0.153 & $\nu$ \\
\hline (33) & Log Hourly Wage on Managerial Ability & T.A7, с.3 & 0.060 & 0.029 & \multirow{3}{*}{$\eta, \nu$} \\
\hline$(34)$ & Log Capital Used on Managerial Ability & T.A15, c.2 & 0.398 & 0.346 & \\
\hline$(35)$ & Log Labor Used on Managerial Ability & T.A15, c.4 & 0.135 & 0.191 & \\
\hline$(36)$ & Hourly Worker Wage Rate & T.A1, c.2 & 0.333 & 0.326 & $\mathrm{~W}$ \\
\hline$(37)$ & Average Interest Rate & T.A13, c.1 & 0.329 & 0.347 & $\mathrm{E}[\log x]$ \\
\hline$(38)$ & Std of Interest Rate & T.A13, c.1 & 0.281 & 0.233 & $\operatorname{Std}[\log x]$ \\
\hline
\end{tabular}




\section{C.3 Details on Calibrated Parameters}

Capital share $(\alpha)$. Table A11 reports details of how we compute $\alpha$. As discussed in Section 5.1, and as shown formally in the Supplemental Appendix, $\alpha$ is pinned down by the capital-labor ratio. To compute the numerator, we calculate the total hours of machine time used by a firm in a given step per month. ${ }^{64}$ We price these at the average hourly rental rate for each machine type, computed using information on all machines rented in our data. For the denominator, we calculate the total monthly labor hours used in a given step. These are priced at the within-firm average predicted hourly wages, predicted from the same regression as in column 6 of Table A7. We then take the ratio of monthly capital to labor expenditure for each step, and use this ratio for machine owners to compute the value of $\alpha$ for each step. Column 4 reports the median value of $\alpha$, and shows that this does not vary substantially across steps. This justifies taking the average across steps. We do this in the last row, where each step is weighted by the median labor expenditure of owners on that step, as a share of labor expenditures across all steps (column 3).

Table A11: Step-level capital intensity

\begin{tabular}{lcccc}
\hline & $\begin{array}{c}\text { Share of firms } \\
\text { performing step } \\
\text { with } \\
\text { modern machines }\end{array}$ & $\begin{array}{c}\text { Share of firms } \\
\text { performing step } \\
\text { with } \\
\text { modern machines } \\
\text { that are owned }\end{array}$ & $\begin{array}{c}\text { Median labor } \\
\text { expenditure for owners, } \\
\text { as share of total } \\
\text { labor expenditure } \\
\text { across steps }\end{array}$ & $\alpha$ \\
\hline Step 3 - Cutting & $(1)$ & $(2)$ & $(3)$ & $(4)$ \\
Step 4 - Planing & $77 \%$ & $23 \%$ & $15 \%$ & 0.59 \\
Step 5 - Thicknessing & $77 \%$ & $14 \%$ & $17 \%$ & 0.61 \\
Step 6 - Edging & $75 \%$ & $12 \%$ & $15 \%$ & 0.46 \\
Step 7 - Sanding & $76 \%$ & $19 \%$ & $17 \%$ & 0.42 \\
Step 8 - Mortising & $32 \%$ & $14 \%$ & $16 \%$ & 0.47 \\
Step 9 - Finishing & $69 \%$ & $22 \%$ & $16 \%$ & 0.52 \\
Average across steps & $52 \%$ & $28 \%$ & & 0.43 \\
\hline
\end{tabular}

Notes: Sample: door producers. Expenditure shares (column 3) are trimmed at the 1st and 99th percentile. Machine owners are defined at the step-level, i.e., firms that own all the machines used in a given step are classified as owners for that step. We restrict attention to the seven most common steps (out of ten) for the production of doors, that is steps 3-9. See the Supplemental Appendix for more details on steps 3-9.

We note two further results that reassure us about the validity of our approach. First, we find that the production process of renters is less capital intensive, which is consistent with the

\footnotetext{
${ }^{64}$ To be precise, we have data on: (i) which production steps each machine is used for and (ii) how many hours the machine is used. For those machines used in more than one step, we assign machine time to steps proportionally to the distribution of machine usage across steps in the data. Machines are rarely used in more than one step and the concentration of machine time across steps is high. For instance, a table saw is used in 1.38 steps, and is used in its most common step (i.e., cutting) $87 \%$ of the time. The average machine is used in 1.2 steps. See the Supplemental Appendix for more details on how we assign machines to steps.
} 
rental market transaction costs estimated in Table 4. Specifically, we find that the capital-labor ratio for owners (averaged across steps) is 1.05, while this is 0.75 for renters. Second, we find that the labor expenditure shares of owners and renters across steps are very similar. This is consistent with the production function being the same for renters and owners, and so validates an important modeling assumption.

Table A12: Calibrated parameters and moments

\begin{tabular}{lcc}
\hline & $\begin{array}{c}\text { Aggregation } \\
\text { weighted by } \\
\text { machine hours } \\
(1)\end{array}$ & $\begin{array}{c}\text { Aggregation } \\
\text { unweighted }\end{array}$ \\
& & $(2)$ \\
\hline Panel A: Calibrated parameters & 776.2 & 579.3 \\
Median Purchase Price of Machines in USD $\left(p_{b}\right)$ & 0.514 & 0.490 \\
Median Hourly Machine Rental Price in USD $\left(p_{r}\right)$ & 0.069 & 0.082 \\
Average depreciation rate $(\delta)$ & 0.494 & 0.684 \\
Share of Machine Capacity Rented from Specialized Providers & & \\
( $\phi /(1+\phi))$ & & \\
\hline Panel B: Moments & 0.531 & 0.533 \\
Average Machine-Level Capacity Utilization & 0.356 & 0.354 \\
Average Firm-Level Capacity Utilization & 0.380 & 0.381 \\
Average Firm-Level Capacity Utilization, Owners & 0.338 & 0.336 \\
Average Firm-Level Capacity Utilization, Renters & 0.151 & 0.152 \\
Average Firm-Level Capacity Rented Out & & \\
\hline
\end{tabular}

Notes: Sample: door producers. Median purchase and rental prices of machines (Panel A) are trimmed at the 1st and 99th percentile and converted to nominal US dollars using an exchange rate of 3,800 UGX/USD.

Machine price $\left(p_{b}\right)$, rental price $\left(p_{r}\right)$, and depreciation rate $(\delta)$. These are reported in Panel A of Table A12. To compute the machine purchase $\left(p_{b}\right)$ and rental prices $\left(p_{r}\right)$ we use our machine-level data, where firms were asked to report the price paid for each machine (if they own it) and the hourly rental rate they pay to use the machine (if they rent it). We take the median across machines for both these prices. To construct $p_{r}$, we additionally subtract from the median hourly rental rate the median cost of labor incurred by machine owners, as we are interested in isolating the share of the rental cost that captures payment to capital. ${ }^{65}$

\footnotetext{
${ }^{65}$ This is estimated with the following procedure. Our data shows that: in $65.5 \%$ of cases the employees of machine owners perform all operations on machines that are rented out to other firms; in $19.9 \%$ of cases the employees of machine owners supervise the employees of firms who are renting their machine; and, in $14.6 \%$ of cases machine owners let the employees of other firms use their machines without supervision. Median hourly wages in carpentry are $\$ 0.26$, so we subtract from the median hourly rental rate: $\$ 0.20=(0.655 \times 0.26)-$ $(0.199 \times 0.5 \times 0.26)$. That is, when the employees of machine owners perform the operations themselves, we remove from the rental price their hourly wage. For similar reasons, we remove half of the hourly wage when the employees of machine owners supervise the employees of machine renters. This information on supervision of renters by machine owners was collected in a short follow-up phone survey conducted about 3 months after the end of the main survey. Details on additional data collection are provided in the Supplemental Appendix.
} 
The depreciation rate $\delta$ is computed as: $1-(V / P)^{1 / A}$, where $V$ is the current machine value, $P$ is the purchase price of the machine and $A$ is the age of the machine in years. We report the average depreciation rate in row 3 of Panel A.

In column 1 machines are aggregated by weighting each machine type by the share of total machine time it accounts for in the data, so that machine types used more intensively get a higher weight. ${ }^{66}$ Column 2 shows that our results are robust to aggregating without weights. We note that machine purchase prices are significantly larger in column 1 than column 2. This is in line with more expensive machines being used more heavily by firms. ${ }^{67}$

Share of machine capacity rented from specialized providers $\left(\frac{\phi}{1+\phi}\right)$. This is reported in Panel A of Table A12, and is defined as $\left(H R_{i}-H R_{o}\right) / H R_{i}$, where $H R_{i}$ are weekly total hours of machine usage reported by renters, and $H R_{o}$ are weekly total hours of machine time that owners report supplying to renters. Since we have a random sample of firms, this ratio would be zero if machine renters were only renting from machine owners. However, Table A12 shows that the machine time used by renters is about twice as large as what machine owners report renting out. This indicates that about 50\% of the rented machine time originates from other providers that are not carpentry firms. Our data further shows that such providers are mostly workshops that specialize in renting out machines: machine renters were asked where they rent their machines from, and around $39 \%$ of door producers report renting from intermediary retailers (while $58 \%$ report renting from other carpentry firms in the same area, and $3 \%$ from other sources such as family and friends). ${ }^{68}$ As described above, in column 1 machines are aggregated weighting each machine type by the share of total machine time it accounts for in the data. In column 2 we show that our results are robust to aggregating without weights.

\section{C.4 Details on Moments}

This section describes the computation and estimation of additional moments not already described in the main text, and should be read in conjunction with Table A10. In each paragraph, we refer to the rows of Table A10 that include these additional computed moments. Two rows are missing: row (12) includes $p_{r}$, already described in the previous section; row (36) includes the average wage from Table A1.

\footnotetext{
${ }^{66}$ The information on machine usage at the firm level was collected in a short follow-up phone survey conducted about 7 months after the end of the main survey.

${ }^{67}$ If a firm uses more than one machine of each type (i.e., more than one thickness planer), then our data contains one observation for each type of machine, and in this case the machine purchase price refers to the last machine purchased by the firm, the current value refers to the average machine, the age to the average machine, and the hourly rental rate refers to the typical machine of that type rented by the firm. Firms use more than one machine of each type in less than $7 \%$ of cases.

${ }^{68}$ Specialized rental workshops likely have higher machine capacity available for rent (since they do not use the machines themselves) and so this can explain why the share of rented machine time accounted for by specialized workshops $(50 \%)$ is higher than the share of renters using specialized workshops (39\%).
} 
Capacity utilization (Rows 13-17). The moments related to capacity utilization are shown in Panel B of Table A12. To compute the average machine-level capacity utilization, we use information from machine owners, who were asked how many hours per week they use their machines for all their products, and how many hours they rent them out to other firms. We consider as total demand the total time that the machine is operated per week (for both own use and for renting out), and as total supply 60 hours per owned machine. To compute the average firm-level capacity utilization, firms were asked how many hours per week they use each machine for the production of all their products. We set full capacity at 60 hours per week. We then recompute the firm-level capacity utilization separately for owners and renters, where owners and renters are defined at the machine level. The average firm-level capacity rented out is computed using only machine owners, and dividing the weekly hours that the machine is rented out by 60 .

Table A13: Interest rate

Fample: $\quad \begin{gathered}\text { Firms that are } \\ \text { borrowing }\end{gathered}$

Average interest rate

Standard deviation of interest rate

Number of firms
0.329

0.281

29

Firms that would need
to borrow to cover
unforeseen expense
$(2)$
0.593
0.432
191

Notes: Sample: carpentry sector. Column 2 reports a hypothetical interest rate for firms that would need to borrow to cover unforeseen expenses, and is trimmed at the 95th percentile to correct for outliers. This information was collected in a short follow-up phone survey conducted about 7 months after the initial survey.

Cost of capital (Rows 37-38). Firm owners who reported borrowing for the business at the time of the survey were asked their interest rate. Column 1 of Table A13 shows that the mean interest rate is $33 \%$, with standard deviation of $28 \%$. However, we note that only 29 carpentry firms reported to be borrowing and provided a value for the interest rate.

To provide more evidence on the cost of capital, in column 2 we report the mean and standard deviation of the hypothetical interest rate that firms expect to face if they had to borrow to cover an unforeseen expense. Specifically, we first asked if firm owners would be able to cover a UGX 1 Million (USD 263) expense, either through borrowing or through own savings. If they said No, then we asked if they could cover lower amounts. For those that said Yes to any of these questions, we then asked if they would be able to cover the expense by borrowing or through savings. To those who would need to borrow, we then asked the interest rate they would expect to face. ${ }^{69}$ First, we note that $39 \%$ of firms reported that they would need to

\footnotetext{
${ }^{69}$ This information is thus available only for firms that would need to borrow to cover it (as opposed to using own savings). This information is missing also for firm owners who would not be able to cover the expense at
} 
borrow. This shows that about $60 \%$ of entrepreneurs have substantial savings, and so likely have a lower cost of capital. Second, comparing columns 1 and 2 suggests that those managers who borrow face a lower interest rate than those who do not have substantial savings and do not currently borrow. Taken together, this evidence shows that there is substantial variation in the cost of capital across firms.

Table A14: Predictors of access to liquidity

\begin{tabular}{|c|c|c|c|c|}
\hline & \multicolumn{2}{|c|}{$\begin{array}{l}\text { Able to cover unforeseen expense } \\
\text { of UGX } 1 \mathrm{M}\end{array}$} & \multicolumn{2}{|c|}{$\begin{array}{l}\text { Would need to borrow } \\
\text { to cover unforeseen expense }\end{array}$} \\
\hline & $(1)$ & $(2)$ & $(3)$ & $(4)$ \\
\hline \multirow[t]{2}{*}{ Manager Ability (Std.) } & $0.059^{* * *}$ & & -0.021 & \\
\hline & $(0.023)$ & & $(0.025)$ & \\
\hline \multirow[t]{2}{*}{ Investment Rate (0-1) } & & $0.508^{* * *}$ & & $-0.553^{* * *}$ \\
\hline & & $(0.132)$ & & $(0.152)$ \\
\hline Sample & All Firms & Door Prod. & All Firms & Door Prod. \\
\hline Subcounty FE & Yes & Yes & Yes & Yes \\
\hline Adjusted $R^{2}$ & 0.054 & 0.062 & 0.099 & 0.181 \\
\hline Observations & 477 & 326 & 475 & 324 \\
\hline
\end{tabular}

Notes: ${ }^{* * *} p<0.01,{ }^{* *} p<0.05,{ }^{*} p<0.1$. OLS regression coefficients, robust standard errors in parentheses. Sample: carpentry sector. Managerial ability: standardized index based on multiple survey questions, see the Supplemental Appendix for details. Investment rate: See Table 3.

In Table A14 we verify that higher ability managers and machine owners face a lower cost of capital. Column 1 shows a positive correlation between managerial ability and whether the manager would be able to cover an unforeseen expense of UGX 1M (with either own savings or a loan). Column 3 shows that, conditional on being able to cover an unforeseen expense, there is a negative association between managerial ability and the probability that the manager would need to borrow to cover the expense (as opposed to using own savings), though this result is imprecisely estimated. Columns 2 and 4 show that firm owners who own a higher share of machines face easier access to capital and have more liquidity available through savings. These results are in line with the model estimates that higher ability managers face a lower cost of capital, and that managers with lower cost of capital are more likely to invest.

Finally, we also show that managers with lower cost of capital, as proxied by their ability to cover the unforeseen expense, are more likely to own machines, even conditional on managerial ability, and that mechanization and investment rates are both higher in areas with easier access to banks, even conditional on managerial ability. These results provide additional evidence of variation in cost of capital across entrepreneurs resulting in heterogeneity in mechanization and investment. See the Supplemental Appendix for more details.

all (neither with a loan nor with own savings), but we note that only 2 firms reported not being able to cover it. 
Labor market frictions (Rows 33-35). To be conservative, for the identification of the labor market friction parameter $\nu$ we prefer to target the bundle of moments described in Section 5, rather than relying exclusively on the direct estimates of $\nu$ from column 6 of Table A7. In particular, we also target: (a) the relationship between wages and managerial ability from column 3 of Table A7, and (b) the correlation between managerial ability and (i) capital stock and (ii) firm size, reported in Table A15. The results from part (a) indicate that an increase in managerial ability of one standard deviation is associated with a $6 \%$ increase in earnings. For part (b), in Table A15 we regress the log value of the capital stock used and log firm size on managerial ability. Our preferred specifications limit the sample to door producers (i.e., columns 2 and 4). These show that a one standard deviation increase in managerial ability is associated with a $40 \%$ increase in capital and a $14 \%$ increase in labor. ${ }^{70}$

Table A15: Capital stock and labor choice

\begin{tabular}{lcccc}
\hline & \multicolumn{2}{c}{ Log Capital Stock Used } & \multicolumn{2}{c}{ Log Number of Workers } \\
& $(1)$ & $(2)$ & $(3)$ & $(4)$ \\
\hline Manager Ability (Std.) & $0.474^{* * *}$ & $0.398^{* * *}$ & $0.113^{* * *}$ & $0.135^{* * *}$ \\
& $(0.094)$ & $(0.111)$ & $(0.028)$ & $(0.036)$ \\
\hline Sample & All Firms & Door Prod. & All Firms & Door Prod. \\
Subcounty FE & Yes & Yes & Yes & Yes \\
Product Controls & Yes & Yes & Yes & Yes \\
Adjusted $R^{2}$ & 0.212 & 0.237 & 0.239 & 0.230 \\
Observations & 421 & 311 & 522 & 381 \\
\hline
\end{tabular}

Notes: ${ }^{* * *} p<0.01,{ }^{* *} p<0.05,{ }^{*} p<0.1$. OLS regression coefficients, robust standard errors in parentheses. Outcome variable in columns 1-2: log value of capital stock used (owned and rented). Product controls: dummies for the most common door type and for producing two-panel doors in the last 3 months. Managerial ability: standardized index based on multiple survey questions, see the Supplemental Appendix for details.

Managers' selection (Rows 26-30). We are interested in the relationship between managerial ability and the decision to become a manager (relative to the outside option of being a worker in the same industry, as suggested by our data). However, managerial ability is available only for managers, and so is predicted by running a regression of our standardized index of managerial ability on a set of individual characteristics available for both managers and workers. ${ }^{71}$ In columns 1-2 of Appendix Table A16 we regress predicted managerial ability (standardized) on a dummy for being a worker. Column 1 shows that workers score about 0.29 of a standard deviation lower on the predicted measure of managerial ability. This result is robust to excluding sub-county fixed effects (column 2).

\footnotetext{
${ }^{70}$ The regressions in Table A15 are robust to excluding product controls.

${ }^{71}$ These are: years of schooling, age, age squared, a dummy for whether attended vocational training, the score on a 4-item Raven matrices test, and the Big five traits, measured through a 10-item Big five test.
} 
In columns 3-4 we regress a dummy for being a manager on the rank of the individual on the same measure of predicted managerial ability described above. To construct the rank, we weight observations so that the weighted sample includes an equal share of managers and workers. We report both standard errors clustered by firm and bootstrap standard errors (with resampling by firm) as the independent variable is constructed using a generated regressor. The results show that an increase in the rank of $10 \mathrm{pp}$ is associated with an increase in the probability of being a manager of about 2-2.8pp. This result is imprecisely estimated once we account for the generated regressor.

Table A16: Outside option and entry choice

\begin{tabular}{lcccc}
\hline & $\begin{array}{c}\text { Predicted Man. Ability (Std.) } \\
\text { (1) }\end{array}$ & $(2)$ & $(3)$ & $(4)$ \\
\hline Worker (0/1) & $-0.285^{* * *}$ & $-0.240^{* * *}$ & \\
& $(0.051)$ & $(0.053)$ & $0.275^{* * *}$ & $0.204^{* * *}$ \\
Rank of predicted & & & $(0.050)$ & $(0.044)$ \\
man. ability (0-1) & & & {$[0.216]$} & {$[0.187]$} \\
& & No & Yes & No \\
\hline Subcounty FE & Yes & 0.012 & 0.014 & 0.014 \\
Adjusted $R^{2}$ & 0.176 & 1,433 & 1,433 & 1,433 \\
Observations & 1,433 & &
\end{tabular}

Notes: ${ }^{* * *} p<0.01,{ }^{* *} p<0.05,{ }^{*} p<0.1$. OLS regression coefficients. Sample: workers and managers in carpentry. Standard errors clustered at the firm level are shown in parentheses, whereas bootstrapped standard errors with 1,000 replications and resampling clustered by firm are provided in square brackets. To create the predicted measure in column 1 (column 2) this regression does (does not) control for sub-county fixed effects.

Finally, Table A17 reports the ratios of the standard deviations of workers to managers for: (i) income (row 1) and (ii) predicted managerial ability (row 2), predicted as described above. Column 1 reports our preferred specification where the standard deviations are calculated netting out sub-county fixed effects. As a robustness check, column 2 shows the ratios without controlling for sub-county fixed effects. The results are similar.

Markups (Row 21). We calculate markups as revenues over variable cost (measured as revenues minus profits), minus 1 . This approach recovers markups under the assumption that profit measures in the survey correspond to variable profits (i.e., managers do not take into account fixed costs when reporting monthly profits). We believe this to be the case given how the profit question was worded. Estimates of markups are reported in Table A1. ${ }^{72}$

\footnotetext{
${ }^{72}$ For robustness, we also calculate markups using hypothetical questions. Managers were asked how much revenues they could generate from UGX 250,000 of intermediate inputs. They were then asked how much of these revenues would: (i) go to wages; (ii) cover other variable costs (e.g., machines, fuel etc.); (iii) be left as variable profits. We compute markups as the ratio of the stated revenues over the sum of intermediate input costs, wage costs and other operating costs. This alternative procedure yields markups that are very similar.
} 
Table A17: Workers-managers gap in variance of income and ability

\begin{tabular}{lcc}
\hline & Sub-county & No Sub-county \\
& FE & FE \\
& $(1)$ & 0.700 \\
\hline Ratio of Workers-Managers Std of Income & 0.898 & 0.925 \\
\hline
\end{tabular}

Notes: Sample: carpentry. First row: ratio of the standard deviation of workers' monthly earnings and managers' average monthly profits. Second row: ratio of the standard deviation of workers' and managers' predicted managerial ability. The statistics in column 1 (column 2) control (do not control) sub-county fixed effects.

\section{Prevalence of Rental Markets Across Countries}

To study the prevalence of the rental market across countries, we use the World Bank Enterprise Surveys (WBES). Importantly for our purposes, in the waves of the WBES collected between 2012-2014 firms are asked their total expenditures on rental of machinery, vehicles and equipment in the fiscal year before the survey. In total, we have this information for 6,836 firms in 44 countries. For each firm, we construct a dummy equal to one if the firm reports any rental market expenditure in the previous year. ${ }^{73}$ Figure A4 plots the share of firms that rent capital in each country, against GDP per capita. ${ }^{74}$ The Figure shows a clear negative correlation, thus confirming that the rental market is indeed less prevalent in more developed economies. Uganda does not appear to be an outlier, showing levels of prevalence of the rental market comparable to other sub-Saharan African countries such as Ghana, Zambia or Sudan.

Figure A4: Prevalence of rental markets for capital across countries

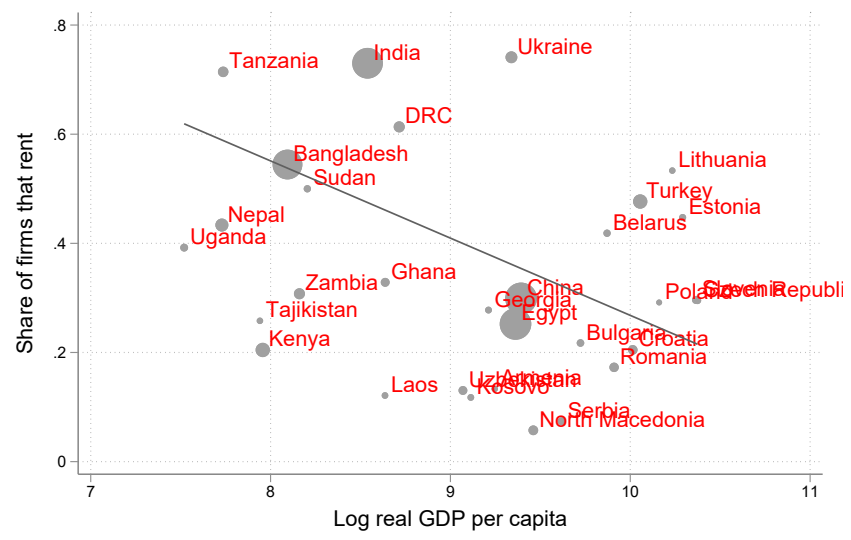

Notes: Data: World Bank Enterprise Surveys (WBES) for 2012-14. Share of firms in each country that reports any rental expenditure on machines/equipment/vehicles, against log real GDP per capita. Countries are weighted by the number of firms in the WBES. We exclude 13 countries with less than 20 firms.

\footnotetext{
${ }^{73}$ Across all countries, $43 \%$ of firms report any involvement with the rental market.

${ }^{74}$ To reduce the impact of outliers, we exclude countries with less than 20 firms and weight each country by the number of firms. Our results are robust to using the full country sample and not weighting the estimates.
} 